University of San Diego

Digital USD

2009-11-01

\title{
The Impact of a Simulation Based Leader Development Training Program on Transformational and Transactional Leadership Behavior
}

Robin Louise McCoy PhD

University of San Diego

Follow this and additional works at: https://digital.sandiego.edu/dissertations

Part of the Leadership Studies Commons

\section{Digital USD Citation}

McCoy, Robin Louise PhD, "The Impact of a Simulation Based Leader Development Training Program on Transformational and Transactional Leadership Behavior" (2009). Dissertations. 796.

https://digital.sandiego.edu/dissertations/796 Digital USD. It has been accepted for inclusion in Dissertations by an authorized administrator of Digital USD. For more information, please contact digital@sandiego.edu. 


\title{
THE IMPACT OF A SIMULATION BASED LEADER DEVELOPMENT TRAINING PROGRAM ON TRANSFORMATIONAL AND TRANSACTIONAL LEADERSHIP BEHAVIOR
}

\author{
by \\ ROBIN LOUISE MCCOY
}

A dissertation submitted in partial fulfillment of the requirements for the degree

Doctor of Philosophy University of San Diego

November 2009

Dissertation Committee

Fred Galloway, Ed.D., Chair

Johanna Hunsaker, Ph.D., Member

George Reed, Ph.D., Member 


\title{
NOTE TO USERS
}

\section{Page(s) missing in number only; text follows. The Manuscript was microfilmed as received.}

\author{
161
}

This reproduction is the best copy available.

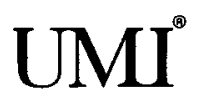


(C) Copyright by Robin Louise McCoy 2009

All Rights Reserved 


\begin{abstract}
Organizations devote considerable resources developing employees' capacity for leadership because they believe that "leaders" are essential in the operations of their organizations. Unfortunately, organizations do not have the time or resources to send their employees off for lengthy leader development training programs. This has contributed to the growing popularity of short-term training programs which are relatively inexpensive to conduct. However, researchers are increasingly requesting more empirical studies that examine the impact of these programs, yet these requests have remained largely disregarded. Additionally, there is a lack for developing methodologies to determine whether or not involvement in a short-term program facilitates change in an individual's transformational and transactional leadership behaviors.
\end{abstract}

To address this lack of inquiry, this study examined the impact of a wellrecognized leader development simulation on transformational and transactional leadership behaviors among participating mid and upper level managers. A quasiexperimental pre-test, post-test research design was used to measure the impact both from the managers' perspective and their direct reports' perspective. Based on an analysis of the assessments completed by 50 managers and 81 direct reports, the findings suggest that managers perceived significant and positive changes in all of their transformational leadership behaviors and reductions in their transactional behaviors. However, their direct reports perceived significant changes in only one dimension of their manager's transformational leadership behavior: individualized consideration. Direct reports felt that their managers spent more time teaching and coaching them, helped them to develop their strengths, and considered their individual needs more as a result of participating in the training program. Direct reports also saw improvements in leadership effectiveness and 
were more satisfied with their managers after the training program. In addition, managers who under-estimated their transformational leadership behavior were rated the highest in transformational leadership by their direct reports. Furthermore, managers who dominated more on the Myers-Briggs perceiving scale than the judging scale were identified as being more transformational than other personality types.

The findings of this study contribute empirical support for the impact of a leader development program and demonstrate that individuals can change some of their transformational leadership behaviors from participation in a short-term training program. 


\section{DEDICATION}

Ryann, Layne, and Spencer Backus

This dissertation is dedicated to my wonderful daughter and my two beautiful grandsons who, continue to be my greatest source for growth and love. 


\section{ACKNOWLEDGEMENTS}

I have a propensity to believe that no one is self-made. There are people and events in our lives that contribute to who we are and who we will become. This has certainly been the case for me and my life. Throughout this dissertation journey, there have been numerous people who have supported me and helped make this journey complete.

My deepest appreciation goes to the members of my committee. My advisor and chair, Dr. Fred Galloway, truly made this dissertation possible. His knowledge, passion, caring nature, tenacity, and friendship will always be held dear. It was truly because of Fred's commitment to this process that I was able to complete the dissertation and be proud of my work. Dr. Johanna Hunsaker provided invaluable and thoughtful guidance from the beginning of the proposed methodology through the final rewrite of chapter five. It was because of Johanna, that I was able to find a "stronger" voice in my findings and for this I am forever thankful. To Dr. George Reed, I am thankful for challenging me with other perspectives, for his wealth of knowledge in leadership studies, and for helping to proofread my writing. Thank you all for your insights and encouragement throughout this process. I could not have completed this work without the collaboration and support you all provided.

In addition to my wonderful committee, I would like to thank Stephanie and Emily from the Institute. From the moment I contacted Stephanie to explore working with her on the Leader Development Simulation, a great relationship developed.

Stephanie was open and willing to having me examine her program and was always available when I needed her, which was often. Emily was a wonderful support to have 
not only because of her experience in evaluation, but also for her examination of my assessment instrument and learning outcomes. Thank you, Stephanie and Emily for believing in this research.

I am also forever thankful to my family and friends who encouraged me to begin this journey and were there throughout the process helping me to fulfill a dream. My daughter, Ryann, who has been with me through thick and thin, I am especially appreciative. She and my grandsons have "shared" me with this dissertation. Thank you for your support and encouragement. I am also thankful to my mother who always believed in me and the importance of education. She is my inspiration to reach out and work hard for what you want.

To my colleagues in the doctoral program, I am eternally indebted. They are some of the greatest friends one could ever ask for or hope to have in their lifetime. We have become a family that continues to grow and flourish. It is with admiration and love that I am especially thankful to have them in my life. I particularly want to thank my dearest friend, Dr. Jan Taylor Morris. We have been on this journey together. Through tears and laughter, I could not have enjoyed this journey without her in my life. She challenged me, helped me to put together the pieces of the puzzle, and always was there when I needed her. You cannot ask for anything more in a friend.

Lastly, I want to thank my beloved, Orb Chamblee. He has been my companion, confidant, and partner throughout this process. From providing me with an exhaustive list of four syllable words to helping me edit my work, I am especially grateful for his patience, intelligence, and love. 


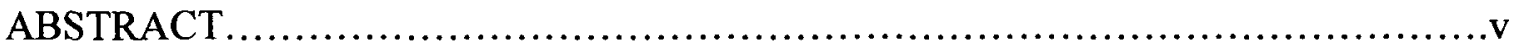

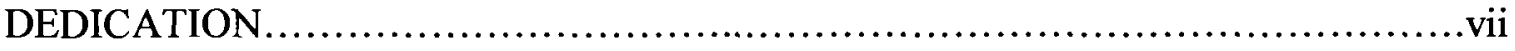

ACKNOWLEDGEMENTS.....................................................iii

TABLE OF CONTENTS.............................................................

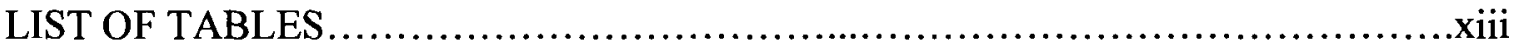

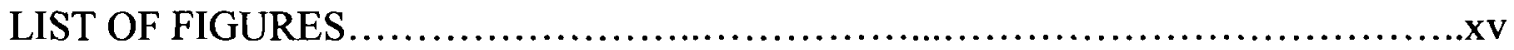

CHAPTER

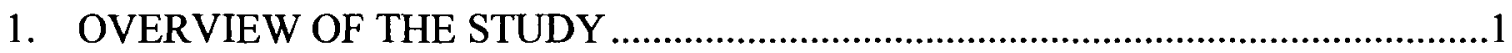

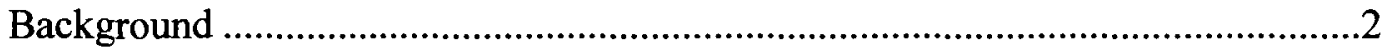

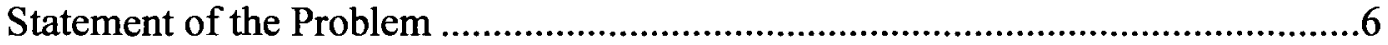

Purpose of the Study ........................................................................................

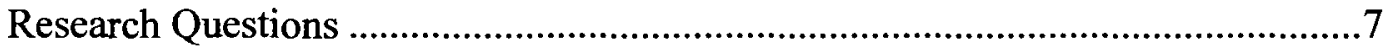

2. A REVIEW OF THE LITERATURE

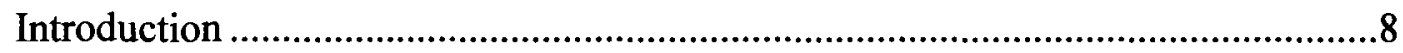

Transactional, Transformational, and Laissez-Faire Leadership Theories ...............8

Leader Development and Training Methods..........................................................13

Transformational Leader Development.............................................................14

Leader Development and Adult Development ...................................................15

Leader Development Methods ...........................................................................20

Leader Development and Self-Awareness ......................................................22

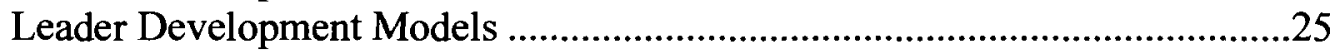

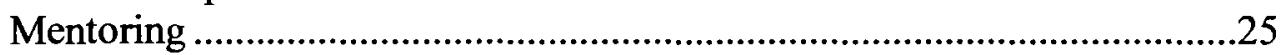

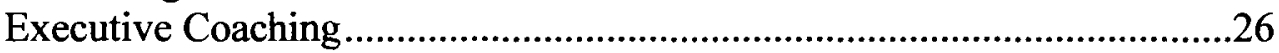

360 Feedback Assessment .......................................................................26

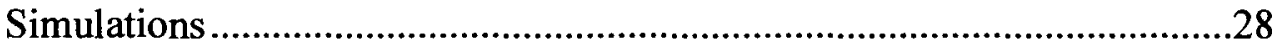

Exploring How Individuals Learn from Leader Development Simulations ........29

Efficacy of Leader Development Programs ............................................................36

Transformational Change and the MLQ..........................................................38

Conclusion to the Review of the Literature.........................................................42

3. RESEARCH DESIGN, METHODOLOGY, AND LIMITATIONS …....................44

The Leader Development Simulation ..................................................................44

Research Methodology ........................................................................................47

Sample and Overview of the Survey Procedures ...................................................48

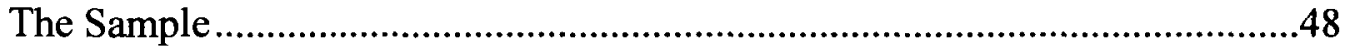


Data Collection: Survey Procedures..............................................................48

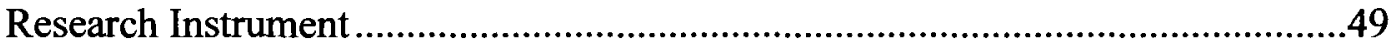

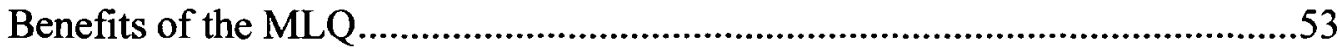

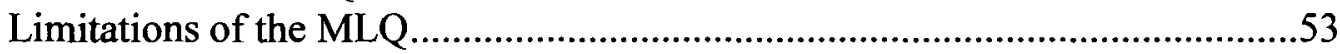

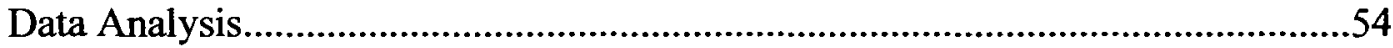

Linear Equations for the Study Models................................................................56

Limitations of the Study's Research Design and Methodology .............................58

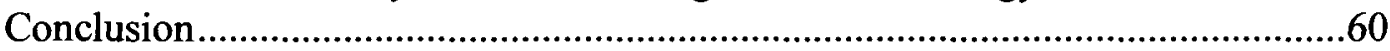

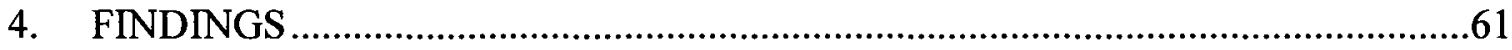

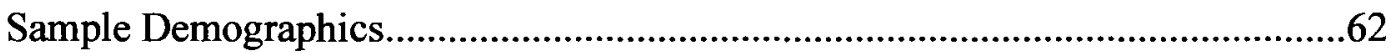

Data Analysis Results for Research Question 1 ....................................................67

Concluding Remarks on Research Question 1 ................................................71

Data Analysis Results for Research Question 2 ……...........................................71

Concluding Remarks on Research Question 2 ………………………….......78

Data Analysis Results for Research Question 3 ...................................................79

Concluding Remarks on Research Question 3 .................................................91

Data Analysis Results for Research Question 4 ……............................................92

Concluding Remarks on Research Question 4 .............................................101

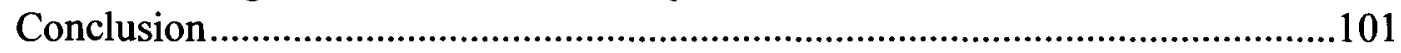

5. DISCUSSION OF FINDINGS AND CONCLUSIONS ………..............................103

Methodology and Findings of the Study .........................................................105

A Brief Review of the Study's Methodology....................................................105

Discussion of the Study's Key Findings ........................................................106

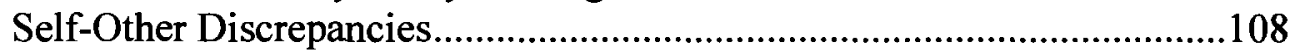

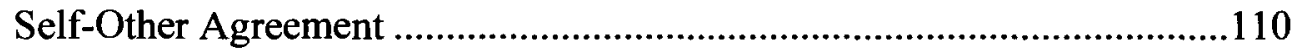

Common Themes for Change .................................................................110

Personality Type and Changes in Behavior................................................111

Leadership Effectiveness.............................................................................113

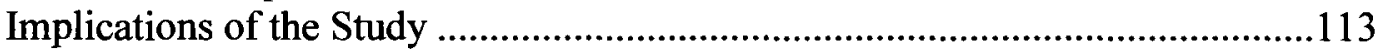

Specific Implications for Leader Development Policy and Practice............113

Specific Implications for Leader Development Evaluation Policy and

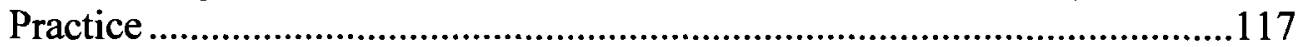

Suggestions for Future Research ..................................................................119

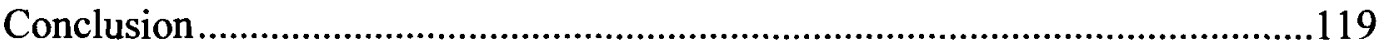

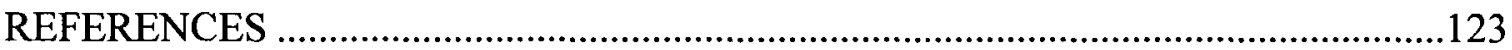

Appendix

A. Multi-factor Leadership Questionnaire Form 5x …….........................................139

B. Invitation to Participate in a Research Study .......................................................143 
C. Learning Outcomes and MLQ Leadership Dimensions..........................................145

D. Permission to Use MLQ by MindGarden ........................................................148

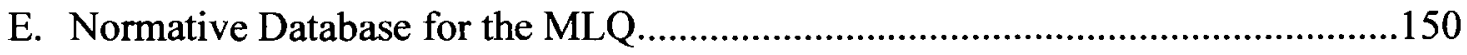

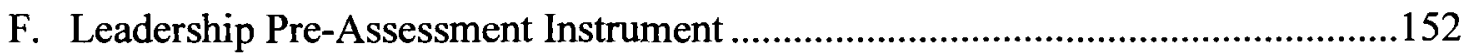

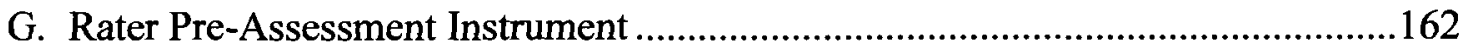




\section{LIST OF TABLES}

Table 1. Demographic Characteristics of Sample and Population Participants p. 64

$\begin{array}{ll}\text { Table 2. Industry Characteristics of Sample } & \text { p. } 65\end{array}$

Table 3. Descriptive Characteristics of the Direct Report Sample p. 66

Table 4. Difference between the pre- and post-test scores - Wilcoxon matched pair $\begin{array}{ll}\text { rank test } & \text { p. } 69\end{array}$

Table 5. Difference between the pre-and post-test scores - Wilcoxon matched pair $\begin{array}{ll}\text { rank test } & \text { p. } 70\end{array}$

Table 6. Mean and standard deviations for leadership and outcome variables p. 73

Table 7. Mean and standard deviations for each leadership dimension $\quad$ p. 74

Table 8. Post Transformational Leadership Categories of Agreement p. 76

Table 9. Post Transactional Leadership Categories of Agreement p. 77

Table 10. Average Self and Other Post-Transformational Leadership Ratings for $\begin{array}{ll}\text { Managers in Different Agreement Groups } & \text { p. } 78\end{array}$

$\begin{array}{ll}\text { Table 11. MBTI Characteristics of Managers } & \text { p. } 79\end{array}$

Table 12. MBTI Preferences and Mean Scores for the Leadership Dimensions $\quad$ p. 81

Table 13. Hierarchical regression between changes in transformational leadership (CTFORM) and demographic variables - Model $1 \quad$ p. 82

Table 14. Demographic Measures and Change in Transformational Leadership $\begin{array}{ll}\text { Behavior } & \text { p. } 83\end{array}$

Table 15. Hierarchical regression between changes in transformational leadership (CTFORM) and demographic variables - Model 2

Table 16. Hierarchical regression between changes in transactional leadership

(CTACT) and demographic variables - Model 3 Managers p. 85

Table 17. Model 4 Changes in Transactional Leadership Behavior p. 86

Table 18. Hierarchical regression between changes in transformational leadership (CTFORM) and demographic variables - Model 1 Direct Reports 
Table 19. Hierarchical regression between changes in transactional leadership (CTACT) and demographic variables - Model 2 Direct Reports

Table 20. Hierarchical regression differences in the differences Model 1 Transformational Leadership

p. 90

Table 21. Demographic Characteristics of the Most and Least Changed p. 94

Table 22. Leadership Outcome Measures

p. 95

Table 23. Changes in the Dimensions of Transformational, Transactional, and LaissezFaire Leadership Behavior - Direct Reports

Table 24. Demographic Characteristics of those with Negative and Positive Change

p. 99

Table 25. Leadership Outcome Measures

p. 100 


\section{LIST OF FIGURES}

Figure 1. Full Range Leadership Model Adapted from Bass \& Avolio (1994)

p. 13

Figure 2. Normal Distribution Curve - Change in Transformational Leadership

Behavior as Perceived by the Direct Reports

p. 93 


\section{CHAPTER ONE \\ OVERVIEW OF THE STUDY}

\section{Background}

Over the next thirty years, forty-percent of the United States workforce will have either retired or be eligible for retirement (United States Department of Labor Statistics, 2008). The forty-percent mostly consist of the baby boomer generation, those born between 1946 and 1964. Many of the baby boomer generation hold higher level positions and serve in formal leadership roles. Organizations will, therefore, face the challenge of replacing this aging population with a much smaller talent pool. The smaller talent pool, known as the millennials, a term coined by researchers Neil Howe and William Strauss (1993), are forecasted to be the most highly educated of any generation in the world. However, the millennials represent a smaller portion of the population than the baby boomers thus creating a disparity. This demographic disparity between the baby boomers and the millennials raises the following questions: What will happen to the next generation of leadership? Will they be prepared to take over and fill the top level positions?

This expected loss of skilled workers has directed many organizations to focus upon leadership mentoring, succession planning, training, and development (Carroll, 2004). Coupled with the loss of knowledge and experience is the rapidly changing technological and political environment in which organizations function. The pace of change facing organizations requires multiple approaches to leader development and requires more adaptive, flexible leadership (Day, 2000). Traditional approaches to leader development often include these components: formal education, mentoring, on the job 
experience, and short-term seminar-based training programs. Non-traditional approaches include, for instance, special training in wilderness settings. Regardless of the approach used, organizations face the problem of deciding upon the type of skills and competencies to be taught and how to evaluate the impact of leader development programs designed to train employees in the field of leadership.

Success as an effective leader depends on more than understanding the technical knowledge of an organization or simply theories of management. It comes from an understanding of such factors as the art of influencing others; understanding the organizational culture and politics; creating a vision and strategic direction for the organization; communicating the vision to the people and customers of the organization; and inspiring, motivating, and aligning people to achieve the vision (Kotter, 1990; Smith, 2001). Donald Schon (1983), in his innovative work, The Reflective Practitioner, describes effective leadership as people who are forced to take a larger view and look at the underlying assumptions that drive actions. Other personal attributes of effective leadership include perseverance, ability to handle emergencies under stress, and positive interpersonal relations (Bass \& Stogdill, 1990; Conger \& Benjamin, 1999; Hunsaker, Mudgett, \& Wynne, 1975; McCauley \& Van Velsor, 2004; Yukl, 1999).

One of the most noteworthy advancements in leader development has been the interest by organizations in transactional and transformational leadership (Bass \& Avolio, 1994). Transactional leadership is regarded as an exchange between the leader and follower for services rendered and often referred to as managing in organizations. Transforming leadership, first described by James MacGregor Burns (1978), refers to "a relationship of mutual stimulation and elevation that converts followers into leaders and 
may convert leaders into moral agents" (p. 4). Later, Bernard Bass (1985) operationalized the concept of transformational leadership and identified four components of transformational leadership: idealized influence (charisma), inspirational motivation, intellectual stimulation, and individualized consideration. Substantial evidence has shown that transformational leadership is significantly related to: job satisfaction, employee innovation, growth in financial performance of organizations, and high levels of employee commitment (Bass \& Avolio, 1996, Bass, Avolio, Jung, \& Berson 2000; Elenkov, 2000; Stashevsky \& Koslowsky, 2006).

Conger (1999) reviewed 15 years of research and found that interest in transformational leadership may be traceable to companies wanting to change and reinvent themselves often due to increased global competition. One of the most practical ways to begin developing transformational leadership is to participate in some form of leader training (Filan, 1999; Gmelch, 2004; Hoppe, 2003; Thomas \& Schuh, 2004). Based on the findings of several research studies (Lowe \& Galen, 1996; McCauley \& Hughes-James, 1994; Young \& Dixon, 1996), scholars recommend that leader development programs offer multiple pedagogies such as survey feedback from an individual's supervisor, peers, and staff (often called 360-degree feedback), experiential exercises, psychological tests, coaching, and action learning projects.

Conger and Benjamin (1999) examined how companies successfully develop the next generation and found that strong leadership is an important element for organizational change, growth, and innovation in these tumultuous times. McCall (1998) suggests those businesses that focus their attention on leader development have a greater advantage over their competition. Many other scholars (Fulmer \& Conger, 2004; Gibler, 
Carter, \& Goldsmith, 2000; Vicere \& Fulmer, 1998) have espoused that developing employees with a well planned leader development program is the best way for organizations to cope with constantly changing business environments.

Many studies have found that training does improve individual leadership behavior (Avolio \& Bass, 1998; Barling, Weber, \& Kelloway, 1996; Sivanthan, Barling, $\&$ Turner, 2003). More importantly, research has established the positive impact of transformational leadership on individual, direct report, and organizational performance (Avolio, 1999; Dvir, Eden, Avolio, \& Shamir, 2002; Sivasubramaniam, Murry, \& Avolio, 2002). Several studies have found that transformational leadership development is better for organizational effectiveness as it relates to subordinate job satisfaction and commitment, improving the performance of work groups, and increasing the importance of leadership in the organizational culture (Avolio \& Bass, 1998; Barling, Loughlin, \& Kelloway, 2002; De Cremer \& Knippenberg, 2002; Dvir \& Shamir, 2003; Zohar, 2002). However, there is considerable debate concerning the impact of leader development programs (Day, 2000; Sonungro, 1997; Vanderberghe, 1999).

Several researchers have expressed the need for more empirical studies that evaluate leader development programs (Collins, 2001; Day, 2000; Lynham, 2000). A small number of studies have used a pre- and post-test assessment methodology to investigate whether a leader development intervention actually changed managers' behavior after a training program (Kelloway, Barling, \& Helleur, 2000; Miller, Umble, Frederick, \& Dinkin, 2007; Parry \& Sinha, 2005; Wilson, 2006). Some used the same instrument pre and post, however a few did not include the same raters in the post study (Parry \& Sinha, 2005; Wilson, 2006). Many used a pre and post research design but the 
training program was an extensive program covering multiple months of training (Avolio \& Bass, 1998; Dvir, Eden, Avolio, \& Shamir, 2002; Sidor, 2007). However, there have been few studies that examine the impact of short-term programs. Short-term programs are relatively inexpensive to conduct and are an approach often used in business settings where time and money for the development of managers are in short supply.

One popular short-term leader development program that includes multiple training methods is the Leader Development Simulation. The Leader Development Simulation is based on a behavioral simulation that was developed almost thirty years ago. It is a person-centered behavioral simulation designed from actual organizational events that can be used as a research tool to study leadership and management behavior in complex organizations (McCall \& Lombardo, 1982). The simulation took almost three years to develop under support from the Office of Naval Research and the the Institute. The researchers conducted extensive field interviews with executives of a glass manufacturing corporation and reviewed multiple technical and business publications to develop the simulation. The simulation is conducted over one day and is part of a five day leader development training program.

Managers participating in the Leader Development Simulation (LDS) go through extensive feedback from a pre 360-degree assessment, Myers-Briggs Type Indicator (MBTI), Fundamental Interpersonal Relations Orientation-Behavior (FIRO-B), and a Reflections retrospective assessment. A few of the managers also use follow-up coaching made available to them from the Institute's executive experts. Given the use of the simulation in allowing the managers to experiment with applications and concepts of teamwork and leadership in a "safe" setting, the Leader Development Simulation has 
received positive feedback from participants. Many of these participants expressed improvements in being more effective as managers and leaders.

Although there are numerous professional and leader development programs available, there are few studies that show the effects of short term training as it relates to changes in transformational leadership behavior. Many of these programs use a 360degree feedback assessment. Some use a short follow-up questionnaire once the managers have finished the program and a few provide mentoring for a while upon completion. However, the real overarching question is: Did the manager improve his or her leadership skills, and if so, how long does the change last, a few months, a year, a lifetime? Additionally, what changes occurred in the manager's leadership skills and behavior as a result of participating in the leader development program?

\section{Statement of the Problem}

With the loss of a significant portion of the workforce (soon reaching up to fortypercent), organizations and managers are faced with a growing need to develop others in the workplace to assume formal leadership positions. Additionally, companies are faced with rapidly changing environments and growing trends in globalization which have emphasized the need to devote more efforts toward leader development (Leskiw \& Singh, 2007). However, less than 44 percent of organizations surveyed had initiated a formalized process that focused on leader development (Giber, Carter, \& Goldsmith, 2000).

To date, there are few studies that examine whether or not change resulting from participating in a relatively condensed leader development training program occurred. Many scholars have proven that change is an on-going process and does not occur instantly (Allio, 2005; Cacioppe, 1998; Humphreys \& Einstein, 2003; Lord \& Hall, 2005; 
Stumpf, 1995; Weiss \& Molinaro, 2005). Learning to lead involves learning to behave differently. Effective leadership depends on what leaders do, not on their qualities or style. The question is: Do managers really change their behaviors in a moderately short amount of time?

\section{Purpose of the Study}

The purpose of this study is to determine the impact of a leadership training program using the Leader Development Simulation simulation on transformational and transactional leadership behavior as measured by the Multi-factor Leadership Questionnaire (MLQ).

\section{Research Questions}

1. What specific transformational and transactional leadership behaviors and skills change as a result of participating in the Leader Development Simulation? If change occurred, what were the behaviors and kills that changed over time?

2. Did the manager's perception of change match that of their direct reports' perception prior to and after the training program?

3. To what extent does personality type and select demographic measures help explain variation in the change in an individual's transformational leadership behavior?

4. To what extent are there any identifiable themes between those who changed the most and those who changed the least? 


\section{CHAPTER TWO}

\section{A REVIEW OF THE LITERATURE}

Introduction

As noted in Chapter One, the purpose of this study is to determine the impact of a leader training simulation program on transformational and transactional leadership behavior. In order to understand the concepts implicit in this purpose, it is necessary to look at the academic research that has been conducted to date, including both the theoretical proposals and the empirical studies.

This review will explore the literature that informs the understanding of leader development programs and the concept of the transforming leader. The first section discusses the theories of transactional and transformational leadership developed by prominent scholars in the field of Leadership Studies. Section two focuses on leader development and training methods that are currently being used in programs globally, section three discusses the efficacy of leadership training programs on leader development, and section four examines transformational and transactional change using the Multi-factor Leadership Questionnaire (MLQ). Together these sections will identify what the literature reveals about the skills, knowledge, and experience gained from current leader development programs.

Transactional, Transformational, and Laissez-Faire Leadership Theories

In 1978, James MacGregor Burns published Leadership, universally considered one of the most influential books in the field of Leadership Studies. Burns describes leadership as "a structure of action that engages persons, to varying degrees, throughout the levels and among the interstices of society" (prologue). 
Burns (1978) analyzed the behaviors and actions of political leaders over his career with the hope of creating a general theory of political leadership. According to Burns, when society "returns from moral and causal questions to ways of practical leadership we might find that there is nothing more practical than sound theory, if we can fashion it" (p. 5). Burns was one of the first to distinguish transforming leadership from transactional leadership. According to Burns, political leaders that motivated others by exchanging rewards for services rendered were considered to be transactional:

Transactional leaders approach associates with an eye to exchanging one thing for another: jobs for votes, or subsidies for campaign contributions. Such transactions comprise the bulk of the relationships among leaders and associates, especially in groups, legislatures and parties. (p. 3)

Burns (1978) suggests that transforming leadership, on the other hand, "occurs when one or more persons engage with others in such a way that leaders and followers raise one another to higher levels of motivation and morality" (p. 20). Burns viewed leadership as transforming, meaning "the kind of leadership that can produce social change" (prologue). Bernard Bass, a contemporary leadership researcher, credits Burns' book with the "surging interest in both leadership research and leadership change" (as cited in Sorenson, 2000 , p. 2). Burns' book, in fact, was the impetus for the development of the field of Leadership Studies and according to the latest reports available there were over 600 Leadership Studies programs in the United States toward the end of the twentieth century (Binard \& Brungardt, 1997).

Bernard Bass (1985) expanded upon Burns' analysis of transactional leadership through his research into the military, public, industrial, and educational sectors. Bass developed a new theory of leadership, the Full Range of Leadership, which implies that 
leaders can exhibit all leadership dimensions: transactional, transformational, and laissezfaire. Bass asserts that the focus of transactional leaders is on an exchange:

Transactional leaders recognize what their associates want to get from their work, and try to see that they get it, if their performance so warrants. It is an exchange between rewards and promises of rewards for appropriate levels of work and leaders respond to the needs and desires of associates as long as they are getting the job done. (p. 17)

Transactional leadership was viewed by some as the most common form of effective leadership behavior in organizations (Avolio, Waldman, \& Yammarino, 1991).

Demonstrating transactional leadership meant that goals were achieved because expectations were clarified and recognition was provided to those who successfully carried out their assignments. Bass (1996) described two types of transactional leadership: contingent reward and management-by-exception.

Contingent reward (CR) motivates others to increase performance because the leader promises rewards in exchange for carrying out assignments. CR is considered an encouraging, fairly effective, and constructive transaction between the follower and leader. Management-by-exception (MBE) is considered less effective and more corrective. Bass (1999) assigned either an active or passive approach to MBE. A leader that was considered to be more prone to action before a problem occurred was considered more desirable and effective. In contrast, a leader that was passive tended to be more reactive and only took action if needed.

Transformational leadership differs from transactional when the leader understands that effective leadership is not just recognizing an associate's needs, rather leadership attempts to advance both the leaders and followers to higher levels of development. Bass (1985) described transformational leaders as those who: raise 
associates' level of awareness in achieving valued outcomes and the strategies for reaching them; encourage associates to transcend their self-interest for the sake of the team, organization, or larger policy; and develop associates' needs to higher levels in such areas as achievement, autonomy, and affiliation which can be both work and nonwork related (p. 17). Transformational leadership has been detected throughout all organizational levels (Avolio \& Bass, 1988a; Avolio, Bass \& Jung, 1996; Avolio \& Yammarino, 2002; Bass \& Avolio, 1993, 1994). However, several researchers (Avolio, Waldman \& Yammarino, 1991; Bass, Avolio, Jung \& Berson, 2000; Hater \& Bass, 1988) have argued that transformational leadership is not a replacement for other leadership styles; rather it expands upon the leader's range of skills.

Although Burns (1978) considered transformational leadership and transactional leadership at opposing ends of the continuum, Bass (1985) postulated that leaders could be both transformational and transactional, or neither, depending on the circumstances. According to Bass (1995), "transformational leadership adds to the contribution of transactional leadership to effectiveness; transformational leadership does not substitute for transactional leadership. The best leaders are both transformational and transactional" (p. 474).

Avolio \& Bass (1988) conducted a series of studies within the military and business sectors and asserted that there are four components of transformational leadership that they termed the four I's: idealized influence, inspirational motivation, intellectual stimulation, and individualized consideration; these are now briefly defined. 
Idealized influence is identified in leaders described by associates as charismatic and role models. Followers thus want to emulate such leaders. Leaders encourage their associates to develop and achieve their full potential (Avolio \& Bass, 1988).

Inspirational leaders are able to articulate shared goals and a mutual understanding of what is important. Transformational leaders are able to inspire their associates by providing a meaningful and challenging work experience (Avolio \& Bass, 1988). Inspirational leaders provide visions of what is possible and they stimulate their associates to see the organizational strategies from new perspectives.

Intellectually stimulating leaders encourage their associates by helping them to see old problems in new ways. They impel their associates to question their own beliefs, assumptions, and values when appropriate. Associates learn to undertake tough problems on their own by being creative and innovative (Avolio \& Bass, 1988).

Individualized consideration implies a mutual understanding between associates and leaders. They understand each other's concerns and developmental needs. The transformational leader who exhibits individualized consideration behavior acts as a coach or mentor to their associates. The leader is able to consider an individual's strengths and recognize the differences in each person (Avolio \& Bass, 1988). Together, the four I's make up the behaviors of a transformational leader.

The last dimension of the Full Range Leadership model is laissez-faire leadership. A laissez-faire leader is essentially a non-leader or an individual who is indifferent to a direct report's needs. Oftentimes a laissez-faire leader avoids making decisions to the detriment of the organization. Laissez-faire leadership is considered the most ineffective style in the Full Range Leadership model. 
Bass and Avolio (1994) created the Full Range Leadership model to describe the range of leadership styles. These styles are graphically depicted on a vertical axis from non-leadership to the more transformational styles in Figure 1 which shows the Full Range Leadership model as depicted by Bass and Avolio.

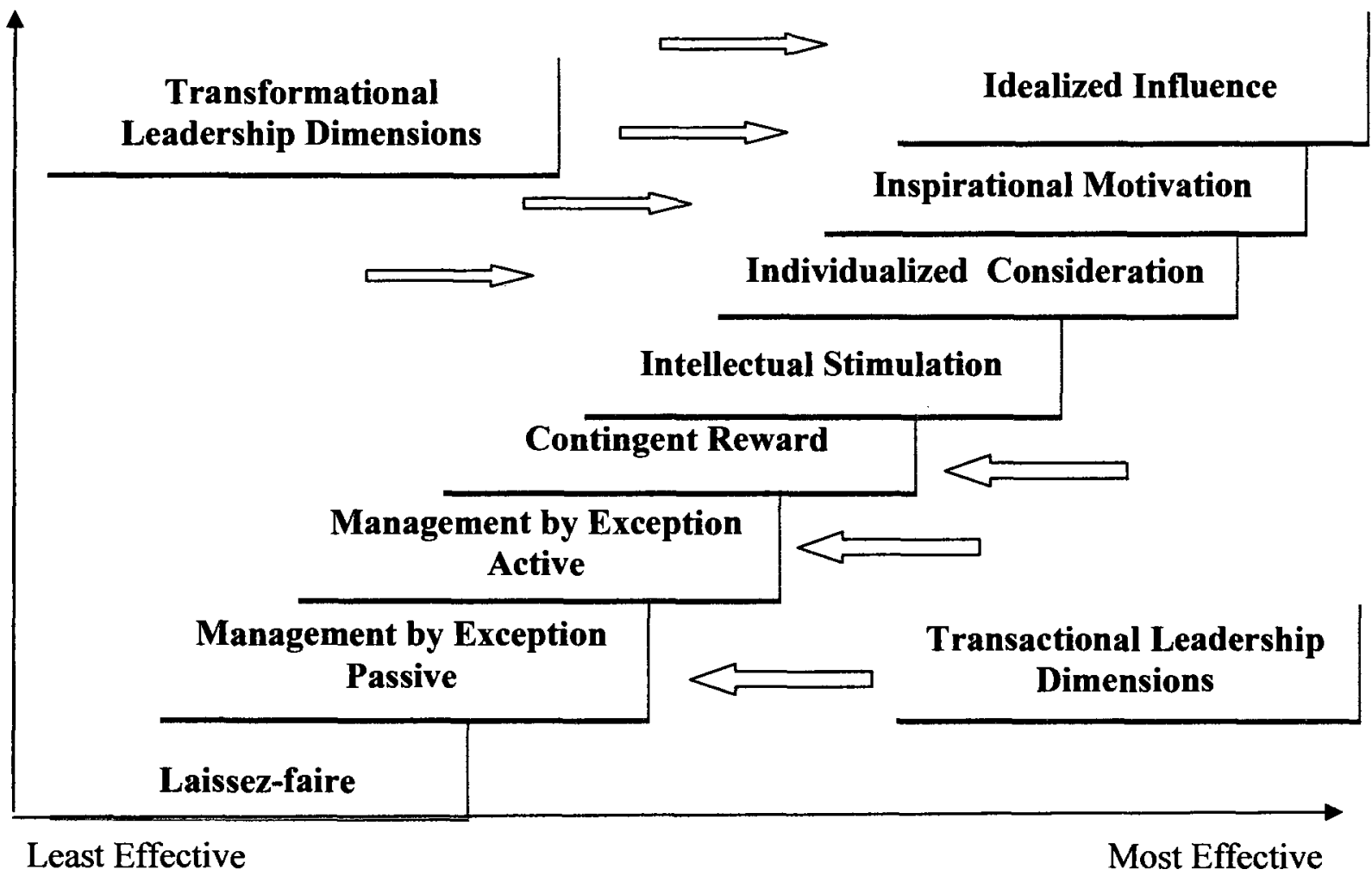

Figure 1. Full Range Leadership Model Adapted from Bass \& Avolio (1994).

Leader Development and Training Methods

Since the 1980s, there has been a significant shift in the types of development programs available for managers. The shift stemmed from the distinction between "management" and "leadership" development (Kotter, 1990; Selznick, 1957). According to Kotter, management dealt with more transactional functions of an organization, 
namely: budgeting, developing strategic plans, organizing, and providing policies and procedures for guidance. Leadership, on the other hand, was said to produce transformational change, often dramatic change that motivated people to develop a future vision together and not just from the top executive level (Bass, 1985). This section of the review will (a) discuss transformational leader development; (b) examine leader development methodologies, (c) explore the relationship between leader development and self-awareness; and (d) provide an explanation of current leader development models.

\section{Transformational Leader Development}

Transformational leadership is about becoming more fully conscious of one's own values and personal identity (Bass, 1985). The assumption is that people who become fully aware of their values and internal self will try to continue working in ways that are consistent with those values. Development is encouraged from "the inside out" and occurs when individuals repeatedly act to align their behaviors with their values (McCauley \& Van Velsor, 2004). McCauley \& Van Velsor argue that personal transformation is a necessary first step in leader development:

For many transformational leader development efforts, a further assumption is that community, organizational, or institutional transformation occurs when a critical mass of transformed leaders act individually and collectively to change norms and cultures of organizations and policies and practices of institutions and systems. Leadership tasks that are frequently valued include helping others become more aware, freer, and more willing to act from their own values and supporting organizational, institutional, and community change in the direction of more decentralized power and autonomy. (p. 199-200)

Many leader development program creators believe that efforts to design personal transformation leadership programs are the most lasting ways to stimulate community change, particularly if they can maintain their transformed behaviors over time (McCauley \& Van Velsor, 2004). Furthermore, many supporters of personal 
transformation efforts believe the skills needed to lead in the "twenty-first century, such as the capacity to work effectively with people from many cultures and backgrounds, the ability to lead toward an uncertain future, and the ability to see patterns or find the big picture from many disparate parts (Heifetz, 1994; Senge, Jaworski, Scharmer \& Flowers, 2004; and Weatley, 1999) are best explored, understood, and internalized through a process of inside out leadership development" (McCauley \& Van Velsor, 2004, p. 200).

If one accepts Heifetz's (1994) definition of leadership as mobilizing people to do adaptive work or as orchestrating positive change, then leader development, as it relates to transformation, is a crucial step in the process of enhancing leadership effectiveness. Another part of leader development is the relationship between leader development and adult development. There are several scholars who view leader development in the context of adult development (Axelrod, 2005; Kegan, 1994; Rost, 1991). The next section will explore the relationship between leader development and adult development.

\section{Leader Development and Adult Development}

Many leadership researchers (Hasegawa, 2003; Kegan \& Lahey, 1984; Kuhnert \& Lewis,1987; Rost, 1991; Zullo, 1997) interested in the connection between leader development and adult development use the constructive/developmental theory outlined by Robert Kegan (1982). Constructive/developmental theory assumes that individuals construct a subjective understanding of the world based on past experiences which then shape future experiences as opposed to their directly encountering an objective "real" world. Constructive/developmental theory highlights sequential patterns in ways that people construct meaning. Kuhnert \& Lewis (1987) focus on three of Kegan's developmental stages and how they relate to transactional and transformational 
leadership: Stage Two Imperial (lower-order transactional), Stage Three Interpersonal (higher-order transactional), and Stage Four Institutional (transformational). According to Kuhnert \& Lewis, Stage Two leaders:

May say that they aspire to higher order transactions (e.g., team spirit, mutual respect), but from the perspective of cognitive/developmental theory they have not developed the organizing processes (subject) necessary for understanding or participating in mutual experiences and shared perceptions (p.652).

Stage Three leaders see their experiences as interpersonal connections between followers and leaders with mutual obligations and goals. Kuhnert \& Lewis (1987) argue that stage three leaders are slightly more developed than stage two leaders because they override some of their personal needs for the needs of others.

Stage Four leaders are seen to be more transformational leaders because they have "developed a subjective frame of reference that defines their selves, not in terms of their connections to others but in terms of their internal values or standards" (p. 653). In stage four, leaders transcend their own agendas for the good of the group and/or organization.

Transformational leaders motivate followers to accept and accomplish difficult goals that followers normally would not have pursued. Transforming leadership is made possible when leaders' end values (internal standards) are adopted by followers, thereby producing changes in the attitudes, beliefs, and goals of followers. It is end values such as integrity, honor, and justice that potentially can transform followers. Further, the commitment of followers to their leaders' values causes leadership influence to cascade through the organization (Kuhnert \& Lewis, 1987, p. 653).

According to Steven Axelrod (2005), a psychoanalyst and executive coach whose most common assignment is developing middle managers, understanding the "normative developmental challenges of [middle managers] can help the coach guide the executive through the transformational task" (p. 120). Axelrod argues that when an executive reaches the transition to midlife a restructuring of a person's personality emerges with an 
increase on awareness, insight, and affiliation. He discusses Erikson $(1950,1958,1968)$ and Gould (1972) in terms of personality believing that as a person ages, growth in one's personality is "built on resilience in the face of setbacks, increased concern with the meaning of life and the process of taking stock, and greater self-acceptance (Axelrod, 2005, p. 122). Axelrod describes adults who continue to develop as those with an increased capacity to accept what is real in life and have a greater self-awareness and authenticity.

Over the course of an executive's career, Axelrod (2005) argues that a person moves from being technically competent with business knowledge (transactional) to more of a whole person and how he/she relates to the self, system and society (transformational). Axelrod acknowledges that executives "move at varying rates and with different degrees of self-awareness along the adult developmental curve" (p. 124). Understanding how adult development relates to leader development can be an effective tool for executives in their on-going efforts to be better individuals and to lead effectively.

James Zullo (1997) attributes the enthusiasm of adult and leader development research to Rost's (1991) postindustrial paradigm of leadership. Zullo applauds Rost for incorporating adult development in the core curriculum of the leadership studies program at the University of San Diego. Zullo brings together, what he calls, the historical movements in human development: 1) research on women's adult development, 2) Kegan's constructive-developmental framework, and 3) McAdams and McClelland's research on power and intimacy. 
Zullo (1997) states that, research on women's adult development by female developmental psychologists has led to the inclusion of affiliation, attachment, and connectedness to the field of leadership development. Jean Lipman-Blumen (2000) developed the Connective Leadership Model explaining how leaders should move beyond competition toward more connected modes of working with and through other people. Adding to the literature, are the moral development theorists Kohlberg (1984) and Gilligan (1982) who discuss justice and care (respectively) in their work with men and women. The justice and care perspectives, as well as the incorporation of research on women by women, have significantly influenced how we now conceptualize and think about adult and leader development.

Zullo's (1997) third movement acknowledged the importance of power and intimacy in adult development. Zullo explains how leadership involves an influence relationship where "both leaders and collaborators must earn the right to influence; not by gender, age, position or status, but by the cogency and persuasiveness of their vision and conviction" (p. 124). Much like Kuhnert \& Lewis (1987), Zullo articulates that leadership is an exercise of mutuality between the self and other.

Another aspect of the relationship between leader development and adult development is what Donald Schon (1983) termed the "reflective practitioner." Reflective practice occurs when people take a larger view and look at the underlying assumptions that drive their actions. Through this process they begin to understand how they relate to others, to the organization, and to a larger system. Understanding how the self can continually be developed as people move through their adult life can improve people's ability to manage the complexities of organizational life. A positive result of 
adult development is the ability to demonstrate adaptive, flexible leadership that remains true to purpose, even during tumultuous times.

Most researchers today argue that leadership typically involves a more complex mix of behavioral, cognitive, and social skills that may develop at different rates and require different learning experiences (Day \& Halpin; 2004; Lord \& Hall, 2005; Zaccaro \& Klimoski, 2001). To learn about leadership and practice complex skills, it has been argued that the leadership role must become part of one's self identity (Lord \& Hall, 2005):

Identity is a central focus because it provides an important structure around which relevant knowledge can be organized; is a source of motivational and directional forces that determine the extent to which the leader voluntarily puts himself or herself in developmental situations; and may provide access to personal material (i.e., stories, core values, etc.) that can be used to understand and motivate direct reports. (p. 592)

Lord \& Hall (2005) postulate that leadership skills move from the novice or micro-level skills (production) to increasingly higher level systems that guide behavior and social perceptions. They suggest that over time, leadership skills become integrated with the development of "one's self-concept and that leader's identities tend to shift from the individual to more collective orientations as their expertise develops" (p. 592). This development over time also depends on the degree to which an individual is willing to change his or her behavior.

Questions about why and how people change has been a consistent focus in leader development programs (Spreitzer \& Quinn, 1996; Walinga, 2008). Change readiness was initially rooted in the early organizational change research such as that of Schein \& Bennis (1965). Change readiness theory began with early studies on "creating readiness" by "reducing resistance to change" (Walinga, 2008, p. 318). Most change readiness 
models higlight two important predictors of change: 1) an awareness of the need for change, and 2) supporting people's perceived ability to change (Walinga, 2008). Walinga (2008) argues that all change, whether organizational or individual, depends on a person's willingness to change. Other researchers (Antonovsky, 1987; Bandura, 1995; Lewin, 1958) describe some form of "personal transformative change" as a process that involves letting go of past assumptions, progressing toward new perspectives, and relearning. Typically, the primary focus of leader development efforts is trying to get individuals to change and improve their leadership abilities. The next section will explore different leader development methods and explain the factors that contribute to the transformational growth process.

\section{Leader Development Methods}

Leader development is a broad term and most leadership scholars today conceptualize leadership as a result of dynamics over an entire social system wherein anyone can exhibit leadership (Day, 2000; Heifetz, 1994; Lord \& Smith, 1999). This system's approach to leadership is useful when explaining leadership as part of a larger social group. Some refer to leadership development as building the organizational capacity for leadership, while leader development focuses on the development at the individual level. This review is focused on a more narrow form of leader development referring to the behavior and skills acquired by an individual while still acknowledging that it may include the capability of eliciting leadership from others.

Managers and leaders are different and according to many in the corporate sector there are too many managers and too few leaders (Conger, 1999; Kotter, 1990; Zaleznik, 1990). Bryman (1992) and House (1995) suggest that many organizations in the United 
States are unable to adapt to a global competitive environment that is continually changing due to too much management and too little leadership; thus the need for leader development. Currently, organizations are devoting significant resources toward leadership training for their employees with the expectation that the investment will result in enhanced overall business performance, both for the individual and the company.

Day (2000) asserts that entire industries are finding it necessary to continually reinvent themselves and are realizing that they must attend to both individual leader and collective leadership development. According to Day, individual leader development includes: self-awareness (e.g., emotional awareness, self confidence, accurate self image), self-regulation (e.g., self-control, trustworthiness, personal responsibility, adaptability), and self-motivation (e.g., initiative, commitment, optimism). Collective leadership development includes: social awareness (e.g., empathy, service orientation, political orientation) and social skills (e.g., building bonds, team orientation, change catalyst, conflict management). Together, organizations should link both individual and collective leadership development as a broader strategy if they want a maximum return on their training investment (Day, 2000).

McCauley \& Van Velsor (2004) suggest the way to expand leadership capacities is to develop the individual with an eye to the roles and processes they may encounter, rather than looking at the traits or characteristics:

Leader development is the expansion of a person's capacity to be effective in leadership roles and processes. Leadership roles and processes are those that facilitate setting direction, creating alignment, and maintaining commitment in groups of people who share common work. (p. 2)

The question that many scholars debate is whether, individuals can be developed or changed in order to be effective leaders (Allio, 2005; Stumpf, 1995; Weiss \& 
Molinaro, 2005). There is a general belief among a number of scholars that individuals can learn and develop in ways that make them more effective in exercising leadership (Heifetz, 1994; Kouzes \& Posner, 1987; Leiberman, 2006). Several scholars have argued that creating multifaceted experiences and providing individuals with the tools to be capable of learning enhances leader development (Kirkbride, 2006; McCall, 1998; Stumpf, 1995).

Leader development "can be interpreted as a form of individual-based differentiation in terms of helping individuals enhance a unique self-understanding and construct independent identities" (Day, 2000, p. 5). By applying self-understanding to both social and organizational imperatives, individuals can understand how to relate to others, build commitments, and develop extended social relationships. Understanding the self and how a person is perceived by others is considered to be the first step in many leader development programs.

\section{Leader Development and Self-Awareness}

Over the past fifteen years, there has been an increasing amount of attention given to self-awareness among management and leadership researchers and its effect on organizational and individual performance (Atwater \& Yammarino, 1992; 1997; Krishnan, 2003; Moshavi, Brown, \& Dodd, 2003; Sosik \& Megerian, 1999; Tekleab, Sims, Jr., Yun, Tesluk, \& Cox, 2008). Self-awareness is connected to the idea that if we know our self and are more cognizant of how we are perceived by others, we can incorporate the information from others into our own self-appraisals and behavior (Moshavi et al., 2003). Studies conducted by Atwater and Yammarino $(1992,1997)$ 
found that individuals who are more self-aware are considered to be more: committed to their jobs, satisfied, and effective leaders and managers.

According to Riggio (2008), nearly every author who writes about leader development mentions that:

Leaders must develop awareness of their own leadership strengths and limitations to capitalize on strengths and overcome shortcomings...leaders need to be open to feedback from assessment tools, to take note of ratings of their leadership from superiors, peers, and direct reports, to heed the advice of their executive coaches, and to personally reflect on and self-critique their leadership. (p. 387)

Several leadership scholars have argued that self-awareness is integral to transformational leadership effectiveness (Atwater \& Yammarino, 1992; Bennis, 1989; Megerian \& Sosik, 1996). Prior research has shown that transformational leaders who are self-aware also possess high levels of self-efficacy and self-confidence while also providing orientation for their followers (Bass, 1985; Megerian \& Sosik, 1996; Sosik \& Megerian, 1999). Goleman (1998) suggests that intrapersonal and interpersonal awareness are key components of emotional intelligence and effective leadership. Sosik and Megerian (1999) found that self-awareness "may support a leader's translation of purpose and meaning in life into invigorating challenges for followers. Such translation of thoughts into actions may enhance ratings of transformational leadership by followers" (p. 384). They imply that leaders who are self-aware are better at "hearing" the emotions of not only their own thoughts and feelings but the thoughts and feelings of others. They also suggest that a leader's agreement with their associates (or self-awareness) about his or her own transformational leadership is associated with leadership effectiveness. Previous research investigating the disparity between selfdescriptions of leadership and descriptions provided by their direct reports, has found that 
the more an individual's rating of their leadership is "in-agreement" with others the more effective they are in their leadership as it effects their direct reports (Atwater \& Yammarino, 1997; Moshavi, Brown, \& Dodd, 2003; Tekleab, Sims, Jr., Tesluk, \& Cox, 2008).

A principle feature of transformational leadership theory is its emphasis on follower development. According to Bass (1995), transformational leaders develop followers into leaders:

They elevate the concerns of followers on Maslow's need hierarchy from needs for safety and security to needs for achievement and self-actualization, increase their awareness and consciousness of what is really important, and move them to go beyond their own self-interests for the good of the larger entities to which they belong. (p. 467)

It has been confirmed in numerous empirical studies that transformational leadership increases direct report's effort and satisfaction (Bass \& Avolio, 1990; Bennett, 2009; Howell \& Frost, 1989; Kirkpatrick \& Locke, 1996; Moshavi, Brown, \& Dodd, 2003; Tekleab, Sims, Jr., Yun, Tesluk, \& Cox, 2008), positively impacts direct report development (Dvir, Eden, Avolio \& Shamir, (2002), and improves direct report performance (Hater \& Bass, 1988; Howell \& Hall-Merenda, 1999; Humphreys, 2002; McColl-Kennedy \& Anderson, 2002). According to Day (2004), "all employees are potential leaders and the major role of a leader is to develop leader skills among employees at all levels of the organization in order to transform their organization (p. ix).

Day (2004) contends that organizations must have leaders beyond those who are in formal leadership positions. Although those in formal leadership positions may have final authority, developing others to have the skills, abilities to understand others' perspectives, take initiative, and provide direction is essential to support the 
organizational leadership at all levels. Transformational leadership involves developing others as well as developing one's self. It brings personal satisfaction by helping others grow and stimulates others to deal with problems that they might not otherwise do within their defined roles.

Self-awareness of one's own leadership and transformational leadership has been shown to positively affect follower satisfaction with their supervisor, increase follower performance, and augment follower self-leadership (Bass \& Avolio, 1990; Dvir, Eden, Avolio \& Shamir, 2002). Therefore one would expect that leader development models that enhance self-awareness along with other dimensions of adult development would better assist managers to become effective leaders.

\section{Leader Development Models}

A variety of leader development models have been introduced in the last twenty years building upon traditional management classroom training to including more integrated approaches of leader development which takes place in the context of the work itself. Leader development models include mentoring, executive coaching, 360-degree feedback, action learning, and behavioral simulations.

\section{Mentoring}

Mentoring is typically defined as "a committed, long-term relationship in which a senior person supports the personal and professional development of a junior person" (Hernez-Broome \& Hughes, 2004, p. 25). There are varying degrees of mentoring programs. Some are highly structured and have been in place for years, while others are more open relationships (Leskiw \& Singh, 2007). In a classical sense, mentoring is a private relationship largely dependent on the chemistry between the mentor and the 
protégé. It was found to be very beneficial in accelerating the transfer of knowledge necessary for leader development (Leskiw \& Singh, 2007). Many organizations are increasingly looking at ways to formalize mentoring programs as part of their on-going professional development efforts (Hernez-Broome \& Hughes, 2004).

\section{Executive Coaching}

Executive coaching involves specific and practical forms of one-on-one learning (Leskiw \& Singh, 2007). Executive coaching is "a powerful developmental activity that influences both work behavior and overall personal well-being" (Axelrod, 2005, p. 118). Oftentimes, the purpose of coaching is to provide some advice and motivation for potential leaders as part of a leader development program. Frequently, personal learning objectives are developed and strategies are identified between the coach and the executive. The coach adds value by examining decisions and behaviors of the executive so that they can improve their leadership abilities and providing frank and honest feedback on the impact of those behaviors.

360-degree Feedback Assessment

A 360-degree feedback assessment provides feedback about an individual from their supervisors, peers, direct reports, others such as customers and/or stakeholders, and also includes a self-assessment. The assessments from various observers regarding an individual's behavior and performance represent an attempt to garner greater selfawareness by seeing oneself as others do. This type of instrument can therefore be used as a tool for leader development (Alimo-Metcalfe, 1998). According to Murphy (2004), over $80 \%$ of all Fortune 500 organizations use some form of 360 -degree feedback as a performance evaluation tool. 
One specific type of 360-degree feedback is the Multi-factor Leadership Questionnaire (MLQ). Bass \& Avolio (1994) developed the MLQ to measure the extent to which leaders exhibit leadership behaviors based on their Full Range Leadership Model (FRLM). According to Bass \& Avolio, the FRLM is used specifically to describe the broadest range of leadership behaviors in order to differentiate ineffective from effective leaders. The constructs comprising the full range leadership model denote the three types of leadership behavior: passive laissez-faire, transactional, and transformational. These behaviors are represented by nine distinct factors, discussed earlier and presented in Figure 1, which are assessed using the Multi-factor Leadership Questionnaire (MLQ) 5x short form presented in Appendix A.

The full range leadership model, as measured by the MLQ, implies that leaders exhibit both transformational and transactional behaviors:

Every leader displays a frequency of both transactional and transformational factors, but each leader's profile involves more of one and less of the other. Those leaders who are more satisfying to their followers and who are more effective as leaders are more transformational and less transactional. (Bass, 1999, p. 11)

According to Bass (1995), transformational leadership contributes to effectiveness, yet "transformational leadership does not substitute for transactional leadership" (p. 474). There has been an abundance of empirical studies supporting the theoretical assumption that the best leaders demonstrate both transformational and transactional behavior (Bass, 1990; Bass, Avolio \& Goodheim, 1987; Kessler, 1993; Lowe \& Galen, 1996; and Waldman, Bass, \& Yammarino, 1990). Currently leader development programs focusing on the FRLM have been completed by more than 1,000 executives, administrators, and managers in both the profit and non-profit industry sectors (Avolio \& Bass, 2002). 


\section{Simulations}

There are two general types of leader development simulations: computer generated and behavioral. Computer generated simulations place individuals in a "simulated" environment where there is turbulence in the business or community. Participants attempt to solve complex leadership problems. Behavioral, or "in-basket," simulations are a second method used in leader development programs. Individuals assume various management roles and are given a "basket" full of memos and emails which range from daily transactional problems to concerns for business survival. Computer and behavioral simulations closely parallel real business activities and participants find their performances mirror the behaviors they exhibit at work.

There is general consensus that leader development simulations help individuals develop the ability to recognize opportunities, gain a more complete view of how they affect the organization, gain self awareness, and develop skills in managerial judgment (Anderson \& Lawton, 1997; Gosen \& Washbush, 1997; Schepereel, 2005). For individuals participating in a leader development simulation, running a simulated company is an authentic experience relative to the experience of making a decision about a case study. Understanding the influence of people both within and outside of an organization and how decisions can influence the success or failure of an organization is an objective of leader development simulations.

Simulations permit managers to apply their knowledge and work experience while learning about leadership in a "safe" environment. Simulations provide almost immediate feedback to managers, reinforce leadership concepts that they have learned, and build confidence in the skills they are developing (Parente, 1995; Wheatley, Roberts, \& 
Einbecker, 1990). Leader development simulations also give managers an opportunity for a "hands-on" activity and bring to life the interdependence between the organization and the community where they operate (Stephen, Parente, \& Brown, 2002).

Many research studies have found that simulations have the advantage of teaching individuals how to solve problems, measure objectives, and forecast results while allowing managers to practice in an environment without risk (Schepereel, 2005; Teach \& Govahi, 1988). Several of these studies have demonstrated that simulations can teach leadership skills such as interpersonal relationship-building, problem-solving, and decision-making in turbulent and complex situations (Anderson \& Lawton, 1997; Wolfe \& Luethge, 2003). In addition, there are a few studies which have concluded that simulations change managers' perspectives with regard to how they make decisions (Scherpereel, 2005; Senge, 1990). The next section will explore how managers participating in simulations learn the skills and competencies to be more effective in exercising leadership.

Exploring How Individuals Learn from Leader Development Simulations The theory that supports leader development using behavioral simulations is based on experiential learning. John Dewey's (1938) book, Experience and Education, serves as a foundation for experiential learning theory. In his book, Dewey described experiential learning theory based on the assumption that knowledge is socially constructed and built on experiences. The quality of the experience, in his opinion, is the primary component of learning.

Other researchers often cited in the simulation research literature who have expanded on Dewey's theory are David Kolb and Roger Fry (1975). Kolb \& Fry 
conceptualized the experiential learning circle and based it on four elements: 1) concrete experience, 2) observation and reflection, 3) the formation of abstract concepts, and 4) testing in new situations. They argue that effective learning entails possession of these four different elements to some degree. In their opinion, experiential learning involves direct encounters with the phenomena being studied. Thus, experiential education has the ability to provide individuals with knowledge and the ability to apply that knowledge in many situations. Simulations use experiential theory to place people into "real" life situations that allow them to learn from their experiences and gain knowledge they can apply later in different situations.

Popper (2004) identified three theoretical principles for the basis of leader development learning: 1) experiential learning, 2) vicarious learning, and 3) transformational learning in a critical period. Popper states that "all the major theories on learning and developmental psychological processes, whether explicitly or implicitly, place experience at the Institute of the learning process (p. 66). Kohlberg (1963), considered one of the most well known adult development theorist in the area of moral development, used a "role taking" approach in his experiments so that individuals had to adopt the perspective of another. Kohlberg's findings showed that the experience of placing oneself in the role of another led to more complex thinking and a better understanding of the other's reasoning.

Popper's (2004) second principle, vicarious learning, involves learning from the observation of others' behaviors. Popper states that "learning by observation is important because it expands the opportunities for learning a broad range of behaviors occurring in situations that are too complex to be created artificially for learning purposes (p. 67). 
Several researchers (Bandura, 1995; Hackett \& Betz, 1995; Maddux, 1995) agree with Popper finding that people who observed others' behaviors, especially when positive reinforcement was received, had a propensity to emulate that person. Furthermore, authors of numerous articles (Kotter, 1988; Kouzes \& Posner, 1987; McCauley \& Van Velsor, 2004) reported that people in organizations learned about leadership by observing others, especially during critical incidences in their lives.

Popper's (2004) third principle, transformational learning in a critical period, is based on the importance of various experiences that occurred in a person's life that critically influenced them and aided their leader development. Kotter (1988) found through interviews with numerous managers, that their adult and leadership development was influenced from earlier experiences in their careers, particularly during a crucial period. Popper summarized his findings by stating that the following principles emerge in most all of the leading developmental learning theories: 1) the central importance of both direct experience and observation of role models in emotional and social development and 2) the existence of periods of more intensive development in various aspects (p. 68). While both case discussions and behavioral simulations are intended to provide active and applied learning, some assert that simulations elicit greater responses from managers than case studies and they are more effective in enhancing self-efficacy (Knotts \& Keys, 1997; Mitchell, 2004; Teach, 1993). Several empirical studies found that simulations, in general, have a perceived benefit especially when compared to traditional lecture seminars or programs (Anderson \& Lawton, 1997; Azriel, et al., 2005; Schepereel, 2003). However, many note that the outcomes are not based on objective measures of learning (Stephen, Parente, \& Brown, 2002; Teach \& Govahi, 1988). While 
these studies agree that integration of knowledge can be taught in multiple ways, the way learning is quantified remains elusive. Therefore, it is essential to explore exactly how individuals, who participate in behavioral simulations, learn and develop before evaluation of effectiveness can be confirmed or denied (Stephen, et al., 2002).

Learning is a complex construct and difficult to quantify. However, the assessment of learning is necessary with regards to behavioral simulations because researchers in the field of simulation and experiential learning are concerned with whether or not learning occurs (Anderson \& Lawton, 1997; Gosen \& Washbush, 2004; Stephen, et al., 2002). Because most simulations are complex, integrative, and involve a team experience, the challenge of how to quantify learning remains.

Another challenge in assessing learning rests with the fact that simulations are rarely used in isolation in leader development programs. Usually the facilitator will incorporate the simulation with coaching and peer review assessments. Therefore, the various types of pedagogical methods used influence the learning that occurs over the course of the simulation experience and it is often difficult to parse out the effects of individual techniques and methods. When researching the impact of simulations one must therefore be alert to intervening variables.

Current literature that evaluates learning from simulations divides assessment of the learning into two parts: the learning process and learning outcomes. There are different theories associated with both. Some important theories associated with the learning process include; Bloom's taxonomy of learning (1956); Tonks \& Armitage's (1997) framework of learning styles; and Bernard Keys' (1990) management learning grid. 
Bloom (1956) believed that teaching should focus on "mastery" of subjects and on the promotion of higher forms of thinking, rather than simply conveying facts. Bloom, along with other educational psychologists, developed a taxonomy of learning that includes three overlapping domains: the cognitive, affective, and psychomotor. Cognitive learning most closely represents what simulations attempt to teach based on six categories for learning: 1) knowledge; 2) comprehension; 3) application; 4) analysis; 5) synthesis; and 6) evaluation.

Another method for conceptualizing the learning process was developed by Tonks \& Armitage (1997). They created a framework for understanding learning based on student learning styles—-holist, serialist, or versatile—and their depth of learning—deep or surface. A holist thinks of several things at once, integrating ideas and concepts as they are encountered. A serialist prefers to deal with the facts and takes one step at a time and a versatile student can switch between the two. By understanding an individual's learning style the researcher can be more adaptive when attempting to quantify the learning that takes place at a given time.

Another prominent researcher, Bernard Keys (1990), developed a Management of Learning Grid founded on the premise that an effective instructional style requires balance of four factors considered essential to effective learning in simulations: 1) the dissemination of new ideas, principles, and concepts; 2) an opportunity to apply content in an experiential environment; 3) feedback as to the result of actions taken; and 4) the relationship between performance at each phase in experience (Keys \& Wolfe, 1990). Keys and Wolfe believed the focus of learning should be on the process and not the outcome. 
The second dimension for evaluating learning according to Keys and Wolfe (1990) is to examine the learning outcomes associated with the simulation. These outcomes are based on several criteria: 1) an individual's perceptions of learning; 2) simulation performance; 3) manager's self-efficacy; and 4) knowledge and skill development based on the objectives of the leader development program.

Many studies have focused on an individual's perceptions of learning (Anderson, 2005; Hemmasi \& Graf, 1991; Van Auken \& Chrysler, 2005). Managers evaluate themselves on criteria believed to be important according to the objectives of the program and based on the researcher's judgment. Often an individual's perception of how much knowledge they gained directly relates to how well they or their team performed on the simulation (Wolfe, 1997).

Performance is often used as a method for quantifying learning outcomes from simulations. Simulations are considered to help managers analyze, synthesize, evaluate, and apply knowledge. It has been hypothesized that successful "players" would perform better with these skills than less successful ones (Wolfe, 1997). However, research on the relationship between simulation performance and learning has suggested that the two variables do not covary (Anderson \& Lawton, 1997; Feinstein \& Cannon, 2002; Washbush \& Gosen, 2001).

Other studies have looked at individual learning outcomes particularly in the area of an individual's self-efficacy (Knotts \& Keys, 1997; Tompson \& Dass, 2000). Selfefficacy is defined as the belief that one has, in their capabilities, to execute and organize the courses of action required for them to attain their goals. This principle suggests the greater an individual's self-efficacy, the better leader the person will become. Therefore, 
simulations that mimic the activities of leadership should provide individuals with greater confidence when they return to the workplace.

Some studies have evaluated learning outcomes based on a predefined set of leadership skills (Anderson \& Lawton, 1997; Teach \& Govahi, 1993). Most of these skills are based on what researchers have found to be necessary in the workplace. There are also several studies that have compared what is learned from simulations versus what is learned from the traditional lecture or case study method (Keys \& Wolfe, 1990; Leonard \& Leonard, 1995).

Common themes associated with the comparative learning studies between cases and simulations suggest that the ability to see the big picture was best developed using cases, whereas developing interpersonal relationships was best learned through simulations (Stephen, et al., 2002). Simulations were also rated best for exhibiting leadership, solving problems creatively, and resolving conflict (Teach \& Govahi, 1993).

Certainly, there are many different theories on how to quantify learning in simulations in terms of the learning process and learning outcomes. There are numerous studies that have focused on these theories to try and understand whether or not simulations are an effective tool for learning and developing leadership competencies (Leonard \& Leonard, 1995; Teach \& Govahi, 1993; Wolfe, 1997). However, there are few empirical studies that measure the efficacy of leader development programs in terms of sustained behavioral change after the training (Avolio \& Bass, 1998; Dvir, Eden, Avolio, \& Shamir, 2002; Kelloway, Barling, \& Helleur, 2000). 


\section{Efficacy of Leader Development Programs}

Researchers have used a variety of learning and methodological techniques to evaluate the effectiveness of leader development programs. These techniques are fundamentally of two kinds: 1) those that examine the relationship between individual change and changes in organizational performance or system's analysis (Wheatley, 1999; Wilbur, 2000); and 2) those that attempt to measure the intangibles of change, namely changes in consciousness (McCauley \& Van Velsor, 2004). Evaluation provides the possibility of examining whether personal transformation occurs and whether the inner change leads to change observable by others. There is an increasing body of evidence in the literature that leadership does make a difference in organizational effectiveness (Alimo-Metcalfe \& Alban-Metcalfe, 2002; Boaden, 2005; Moshavi, Brown, \& Dodd, 2003) however, there is considerable controversy over how to measure the change from leader development programs (Avolio \& Hannah, 2008; Bycio, Hackett, \& Allen, 1993).

How does one decide whether the leader development program was successful? Some scholars (Hunter, Bedell-Avers, \& Mumford, 2007) argue that an assumption is often made which presupposes that, “all employees require leadership and that leadership impacts each of them equally" (p. 437). Other researchers (Eagly, Makhijani, \& Klonsky, 1992; Hunter, Bedell-Avers, \& Mumford, 2007; Pawar, 2003) have suggested that the efficacy of leader development programs cannot be evaluated without fully understanding the organizational context that created the need for leadership to be exercised. It has been argued that different types of organizational context can generate varying degrees of a need for transformational leadership (Bass, 1998; Pawar, 2003). For example, the influence of a highly technological orientation expected to operate largely within the 
bounds of technical and economic rationality could constrain the occurrence of transformational leadership (Pawar, 2003). The applicability of transformational leadership for organizations working toward social movements will likely be needed more than those in a technological system which tends to be heavily task-oriented.

Kelloway and Barling (2000) argue that the intervention could only be deemed a success, if the leaders' direct reports saw an increase in certain leadership behaviors. Over 35 studies have reported positive relationships between transformational leadership and follower performance (Kirkpatrick \& Locke, 1996). The concept that several, and in some cases, all dimensions encompassing transformational leadership influence organizational attitudes and profitability outcomes is well established in the leadership literature (Avolio, 1999; Bass, 1985; 1990; Conger \& Kanungo, 1987; Moshavi, Brown, \& Dodd, 2003). A meta-analysis by Lowe, Koreck, and Sivasusbranabiam (1996) reported modest to substantial links between facets of transformational leadership and work performance among direct reports.

Researchers have studied the relationship between the behaviors associated with transformational and transactional leadership and direct reports' productivity, job satisfaction, and leadership effectiveness for the past several decades. Therefore it is reasonable to examine the relationship between self-other agreement and leadership effectiveness. While a complete list of all of the studies is beyond the scope of this review, several studies will be discussed because of their relevance to this dissertation. Common to these studies are: 1) the MLQ 5x form was used to measure the manager's transformational leadership behavior based on assessments by direct reports, 2) managers had been engaged in some form of a leader development program, and 3) the 
extent of difference between self evaluations and the assessment of others (self-other agreement) was analyzed.

\section{Transformational Change and the MLQ}

Kelloway, Barling, and Helleur (2000) examined the effects of leadership training on direct reports' observations of transformational leadership. Forty department managers working in a health care corporation were randomly assigned to one of four groups: 1) no training, no counseling, 2) no training, counseling, 3) training, no counseling, and 4) training and counseling. The training consisted of a one day workshop familiarizing the managers with transformational leadership concepts and application in the workplace. In a one-hour counseling session, participants were given the feedback from their direct reports regarding their leadership style and their MLQ scores were explained. A pre-test was conducted prior to the interventions and a post-test was conducted six months after the intervention. In a sample of 3,177 participants, pre-test results indicated no significant difference in direct reports' ratings of managers' transformational leadership $(F=1.12$, ns). Post-test data resulted in a significant model $(F=4.92, p<0.05)$. Managers who either participated in the training or feedback sessions were rated as exhibiting more transformational leadership than those who did not receive the interventions. The group that received both training and feedback were not rated as being more transformational than the groups receiving either training or feedback. Their results suggest that either approach can be an effective intervention to increase transformational leadership behavior and leadership behavior can be changed over a relatively brief period of time.

Dvir, Eden, Avolio, and Shamir (2002) conducted a longitudinal, randomized field experiment on 54 military cadets, 90 of their direct followers, and 724 of their 
indirect followers testing the impact of transformational leadership, enhanced by training on follower development and performance. Cadets in the experimental group received a three-day workshop designed to inculcate the major propositions of transformational leadership theory $(n=32)$ while cadets in the control group participated in a three-day routine diverse leadership training workshop $(n=22)$. Cadets were randomly selected into one of the two types of training and all leaders were men aged 18-22. The experimental group used the 20 transformational leadership items using the MLQ 5x form. The posttest measurement occurred six months after the leadership training workshops.

Twelve trainers from the Israel Defense Forces (IDF) School for Leadership Development participated in this study as trainers of cadets. Seven trainers were randomly assigned to participate in delivering the transformational leadership model to the experimental cadets and five trainers were assigned to the control training with no preliminary transformational training workshop. Measures were analyzed using seven developmental concepts: self-efficacy, collectivistic orientation, critical-independent approach, extra effort, active engagement, internalization of moral values, and selfactualization needs.

All but two of the developmental coefficient alphas were above .70 , and most exceeded .80 . Alphas were .60 and .69 for self-efficacy and collectivistic orientation in only one subsample. Significance between the experimental group and the control group was found for: 1) self-efficacy ( $p<.05)$, extra effort $(p<.05)$, and critical-independent approach $(p<.01)$. Significance was not found in: collectivistic orientation, active engagement, internalization of moral values, or self-actualization needs. Transformational leadership enhanced at least one measure each of morality, motivation 
and empowerment. The influence of transformational leadership was not established for the direct followers' internalization of moral values, active engagement, and selfactualization needs.

Avolio and Bass (1998) conducted a field study to examine the impact of a leader development program using pre and post ratings from the MLQ $5 x$ form. The leader development program focused on two modules: a three day basic workshop and afterward a two to three day advanced workshop. The time interval between the two workshops was approximately three months. The program included basic knowledge regarding the full range leadership model, simulations, exercises, and emphasis on action learning. Feedback from the MLQ $5 \mathrm{x}$ form was also provided during the basic workshop. Additionally, individuals were asked to write a personal leadership development plan. Sixty-six participants were included in this study. The post-test was conducted between six months and two years later using the MLQ scores from their followers. Significant gains appeared for idealized influence $(p<.05)$ and intellectual stimulation $(p<.02)$ in those individuals who had included them as a plan for change. There was no significant difference between any of the other dimensions whether it was a stated goal or not. Most individuals showed a least some improvement in one or more components, although the changes were not significant. The results from this study suggest that some dimensions of transformational leadership can be taught within a relatively brief amount of time. However, conducting post-tests that range from six months to two years is a rather large range of time. It was not clear from the study if the changes were seen more in the short term, i.e. six months, or the long term, two years. 
Cunningham \& Kitson (2000) conducted a pre and post study of four senior nurses and 22 ward sisters to explore the effects of an 18-month Registered Clinical Nurse Leadership Program. A learning outcome for the program was to determine if the training had an impact on improved patient care. The pre-test was conducted two months before the intervention and the post-test was conducted two months after the 18 month intervention. A paired sample t-test showed significant changes $(p<.05)$ for inspirational motivation, individualized consideration, extra-effort, and effectiveness according to the nurses followers. All other transformational and transactional dimensions were not significantly different between the pre- and post-assessments. Limitations of their study were the relatively small sample size.

Corrigan, Lickey, Campion, \& Rashid (2000) examined 27 leaders of rehabilitation teams who had participated in a one day workshop on leadership training. The learning outcomes of the training specifically related to the behaviors and outcomes identified in the MLQ. Results showed significant improvements in individualized consideration and active management-by-exception. The pre-test was done right before the workshop and the post-test was conducted immediately after the workshop. The results were based on a self-assessment and did not include assessments from other work colleagues.

Additionally, a follow-up study was not conducted to assess whether changes were sustained over time.

Taken together, these studies have shown that transformational leadership can be improved upon from a leader development intervention as measured by the direct reports' opinions. Kelloway, Barling, and Helleur (2000) found improvements in transformational leadership after a relatively brief intervention consisting of either a one day workshop 
and/or a one hour counseling session. In the study by Dvir, Eden, Avolio, and Shamire (2002), the intervention consisted of a three-day transformational leadership training workshop. The most extensive training examined came from the Avolio and Bass (1998) study where they found some improvements in two of the four dimensions of transformational leadership.

\section{Conclusion to Review of the Literature}

This literature review suggests that a number of interventions designed to develop leadership have been the subject of behavioral sciences research designed to determine whether they have any positive impact. Furthermore, Bass \& Avolio's (1994) Full Range Leadership Model has been widely used in numerous leader development programs and accepted as a reasonable measure of leader effectiveness. Most of the research involves developing managers in organizations from lower-level to upper-level positions. Regardless of organization type, the literature is mixed with regard to the efficacy of leader development training and education in improving overall business performance, at least as measured by those who observe the leader on a regular basis. Oftentimes, evaluation of leader development programs are rarely undertaken or limited in scope (Riggio, 2008).

Organizations devote considerable resources developing employees' capacity for leadership because they believe that "leaders" are essential in the operations of their organizations (Riggio, 2008). Human capital greatly impacts a company's ability to succeed. In order to justify investment in leader development programs, decision makers require additional definitive measures that can determine the full impact of training. This literature review has led to the observation that there is a lack for developing 
methodologies to determine whether or not involvement in a leader development program facilitates change in an individual's transformational and transactional leadership behaviors. Additionally, there are few empirical studies that measured the efficacy of a relatively condensed ( 5 day) leader development program using a behavior simulation. 


\section{CHAPTER THREE}

\section{RESEARCH DESIGN, METHODOLOGY, AND LIMITATIONS}

The intent of this study was to examine the impact of a leader simulation experience on an individual's transformational and transactional leadership behavior as measured by changes in the Multi-factor Leadership Questionnaire Form 5x (MLQ). Specifically, this research study was designed to measure and determine whether managers and their direct reports perceive transformational and transactional leadership changes as a result of participation in a leader development training program using a behavioral simulation. The research investigated whether sustained changes in managers' transformational and transactional leadership behaviors can be attributed to the Leader Development Simulation (LDS) conducted by the Institute (CCL).

The Leader Development Simulation

The LDS is based on a simulation that was developed thirty years ago. It is a person-centered behavioral simulation designed from actual organizational events that is used as a research tool to study leadership and management behavior in complex organizations using a team exercise involving role play (McCall \& Lombardo, 1982). The simulation took almost three years to develop under support from the Office of Naval Research and the Institute under the direction of management scholar Henry Mintzberg. The researchers conducted extensive field interviews with executives of a glass manufacturing corporation and reviewed multiple technical and business publications to develop the simulation. The simulation was developed to replicate a day in a manager's work life. 
The LDS has been updated several times with the most recent revision occurring in July 2006 when three new management positions were added, an international component was integrated into the business, and a greater emphasis on leading in complex situations was incorporated. The LDS is part of a five-day leader development course. People who participate in the program are primarily mid-level and upper-level managers within a variety of business organizations. Each manager receives a 360-degree feedback assessment from their supervisors, peers, and direct reports along with selfassessments on their Myers Briggs Type Indicator (MBTI) personality type and their Fundamental Interpersonal Relations Orientation-Behavior (FIRO-B) interpersonal needs two months prior to attending the leader development program.

Day one of the training program consists of an overview and managers are given evening "work" to prepare for the simulation the next day. Participants become members of the Leader Development Simulation, Incorporated's top management team. Positions range from president to plant manager. Each participant selects their position based on their individual learning needs. Participants who want to be in the role of president must speak to the group highlighting why they should serve in the highest position and a vote is taken to determine who will be given the role. Once roles are selected, all participants receive emails and reports to review, a history of the company, product information, and financial data. A total of 172 problems and opportunities are presented ranging from strategic investments to soaring energy costs and personnel issues.

On the second day the simulation is conducted and managers are again given evening work. Three separate debriefing sessions occur for the remainder of the week to "unpack" the LDS exercise in order to allow participants to assess their strengths and 
weaknesses. The first debriefing occurs on day three allowing for participants to reflect on the simulation and get their immediate reactions. The second debriefing addresses each of the three divisions of the simulated company in terms of team effectiveness. The third debriefing is for feedback from peers who participated in the simulation and from the faculty members who observed the manager's behavior. Day four is reinforcement of the learning that has taken place over the past three days. Managers revisit the simulation for additional insights into complex organizational challenges and are provided with an overview of the Institute's research on how to navigate through complex leadership challenges.

Feedback from the 360-degree assessment regarding participants' strengths and development needs are provided to the managers on the fourth day and participants also reflect on their learning from the previous four days. The last day of the training is designed for managers to set goals based on the most important things they have learned and to develop an action plan in the context of classroom learning groups. The learning outcomes for managers participating in the leader development simulation as expressed by the Institute (2008) are:

- To gain self-awareness and obtain an accurate picture of their strengths and weaknesses.

- To learn how to give and receive developmental feedback.

- To know how to influence across boundaries and navigate complex leadership issues.

- To understand the impact they have on an organization. 
- To set strategy and direction for those they lead, understanding the balance between tactical and strategic possibilities.

- To communicate effectively and manage personality differences more effectively.

The Leader Development Simulation and complete five day program is clearly demanding. Each training program typically involves 20 to 24 managers, three faculty observers, and one technician. Ninety days after the program, a retrospective assessment is conducted to measure the perceived degree of a manager's behavioral change.

A few of the managers also use follow-up coaching made available to them from the Institute's executive coaches. Given the use of the simulation in allowing the managers to experiment with applications and concepts of teamwork and leadership in a "safe" setting, the Leader Development Simulation (LDS) has received positive feedback from participants. Several participants have expressed improvements in being more effective as managers and leaders in written testimonials.

\section{Research Methodology}

The framework for this study was conducted using a quasi-experimental research design to explore the impact of the LDS on transformational and transactional leadership behavior. Quantitative research methodologies were conducted to provide an understanding of the research results. A pre-test was conducted one month before the managers engaged in the LDS using the MLQ $5 \mathrm{x}$ assessment instrument from both the managers and their direct reports. Two months after managers completed the LDS leader development program, a post-test was conducted using the same MLQ 5x assessment instrument to evaluate changes in transformational behavior. Once change was measured, those managers who showed positive and negative gains in their transformational 
leadership assessment scores were examined to understand the differences between the groups.

Sample and Overview of the Survey Procedures

The Sample

The sample included mid to upper level managers of national and international companies who participated in the LDS between December 12, 2008 and July 17, 2009. Additionally, one to five of the manager's direct reports were sampled. In order to be included, direct reports had to be individuals who observed their manager's behavior at least weekly.

Data Collection: Survey Procedure

I received permission from the Institute (CCL) to administer the MLQ 5x survey instrument to their LDS participants in January of 2008 and was able to briefly observe the simulation, as a silent "outside" member on April 21, 2008 to ensure that it was appropriate for this study. Data collection began upon approval by both the University of San Diego's Institutional Research Board (IRB) and the dissertation committee. One month before each LDS course, a list of participants was generated and given to me by the Institute.

An email (Appendix B) was sent to all participants requesting their voluntary participation in the study one month before and two months after participating in the LDS. The email contained essential information important to this study including: IRB required elements, a security enabled encryption hyperlink to the survey hosted by SurveyMonkey.com, and incentive for participation. The incentive given was a $\$ 25$ American Express gift card and a free $\$ 75$ webinar hosted by the Institute if the managers 
completed both the pre and post-test survey. Managers were provided with the results of this study including an aggregated report of the findings from their direct reports if at least three direct reports completed the assessments of their manager. Those managers with two or fewer direct reports were only provided with the total aggregated data for this study.

Managers who completed the survey were asked to provide the names and email addresses of at least two direct reports up to a maximum of five whom they interacted with at least weekly. Bass \& Avolio (2004) recommend that all persons reporting to an individual within the organization be contacted to rate the leader. However, it is necessary to understand the degree of contact the direct reports have with the manager. If, for example, the direct reports rarely see their manager, i.e. they are not geographically close to the manager, their ratings of leadership may be less useful; therefore only those direct reports that interacted with their manager weekly were included in this study.

Data were collected during the period of November, 2008 and September of 2009. Total managers participating in the LDS courses over the seven months were 182 . A total of 50 managers completed both the pre and post survey and 81 direct reports completed both the pre and post survey.

\section{Research Instrument}

There are multiple ways to measure changes in leader development: impact on organizational performance; 360-degree feedback assessments; linking program outcomes with performance indicators; and the MLQ 5x. The MLQ 5x assessment was chosen as the survey instrument for this study due to its overall alignment to the LDS course objectives as well as its ease of use (see Appendix C for the MLQ and LDS 
outcome measurement assessments). Permission was given to use the MLQ 5x form by Mind Garden International (Appendix D).

The MLQ is a validated instrument with 36 leadership questions and nine outcome items using a five point Likert-scale based on a model developed by Bernard Bass and Bruce Avolio (1994). The model denotes a leader's performance on a range of leadership behaviors, from the least potent, laissez faire, to the most potent, idealized (charismatic) leadership (Bass \& Avolio, 2000). Originally copyrighted in 1995, with further copyrights secured in 2000 and 2004, the MLQ is published by Mind Garden, Inc., Redwood City, California (Bass \& Avolio, 1995, 2004).

The MLQ was selected for use in this study because of its basis in transformational leadership theory. Many supporters of personal transformation efforts believe that the skills needed to lead effectively are developed more successfully if an individual begins change from the inside out. The MLQ is focused on behaviors observed by individuals that transform people and organizations. The MLQ measures an individual's "full-range" of leadership behavior (Antonakis, Avolio, \& Sivasubramaniam, 2003; Bass \& Avolio, 1994). Transformational leadership is identified with the following factors (Bass \& Avolio, 1994):

1. Idealized Attributes (IA) These leaders are admired, respected and trusted. They go beyond their self-interest for the good of the group and act in ways that build confidence.

2. Idealized Behaviors (IB) Leaders specify the importance of having a strong sense of purpose and talk about their values and beliefs. They emphasize the importance of having a collective sense of mission. 
3. Inspirational Motivation (IM) These leaders behave in ways that motivate others by providing meaning and challenge to their followers' work. They display enthusiasm and optimism. The leader encourages followers to envision attractive future states for themselves.

4. Intellectual Stimulation (IS) These leaders stimulate others to be innovative and creative by questioning assumptions, reframing problems, and approaching old situations in new ways.

5. Individualized Consideration (IC) These leaders understand each individual's need for achievement and growth by acting as a coach or mentor. They help to develop others to higher levels of potential and provide a supportive climate in which to grow.

Transactional leadership behaviors are associated with constructive and corrective action. Transactional leaders who set goals and define expectations and behavior are more commonly associated with management functions in organizations. Transactional leadership is associated with the following factors (Bass \& Avolio, 1994):

1. Contingent Reward (CR) These leaders reward expectations when goals are achieved or performance measures are met. They clearly communicate who is responsible for achieving performance goals and they express satisfaction when goals are met.

2. Management-by-Exception: Active (MBEA). Leaders specify standards for compliance and what constitutes ineffective performance. They may punish followers for being out of compliance and they closely monitor mistakes and errors. 
3. Management-by-Exception: Passive (MBEP). These leaders fail to intervene until problems become serious and they wait for things to go wrong before taking action.

The MLQ was revised from its original version in 1985. The original 6-factor model proposed by Bass (1985) now includes splitting Idealized Influence into two categories; Idealized Influence - Attributed (IA), Idealized Influence - Behavior (IB), and splitting Management-by-Exception into Active (MBEA) and Passive (MBEP) dimensions. The factor structure of the MLQ has been validated by both discriminatory and confirmatory factor analysis and it has been used in over 500 graduate level theses and doctoral research studies. Reliability coefficients range from .74 to .94 (Bass \& Avolio, 2004, p. 48). Appendix E provides a detail of the total number of raters and leaders that are currently included in the MLQ normative database (Avolio \& Bass, 2004). Confirmatory factor analysis of the nine-factor MLQ model for all 45 items was conducted in 2003 yielding ranges between 0.34 for management-by-exception to 0.81 for idealized influence attributes. There was a clear pattern of consistency for the nine factor model across regions and multiple raters.

Scoring for the 45-question MLQ comprises an average score for each dimension. To meet the criteria of a transformational leader, the subject must demonstrate a three or higher on a five point Likert-scale ranging from 0 (not at all) to 4 (frequently, if not always) in at least one of the four transformational dimensions (IAB, IM, IS, or IC). There are two ways to test the effectiveness of changes in leadership behavior as a result of participating in the LDS. The narrow approach to evaluate change is to correlate each individual MLQ item with a LDS learning outcome. The general approach is to aggregate 
each transformational leadership behavioral construct, i.e. the four l's of transformational leadership, with each of the LDS learning outcomes. The aggregated construct approach was used for this research study.

Benefits of the $M L Q$

- The instrument has 360 degree feedback capabilities. It is used to assess perceptions of an individual's leadership effectiveness from their supervisors, direct reports, and peers within many different levels of an organization.

- The MLQ can discriminate between discrete variables encompassing the FullRange Leadership model from laissez-faire leadership style to idealized-influence.

- The instrument emphasizes development by including items that measure both the personal and intellectual development of self and others.

- The MLQ is based on a model that links leadership style to expected performance outcomes (Dum dum, Lowe, \& Avolio, 2002).

Limitations of the $M L Q$ :

- Several empirical studies have found high correlations among the five constructs of transformational leadership (Bycio, Hackett, \& Allen, 1995; Tepper \& Percy, 1994; Yukl, 1999).

- There have been studies that have found variation using confirmatory factor analysis among different types of organizations and some researchers have hypothesized that evaluations of leadership may be affected by the context in which leadership is observed and evaluated (Bullis, Kane, \& Tremble, 1997; Tajeda, Scandura, \& Pillai, 2001; Yukl, 1999). 
There were eight additional questions included with the MLQ 5x survey instrument for the leader pre-test survey (Appendix F) and seven additional questions included for the rater pre-test assessment (Appendix G). Most of the leader pre-test survey questions added were demographic: age, gender, education, type of industry in which they work, number of years of supervisorial experience, position title, and how long have they been working within the position title. Leaders were also asked to answer how open they were to changing their leadership behavior and why they chose to participate in the LDS.

The rater pre-test assessment included the MLQ5x instrument and seven additional questions. There were 4 basic demographic questions: age, gender, how long working for their current organization, number of months reporting to the person they were rating, and frequency of interaction with their manager. Two additional questions were added to garner their satisfaction with their current job and the person they were rating. The posttest assessments were only the questions provided on the original MLQ 5x form.

\section{Data Analysis}

In order to help inform this analysis, quantitative research methodologies were used. Quantitative methods used included a pre-assessment and post-assessment research design for both the managers (self) and their direct reports (other). Multiple approaches to measuring self-other ratings have been applied in research studies measuring some form of a self-awareness construct (Moshavi, Brown, \& Dodd, 2003). Early research used the absolute value of the difference between the self and others ratings. This method was criticized due to: potential for unreliability, spurious correlations with other variables, and difficulty interpreting results (Moshavi, Brown, \& Dodd, 2003). As a result, several researchers have suggested that to overcome these problems with difference scores other 
approaches should be used: within-and-between analysis (WABA) (Danserau, Alutto, \& Yammarino, 1984), categories of agreement (Atwater \& Yammarino, 1992), and polynomial regression (Edwards, 1994). The most commonly-used approach, and the one used in this study, was the categories of agreement approach (Atwater \& Yammarino, 1992; Sosik, 2001; Yammarino \& Atwater, 1997).

The categories of agreement approach uses three categories: underestimators, overestimaters, and in-agreement. Underestimators rate themselves lower than do relevant others, overestimaters rate themselves higher, and in-agreement individuals tend to rate themselves relatively similar to others. In-agreement individuals are said to be relatively more self-aware than the other two categories (Atwater \& Yammarino, 1997; Moshavi, Brown, \& Dodd, 2003). Mabe and West (1982) conducted a meta-analysis reviewing the validity of self-evaluation and they found individuals who were associated with accurate evaluations (in-agreement) were intelligent, driven more toward high achievement, and had a more accurate evaluation of their ability. Yammarino and Atwater (1997) suggest that managers who exhibit "in-agreement" ratings from their direct reports are the best performers. They found correlations between performance and transformational leadership behavior were the greatest for managers who were inagreement with their direct reports.

Several studies have used performance of the leader as an indicator of leadership effectiveness (Atwater \& Yammarino, 1992; Bass \& Yammarino, 1991; Howell \& Avolio, 1993; Lowe, Kroeck, \& Sivasubramaniam, 1996). These studies found that managers who were in-agreement with their direct reports regarding transformational 
leadership behavior were rated as being more effective than managers that were either over-estimators or under-estimators.

Atwater and Yammarino (1992) developed a procedure for categorizing leaders utilizing difference scores. Those scores that deviate most from the mean difference are either under-estimators or over-estimators. Specifically, individuals whose difference scores were one-half standard deviation or more above the mean difference score were categorized as over-estimators, those who were one-half standard deviation or more below the mean difference score were under-estimators, and those within one-half standard deviation, plus or minus, of the mean were categorized as in-agreement.

Linear Equations for the Study Model

The unit of analysis was the change in a manager's behavior as a result of participating in the LDS leader development intervention. Eighteen regression models were used. Six models involved the determinants for changes in the manager's transformational and transactional behavior, six models included the determinants for changes according to the direct reports' perceptions in the manager's transformational and transactional behavior, and six models compared the managers' scores with their direct reports in regard to transformational and transactional behavior. The dependent variable was the change in a manager's behavior as measured by the difference between pre and post leadership behavior scores on each of the three dimensions of transformational and transactional behaviors (i.e. $\mathrm{TF}$ (post)-TF(pre)=DTF(dif), TA(post)$\mathrm{TA}($ pre $)=\mathrm{DTA}(\mathrm{dif}))$ and the independent variables included personality type, gender, rating of transformational leadership during pre-test, self-other agreement, job position, type of industry, and the manager's willingness to change. Regression analysis was used 
to determine how each independent variable was related to changes in the manager's transformational and transactional leadership behavior. The manager's model is represented as:

$\begin{aligned} \mathrm{DTF}= & \mathrm{A}_{0}+\mathrm{A}_{2} \mathrm{MBTI}+\mathrm{A}_{3} \mathrm{GEN}+\mathrm{A}_{4} \mathrm{TFPRE}+\mathrm{A}_{5} \mathrm{SO}+\mathrm{A}_{6} \mathrm{JP}+\mathrm{A}_{7} \mathrm{IND}+\mathrm{A}_{8} \mathrm{WTC} \\ & \mathrm{DTA}=\mathrm{A}_{0}+\mathrm{A}_{2} \mathrm{MBTI}+\mathrm{A}_{3} \mathrm{GEN}+\mathrm{A}_{4} \mathrm{TFPRE}+\mathrm{A}_{5} \mathrm{SO}+\mathrm{A}_{6} \mathrm{JP}+\mathrm{A}_{7} \mathrm{IND}+\mathrm{A}_{8} \mathrm{WTC}\end{aligned}$ Where:

$\mathrm{DTF}=$ Difference in transformational behavior pre and post

DTA $=$ Difference in transactional behavior pre and post

$\mathrm{A}_{2} \mathrm{MBTI}=$ Myers Briggs Type Indicator

$\mathrm{A}_{3} \mathrm{GEN}=$ Gender

$\mathrm{A}_{4} \mathrm{TFPRE}=$ Transformational rating prior to participating in LDS

$\mathrm{A}_{5} \mathrm{SO}=$ Self-other agreement

$\mathrm{A}_{6} \mathrm{JP}=\mathrm{Job}$ Position

$\mathrm{A}_{7} \mathrm{IND}=$ Industry

$\mathrm{A}_{8} \mathrm{WTC}=$ Willingness to change

The direct reports' model is represented as:

$\mathrm{SDTF}=\mathrm{B}_{0}+\mathrm{B}_{2} \mathrm{MBTI}+\mathrm{B}_{3} \mathrm{GEN}+\mathrm{B}_{4} \mathrm{TFPRE}+\mathrm{B}_{5} \mathrm{SO}+\mathrm{B}_{6} \mathrm{MON}+\mathrm{B}_{7} \mathrm{IND}$

$\mathrm{SDTA}=\mathrm{B}_{0}+\mathrm{B}_{2} \mathrm{MBTI}+\mathrm{B}_{3} \mathrm{GEN}+\mathrm{B}_{4} \mathrm{TFPRE}+\mathrm{B}_{5} \mathrm{SO}+\mathrm{B}_{6} \mathrm{MON}+\mathrm{B}_{7} \mathrm{IND}$

SDTF $=$ Direct report difference in transformational behavior pre and post

SDTA $=$ Direct report difference in transactional behavior pre and post

$\mathrm{B}_{2} \mathrm{MBTI}=$ Myers Briggs Type Indicator

$\mathrm{B}_{3} \mathrm{GEN}=$ Gender

$\mathrm{B}_{4} \mathrm{TFPRE}=$ Transformational rating prior to participating in LDS 
$\mathrm{B}_{5} \mathrm{SO}=$ Self-other agreement

$B_{6} \mathrm{JP}=$ Number of months reporting to leader

$\mathrm{B}_{7} \mathrm{IND}=$ Industry

Quantitative data were collected from the managers and direct reports as the surveys were completed. Data were then downloaded and analyzed in the Statistical Package for the Social Sciences (SPSS) software. The findings from the regression models, descriptive statistics, and correlations are reported in Chapter Four.

Limitations of the Study's Research Design and Methodology

Leadership and the perception of leadership behavior is in the "eye of the beholder," therefore all ratings collected for this research represents people's perceptions of leaders and may or may not reflect their actual behavior. This section of the chapter will detail the limitations of the study beginning with the obvious generalizability issues and concluding with the larger issues of leader development.

Data was gathered for this study from those who chose to participate in the LDS development program and therefore, has limited opportunity to be generalizable to other populations. Managers who chose not to participate in this program may or may not be different than those who did participate. However, the sample for this study includes a diverse range of individuals from different industries, varying age ranges, and disparate educational backgrounds.

Another limitation of the study is in the method of data collection. Often times a survey does not fully capture all of the subtleties associated with an individual's responses. Probing and in-depth discussions are not feasible for quantitative studies. Additionally, variables used to assess the impact of the LDS on transformational and 
transactional leadership may not encapsulate all of the experiences of the program. It could be possible that a manager may indeed change as a result of participation in the LDS, just not by ways that were measured by the survey instrument.

A further limitation of this study concerns the use of an artificial environment to produce change. This study attempted to determine if a week-long simulation designed for leader development could impact behavior. An extreme analogous scenario is that of the addict that enters a rehabilitation program to change his or her behavior. Usually the program is in a protected environment that does not perfectly replicate the "real" world in which they live. Once the addict leaves the artificial environment and reenters their natural surroundings replete with the influences that created the addictive behavior, the addict may revert back to old habits. This study made an attempt to determine whether managers could be developed into leaders within a relatively brief amount of time. Once they leave the simulated environment of the LDS and go back to the workplace, it may not be possible for them, assuming that they have been changed by the simulation, to apply what they have learned in their natural environments in meeting complex challenges and they may revert back to pre-LDS behaviors. In order to offset the potential bias of temporary - rather than long-term — behavior modification, this study incorporated a two-month post assessment using the same instrument and same raters.

Lastly, there could be potential for researcher bias. I am an instructor and use simulations to increase learning in the classroom. However, the data collected for this study were analyzed using well established statistical methodologies which, dissociates the researcher from the data and reduces researcher bias. 


\section{Conclusion}

With the inevitable loss of talent from people in leadership positions due to retirement of the baby boomer generation, this study is both timely and needed to confirm or deny that transformational leadership behavior can be improved upon after a moderately condensed leader development simulation experience. Most organizations do not have the time or extra resources to send its mid-level managers off for long extended educational programs. Additionally, many organizations are committing resources to train its managers without knowing if the investment actually helps improve their employees. Presently, there is a greater need to develop more managers by improving their leadership skills and behaviors within a limited time and with limited resources.

This study contributes to the literature given that few studies have been conducted to test whether managers changed their behavior after participating in a relatively condensed (5 day) leader development program from the direct reports' viewpoint. One reason for the lack of research is due to the fact that, if studies showed that managers did not change over time, even in the short term, many leader development programs would have the burden of justifying their value and importance.

There is also debate regarding whether or not an individual can change behaviors in a relatively short period of time. Many of the studies which have shown that managers in a leader development program changed were self-reported and qualitative. This study provides quantitative data to identify why some changed more than others. Additionally, this study identified those behaviors and skills that did not change and provides administrators of the leader development program areas to improve upon for their leadership training. 


\section{CHAPTER FOUR}

\section{FINDINGS}

This study was conducted to determine the impact of a leader training program (the Leader Development Simulation) on transformational and transactional leadership behavior as measured by the Multi-factor Leadership Questionnaire Form 5x (MLQ). In this chapter, the results of the analyses for this study are presented in three sections. The first section describes the sample participants and provides frequencies and other descriptive statistics. The second section examines the relationship between participants' perceptions and their direct reports' perceptions of leadership behaviors prior to and after participating in the training program. The final section reports the results of analysis to help explain changes in an individual's leadership behavior.

The research addressed the following questions:

1. What specific transformational and transactional leadership behaviors and skills changed as a result of participating in the Leader Development simulation? If change occurred, what were the behaviors and skills that changed?

2. Did the manager's perception of change match that of their direct reports' perception prior to and after the training program?

3. To what extent does personality type and select demographic measures help explain variation in the change in an individual's transformational and transactional leadership behavior?

4. To what extent are there any identifiable themes between those who changed the most and those who changed the least? 


\section{Sample Demographics}

A summary of responses to the demographic section of the questionnaire is presented in Table 1. A total of 50 individuals responded to all demographic questions regarding their gender, age, level within the organization, education, number of months in current position, and the number of years of supervisorial experience. The table displays the actual number of responses for individual categories and the percent of responses for each individual category. Additionally, the demographics are included in Table 1 for the entire population of managers that attended the Leader Development Simulation (LDS) in order to compare sample data with the population data.

As Table 1 indicates, of the 50 managers that participated in the study and in the LDS programs, the percent of men $(60 \%)$ and women $(40 \%)$ are exactly the same for the sample and population. Organizational level for the sample slightly differed from the population with more middle managers (33.3\%) participating in the study than those in the LDS (26.6\%). Additionally, there was a slightly smaller percent of upper level and executive/top level managers, $4.3 \%$ and $3.6 \%$ respectively between the sample and the population. The reason for the differences could be due to the time involved to participate in the study. Upper level/executive managers may have more limited time to complete the assessments and therefore did not want to participate in the study. Additional phone calls and emails were sent to upper level participants with only minor increases in their participation.

Education among the sample participants slightly differed for college educated managers by two percent. The sample and population were equally matched for managers with a master's degree (40\%). However, the sample was slightly more educated with 
more managers obtaining a doctorate degree $(18 \%)$ than the population $(6 \%)$. However, in absolute values, there were nine managers with a doctorate in the sample and eleven managers with a doctorate in the population, a difference of two individuals.

The remaining demographic characteristics, months in the current position and number of years of supervisorial experience, were not obtained by the administrators of the LDS and were gathered for purposes of this study. The majority of managers participating in this study have been in their current position for more than three years $(38 \%)$ and have more than ten years of supervisorial experience $(46 \%)$. 
Table 1. Demographic Characteristics of Sample $(n=50)$ and Population Participants (N $=182)$

\begin{tabular}{|c|c|c|c|c|}
\hline \multirow[t]{2}{*}{ Variable } & \multicolumn{2}{|r|}{ Sample } & \multicolumn{2}{|c|}{ Population } \\
\hline & $\mathrm{n}$ & Percent & $\mathrm{N}$ & Percent \\
\hline \multicolumn{5}{|l|}{$\overline{\text { Gender }}$} \\
\hline Male & 30 & 60 & 109 & 60 \\
\hline Female & 20 & 40 & 73 & 40 \\
\hline \multicolumn{5}{|l|}{ Organization Level } \\
\hline First Level Hourly & 4 & 8.3 & 16 & 8 \\
\hline Middle Manager & 17 & 33.3 & 48 & 26.6 \\
\hline Upper Level Manager & 18 & 35.4 & 72 & 39.7 \\
\hline Executive/Top Level & 11 & 22 & 46 & 25.6 \\
\hline \multicolumn{5}{|l|}{ Education } \\
\hline College Experience & 21 & 42 & 73 & 40 \\
\hline Masters Degree & 20 & 40 & 73 & 40 \\
\hline Doctorate Degree & 9 & 18 & 11 & 6 \\
\hline Other (Professional) & 0 & 0 & 25 & 14 \\
\hline \multicolumn{3}{|l|}{ Months in position } & $\mathrm{N} / \mathrm{P}$ & $N / P$ \\
\hline$<6$ months & 5 & 10 & & \\
\hline $6-12$ months & 4 & 8 & & \\
\hline $13-24$ months & 16 & 32 & & \\
\hline $25-36$ months & 6 & 12 & & \\
\hline$>36$ months & 19 & 38 & & \\
\hline \multicolumn{3}{|c|}{ Years supervisorial experience } & $\mathrm{N} / \mathrm{P}$ & $\mathrm{N} / \mathrm{P}$ \\
\hline$<1$ year & 1 & 2 & & \\
\hline $1-3$ years & 10 & 20 & & \\
\hline $4-6$ years & 7 & 14 & & \\
\hline $7-9$ years & 9 & 18 & & \\
\hline 10 or more years & 23 & 46 & & \\
\hline
\end{tabular}

Notes: $\mathrm{N} / \mathrm{P}=$ Not provided

Managers that participated in this study came from a diverse array of industries as shown in Table 2. The majority of managers came from the finance, health, and manufacturing industries. 
Table 2. Industry Characteristics of Sample $(n=50)$

\begin{tabular}{lrr}
\hline Industry & \multicolumn{2}{c}{ Sample } \\
& $\mathrm{n}$ & Percent \\
\hline Education & 3 & 6 \\
Finance & 12 & 25 \\
Government & 4 & 8 \\
Non-profit & 3 & 6 \\
Health & 14 & 28 \\
Human Services & 2 & 4 \\
Manufacturing & 10 & 20 \\
Military & 2 & 4 \\
\hline
\end{tabular}

Table 3 displays the descriptive characteristics for the 81 direct reports that completed both the pre- and post-assessments of their managers. The majority of responding direct reports were female (58\%). Most (74.1\%) of the respondents were between 31-50 years of age with none being over 61 years of age. The number of months that the respondents have been reporting to their managers ranged from less than six months $(10.1 \%)$ to more than three years $(17.7 \%)$. The majority of the respondents have been reporting to their managers between six and 24 months (53.2\%). The usual interaction between the direct reports and their managers were important to this study in view of the fact that the manager's leadership behaviors were being evaluated. Managers were asked to only provide names of direct reports that they typically interacted with at least on a weekly basis. The majority of the respondents did say they interact with their managers at least daily if not multiple times within a day (71.4\%) with only a few (3.6\%) saying that they interact with their managers a few times a month. 
Table 3. Descriptive Characteristics of the Direct Report Sample $(n=81)$

\begin{tabular}{lll} 
Characteristic & \multicolumn{2}{l}{ Sample } \\
& $\mathrm{n}$ & Percent \\
& & \\
\hline Gender & 34 & 42.0 \\
Male & 47 & 58.0 \\
Female & & \\
& & \\
Age & 9 & 11.1 \\
$22-30$ & 25 & 30.9 \\
$31-40$ & 35 & 43.2 \\
$41-50$ & 12 & 14.8 \\
$51-60$ & 0 & 0 \\
$61+$ & & \\
& & \\
Number of months reporting to Manager & 8 & 10.1 \\
$<6$ months & 21 & 26.6 \\
$6-12$ months & 21 & 26.6 \\
$13-24$ months & 15 & 19.0 \\
$25-36$ months & 14 & 17.7 \\
$>36$ months & & \\
& & \\
Usual interaction with the Manager & 32 & 38.1 \\
Multiple times in a day & 28 & 33.3 \\
Daily & 19 & 22.6 \\
Few times a week & 2 & 2.4 \\
Weekly & 3 & 3.6 \\
Bi-monthly & & \\
& &
\end{tabular}

Direct reports were asked about their current satisfaction with their job and the person that they were rating on a five-point scale ranging from very dissatisfied (1) to very satisfied (5). The mean rating for satisfaction with their current job among the direct reports was 4.19 with a standard deviation of 0.79 . The mean score for satisfaction with the person they were rating was 4.36 with a standard deviation of 0.86 . Overall the direct reports were satisfied with their current job and the person they were rating. 
Data Analysis Results for Research Question 1

This study explored the impact of a leader training simulation on transformational and transactional leadership behavior. The first of the four research questions that drove this dissertation's study focused specifically on the changes that occurred as a result of participation in The Leader Development simulation. Explicitly, Research Question 1 asked: What specific transformational and transactional leadership behaviors and skills changed as a result of participating in the Leader Development Simulation? If change occurred, what were the behaviors and skills that changed? The results generated by the participants' and their direct reports' replies to the survey's response items, provided answers to this question, and are reported in this section.

Among the managers invited to participate in this study, 54 (29.7\%) completed the pre-assessment and $50(27.5 \%)$ completed the post-assessment. Of the 50 managers who completed the survey, 10 managers did not have any direct report data; four managers did not have individuals reporting directly to them and the remaining six managers did not have any of their direct reports respond to this study. Analysis of Variance (ANOVA) was conducted to see if there was a difference between the two groups of those 10 managers without direct reports and those with direct reports. No significant difference was found between the two groups. Among the direct reports invited to participate in this study, 81 completed both the pre- and post-assessment for 40 managers. Each manager was responsible for one to four direct reports. When reporting the findings comparing managers and their direct reports for this study, 40 managers and their direct reports are included. When reporting findings for the total manager responses, 50 managers are included. 
As discussed earlier in Chapter Two, to meet the criteria of a transformational leader, the subject must demonstrate a three or higher on a five point Likert-scale in at least one of the five transformational dimensions (Idealized Influence Attributed, Idealized Influence Behavior, Inspirational Motivation, Intellectual Stimulation, or Individualized Consideration), a two or lower in transactional leadership, and a one or lower in laissez-faire leadership (Bass \& Riggio, 2006).

In an attempt to answer the first research question, pre-test scores were compared with post-test scores to determine whether there were discernable changes in transformational and transactional leadership behavior. The expectation would be that post-test scores would be higher than the pre-test scores for transformational leadership behaviors and post-test scores would be lower than the pre-test scores for transactional and laissez-faire leadership behaviors. To determine this, the Wilcoxon matched pair signed rank test between the pre- and post-test scores for each of the leadership factors was applied. The results are shown in Table 4 for the managers and Table 5 for the direct reports.

The results presented in Table 4 show that on almost all dimensions, there were statistically significant differences $(p<.05)$ between the managers' self-ratings for the pretest and post-test scores. The only exceptions were on two factors; contingent reward and management-by-exception active (MBEA). While these two factors did not show significant differences there was a slight increase in contingent reward and a decrease in MBEA. 
Table 4. Difference between the pre- and post-test scores - Wilcoxon matched pair rank test (Managers $n=50$ )

\begin{tabular}{|c|c|c|c|c|}
\hline Factor & $\begin{array}{c}\text { Pre-test } \\
\text { Score Mean }\end{array}$ & $\begin{array}{c}\text { Post-test } \\
\text { Score Mean }\end{array}$ & $\begin{array}{l}\% \text { increase } \\
\text { (decrease) }\end{array}$ & $Z$ \\
\hline \multicolumn{5}{|l|}{ Transformational leadership } \\
\hline Idealized attribute & 2.85 & 3.17 & 11.2 & $-4.04 * *$ \\
\hline Idealized behaviors & 3.00 & 3.27 & 9.0 & $-2.78 * *$ \\
\hline Inspirational motivation & 3.07 & 3.27 & 6.5 & $-2.00^{*}$ \\
\hline Intellectual stimulation & 2.89 & 3.27 & 13.1 & $-3.54 * *$ \\
\hline Individualized consideration & 3.06 & 3.33 & 8.8 & $-3.17 * *$ \\
\hline Aggregated Transformational & 2.97 & 3.27 & 10.1 & $-3.62 * *$ \\
\hline \multicolumn{5}{|l|}{ Transactional leadership } \\
\hline Contingent reward & 2.99 & 3.06 & 2.3 & -1.26 \\
\hline MBEA & 1.85 & 1.67 & $(9.7)$ & -1.42 \\
\hline MBEP & 0.93 & 0.70 & $(24.7)$ & $-3.20^{* *}$ \\
\hline Aggregated Transactional & 1.92 & 1.79 & $(6.8)$ & $-2.02^{*}$ \\
\hline \multicolumn{5}{|l|}{ Non-leadership } \\
\hline Laissez-faire & 0.54 & 0.33 & (38.9) & $-2.65 * *$ \\
\hline Extra Effort & 2.73 & 3.07 & 12.5 & $-4.35 * *$ \\
\hline Leadership Effectiveness & 3.10 & 3.29 & 6.1 & $-3.01 * *$ \\
\hline Satisfaction & 2.89 & 3.07 & 6.2 & $-2.41^{*}$ \\
\hline
\end{tabular}

Notes: ${ }^{*}$ Significant at the 0.01 level (2-tailed)

* Significant at the 0.05 level (2-tailed)

Table 5 presents the pre-test and post-test values for each of the behavioral factors as well as the outcome measures according to the managers' direct reports. As shown in table 5, individualized consideration was the only dimension that showed a significant improvement after the manager's participated in the training $(p<.05)$. However, two of the outcome measures, leadership effectiveness and satisfaction with the leader also showed significant improvement $(\mathrm{p}<.05)$. Although the direct reports did not see much change in their manager's behavior except for Individualized Consideration, they do 
believe that their managers became more effective as leaders and they were more satisfied with their manager's methods of leadership.

Table 5. Difference between the pre-and post-test scores - Wilcoxon matched pair rank test (Direct Reports $n=81$ )

\begin{tabular}{|c|c|c|c|c|}
\hline Factor & $\begin{array}{l}\text { Pre-test } \\
\text { Score Mean }\end{array}$ & $\begin{array}{l}\text { Post-test } \\
\text { Score Mean }\end{array}$ & $\begin{array}{l}\% \text { increase } \\
\text { (decrease) }\end{array}$ & Z \\
\hline \multicolumn{5}{|l|}{ Transformational leadership } \\
\hline Idealized attribute & 3.01 & 3.11 & 3.3 & -1.08 \\
\hline Idealized behaviors & 2.69 & 2.82 & 4.8 & -0.81 \\
\hline Inspirational motivation & 2.95 & 3.02 & 2.4 & -0.40 \\
\hline Intellectual stimulation & 2.78 & 2.78 & 0 & -0.19 \\
\hline Individualized consideration & 2.69 & 2.91 & 8.2 & $-2.07^{*}$ \\
\hline Aggregated Transformational & 2.83 & 2.93 & 3.5 & 0.17 \\
\hline \multicolumn{5}{|l|}{ Transactional leadership } \\
\hline Contingent reward & 2.85 & 2.99 & 4.9 & -0.98 \\
\hline MBEA & 1.53 & 1.53 & 0 & -0.12 \\
\hline MBEP & 0.82 & 0.77 & $(6.1)$ & -0.38 \\
\hline Aggregated Transactional & 1.74 & 1.76 & 1.1 & -0.59 \\
\hline \multicolumn{5}{|l|}{ Non-leadership } \\
\hline Laissez-faire & 0.58 & 0.39 & $(32.8)$ & -1.64 \\
\hline Extra Effort & 2.90 & 2.98 & 2.8 & -0.20 \\
\hline Leadership Effectiveness & 3.05 & 3.31 & 8.5 & $-2.46^{*}$ \\
\hline Satisfaction & 3.08 & 3.31 & 7.5 & $-2.21^{*}$ \\
\hline
\end{tabular}

Notes: ${ }^{* *}$ Significant at the 0.01 level (2-tailed)

* Significant at the 0.05 level (2-tailed)

While other measures did not display significance at a statistical level, the results do show that direct reports did see positive increases in their manager's transformational leadership behavior. There was a slight increase in contingent reward behaviors, no change for MBEA, and decreases in both MBEP and laissez-faire leadership values. 


\section{Concluding Remarks on Research Question 1}

According to the self-ratings of managers, their perceptions two-months after the training program indicate a statistically significant increase $(p<.05)$ in all of the transformational leadership dimensions. The managers also perceived a slight increase in their contingent reward behavior and a slight decrease in their MBEA behaviors although the decrease was not statistically significant. Additionally, there was a significant decrease $(p<.05)$ in their MBEP and laissez-faire behaviors.

The ratings from the managers' direct reports were not as significant. Individualized consideration was the only transformational leadership dimension that showed a significant improvement $(p<.05)$ after the training. There were slight increases in the other transformational dimensions except for intellectual stimulation but they were not significant. In addition, while laissez-faire leadership behaviors declined by $32.8 \%$ according to the direct reports, the change was not statistically significant according to the Wilcoxon pair signed rank test. Direct report scores did show a significant improvement $(p<.05)$ in two of the outcome measures demonstrating a belief that their managers' were more effective as leaders and they were more satisfied with their managers after the training.

\section{Data Analysis for Research Question 2}

One of the overarching learning outcomes for those participating in the LDS is to gain self-awareness and obtain an accurate picture of the manager's strengths and weaknesses. Self-appraisals have been investigated from a number of perspectives focusing on agreement between self-ratings and the ratings of others, specifically peers, 
supervisors, and direct reports (Atwater \& Yammarino, 1992; Harris \& Schaubroeck, 1988; Kirshnan, 2003).

Three general conclusions have resulted from this work. First, self-ratings differ from the ratings of others. While peers, supervisors, and direct reports tend to be consistent with each other, self-ratings are often inflated (Atwater \& Yammarino, 1992; Harris \& Schaubroeck, 1988). Second, oftentimes self-ratings tend to be inflated due to social desirability biases and belief in one's ability to improve (Podsakoff \& Organ, 1986). Third, those that inaccurately rate themselves tend to be poorer performers than their more accurate counterparts (Atwater \& Yammarino, 1992; Bass \& Yammarino, 1991). In order to understand how managers perceive their leadership behavior when compared to their direct reports, the second research question asked: Did the manager's perception of change match that of their direct reports' perception prior to and after the training program?

Means and standard deviations for the leadership and outcome variables for both the managers and their direct reports are presented in Table 6. As shown in the table, average self-ratings of pre-transformational leadership were higher than direct report ratings for the aggregated transformational leadership dimension. Independent samples ttest analysis revealed that self-awareness between pre- and post-mean scores were significantly different. Managers perceived they were exhibiting more transformational behavior than did their direct reports $(p<.01)$ after the training. Pre-mean scores were also significantly different for the aggregated transactional behavior dimension $(\mathrm{p}<.05)$ which illustrates that managers, on average, felt that they were more transactional before the training program than did their direct reports. However, after the program, both the 
managers and the direct reports (DR) perceptions were more aligned, showing that managers may have become more self-aware of their transactional leadership behavior.

Table 6. Mean and standard deviations for leadership and outcome variables $(n=40)$

\begin{tabular}{|c|c|c|c|c|}
\hline \multirow[t]{2}{*}{ Variable } & \multicolumn{2}{|c|}{ Mean } & \multicolumn{2}{|c|}{ SD } \\
\hline & Self & DR & Self & DR \\
\hline \multicolumn{5}{|c|}{ Aggregated Transformational leadership } \\
\hline Pre & 3.00 & 2.83 & .35 & .61 \\
\hline Post & 3.29 & $2.93 * *$ & .46 & .54 \\
\hline \multicolumn{5}{|c|}{ Aggregated Transactional } \\
\hline Pre & 1.89 & $1.74^{*}$ & .30 & .33 \\
\hline Post & 1.81 & 1.76 & .36 & .35 \\
\hline \multicolumn{5}{|c|}{ Laissez-faire } \\
\hline Pre & 0.48 & 0.58 & .52 & .65 \\
\hline Post & 0.28 & 0.39 & .32 & .43 \\
\hline \multicolumn{5}{|c|}{ Extra Effort } \\
\hline Pre & 2.77 & 2.90 & .48 & .78 \\
\hline Post & 3.11 & 2.98 & .52 & .81 \\
\hline \multicolumn{5}{|c|}{ Leadership Effectiveness } \\
\hline Pre & 3.16 & 3.05 & .47 & .82 \\
\hline Post & 3.34 & 3.31 & .47 & .59 \\
\hline \multicolumn{5}{|c|}{ Satisfaction } \\
\hline Pre & 2.93 & 3.08 & .55 & .82 \\
\hline Post & 3.13 & 3.31 & .62 & .68 \\
\hline
\end{tabular}

Notes: **Significant at the 0.01 level (2-tailed)

* Significant at the 0.05 level (2-tailed)

Table 6 also shows that for all other variables, the difference between self-ratings and direct report ratings were not statistically different prior to or after the program.

Table 7 breaks down the aggregated transformational and transactional leadership behaviors into the separate dimensions. Mean score difference tests were conducted to identify which specific dimensions were significantly different between managers’ ratings and direct reports' ratings. 
Table 7. Mean and standard deviations for each leadership dimension $(n=40)$

\begin{tabular}{|c|c|c|c|c|}
\hline \multirow[t]{2}{*}{ Variable } & \multicolumn{2}{|c|}{ Self } & \multicolumn{2}{|c|}{ Direct Report } \\
\hline & Mean & SD & Mean & SD \\
\hline \multicolumn{5}{|c|}{ Idealized Influence - Active } \\
\hline Pre & 2.88 & 0.46 & 3.01 & 0.67 \\
\hline Post & 3.19 & 0.54 & 3.11 & 0.58 \\
\hline \multicolumn{5}{|c|}{ Idealized Influence - Behavior } \\
\hline Pre & 3.02 & 0.45 & $2.69^{*}$ & 0.72 \\
\hline Post & 3.29 & 0.68 & $2.82^{* *}$ & 0.54 \\
\hline \multicolumn{5}{|c|}{ Inspirational Motivation } \\
\hline Pre & 3.09 & 0.57 & 2.95 & 0.80 \\
\hline Post & 3.31 & 0.57 & $3.02^{*}$ & 0.64 \\
\hline \multicolumn{5}{|c|}{ Intellectual Stimulation } \\
\hline Pre & 2.93 & 0.52 & 2.78 & 0.59 \\
\hline Post & 3.27 & 0.48 & $2.78^{* *}$ & 0.66 \\
\hline \multicolumn{5}{|c|}{ Individualized Consideration } \\
\hline Pre & 3.09 & 0.49 & $2.69^{* *}$ & 0.65 \\
\hline Post & 3.38 & 0.49 & $2.91^{* *}$ & 0.79 \\
\hline \multicolumn{5}{|c|}{ Contingent Reward } \\
\hline Pre & 2.99 & 0.47 & 2.85 & 0.65 \\
\hline Post & 3.06 & 0.50 & 2.99 & 0.59 \\
\hline \multicolumn{5}{|c|}{ Management-by-exception Active } \\
\hline Pre & 1.81 & 0.70 & 1.53 & 0.79 \\
\hline Post & 1.71 & 0.70 & 1.53 & 0.89 \\
\hline \multicolumn{5}{|c|}{ Management-by-exception Passive } \\
\hline Pre & 0.87 & 0.52 & 0.82 & 0.56 \\
\hline Post & 0.67 & 0.45 & 0.77 & 0.58 \\
\hline \multicolumn{5}{|c|}{ Laissez-faire } \\
\hline Pre & 0.48 & 0.52 & 0.58 & 0.65 \\
\hline Post & 0.28 & 0.32 & 0.39 & 0.43 \\
\hline
\end{tabular}

Notes: ${ }^{* *}$ Significant at the 0.01 level (2-tailed)

* Significant at the 0.05 level (2-tailed) 
Table 7 shows that Idealized Influence-- Behavioral (IIB) is significantly different between managers' perceptions and their direct reports' perceptions both before the program $(\mathrm{p}<.05)$ and after the program $(\mathrm{p}<.01)$. While IIB did increase from pre- to posttest time periods according to the direct reports, the differences between the managers and direct reports became more significant after the program $(0.47)$ than before the program (0.33).

Inspirational Motivation (IM) also showed significantly different scores after the training $(\mathrm{p}<.05)$. Prior to the training, both managers' and direct reports' perceptions of IM behaviors were only slightly different $(0.15)$. However, after the training, managers and direct reports had significantly different $(\mathrm{p}<.05)$ awareness of IM behaviors $(0.29)$. While both managers and direct reports indicated an increase in IM behavior, managers perceived that they engaged in more IM behavior than did their direct reports.

Intellectual Stimulation (IS) scores did not change for the direct reports (2.78) and there was not a significant difference between managers' and direct reports' assessments. After the training, managers reported an increase in their IS behaviors $(0.34)$ and their opinions were significantly different from their direct reports $(p<.01)$. Yet again, the managers believed they were exhibiting more intellectually stimulating behaviors after the training than did their direct reports.

Individualized Consideration (IC) was the only variable that showed a significant difference between managers and direct reports prior to and after the training as shown in both Tables 6 and 7. While both post-assessment scores for managers (3.38) and direct reports (2.91) increased from pre-assessment scores, the difference between their pre- 
assessment scores $(0.40)$ and post-assessment scores $(0.47)$ was significantly different $(\mathrm{p}<.01)$

The model to analyze whether managers' and their direct reports' perceptions of leadership behavior were similar or different was the categories of agreement approach developed by Atwater \& Yammarino (1992). Managers were classified into underestimators, in-agreement, or over-estimators based on the mean difference scores between self-ratings of transformational and transactional leadership behaviors and the ratings provided by their direct reports. Table 8 provides the frequencies in each category for those managers classified as either under, over, or in-agreement with their direct reports in terms of the managers' transformational leadership behavior. More women $(31.3 \%)$ were under-estimators than were men $(25.0 \%)$ and more men were in-agreement with their direct reports $(41.7 \%)$ than women $(37.5 \%)$. Furthermore, slightly more men were over-estimators $(33.3 \%)$ than were women $(31.3 \%)$. There were no significant differences between the changes in transformational leadership behavior whether the direct reports were in-agreement or not in-agreement.

Table 8. Post Transformational Leadership Categories of Agreement $(n=81)$

\begin{tabular}{lcccc}
\hline Category & \multicolumn{1}{c}{$\begin{array}{c}\text { Sample } \\
\text { Percent } \\
\text { Mgrs }\end{array}$} & & \multicolumn{2}{c}{ Percent } \\
& & & $\mathrm{n}=24$ & $\mathrm{n}=16$ \\
& & & & \\
\hline Under-estimators & 11 & 27.5 & 25.0 & 31.3 \\
In-agreement & 16 & 40.0 & 41.7 & 37.5 \\
Over-estimators & 13 & 32.5 & 33.3 & 31.3 \\
& & & & Female
\end{tabular}

Table 9 provides the results for the differences in post-transactional scores and agreement categories. On both ends of the spectrum, male managers thought they were 
less transactional (41.7\%) and female managers thought they were more transactional $(62.5 \%)$ after the training program.

Table 9. Post Transactional Leadership Categories of Agreement ( $\mathrm{n}=\mathbf{8 1}$ )

\begin{tabular}{lcccc}
\hline Category & \multicolumn{1}{c}{ Sample } & \multicolumn{2}{c}{ Percent } \\
& Mgrs & Percent & Male Mgrs & Female \\
& & & $\mathrm{n}=24$ & $\mathrm{n}=16$ \\
\hline Under-estimators & 13 & 32.5 & 41.7 & 18.8 \\
In-agreement & 12 & 30.0 & 37.5 & 18.8 \\
Over-estimators & 15 & 37.5 & 20.8 & 62.5 \\
& & & & \\
\hline
\end{tabular}

Given that self-ratings are generally inflated and the noted disparities in many self-other ratings are not aligned with the individual being evaluated, it is important to determine the source of category differences. Analysis was conducted to see if those categorized as under-estimators were those providing low self-ratings, or whether the under-estimators were those rated highest (most transformational) by their direct reports. Negative difference scores might be the result of under-estimators. To address this issue, the average self-ratings and direct report ratings for each agreement category are presented in Table 10.

As shown in Table 10, those categorized as over-estimators had a direct report rating lower than the rating for those in the under-estimator or agreement groups. Thus, those categorized as over-estimators rated themselves higher and were rated by their direct reports lower than those in either the agreement or under-estimator categories. Additionally, those categorized as under-estimators were rated the highest by their direct reports than those in either of the other categories. This could indicate that those who express humility are viewed more favorably by their direct reports. 
Table 10. Average Self and Other Post-Transformational Leadership Ratings for Managers in Different Agreement Groups

Agreement between self-ratings and direct report ratings

Self-Rating

Direct Report Rating

Under-estimators

Concluding Remarks on Research Question 2

Self-awareness is a key learning objective for those participating in the Leader Development Simulation. Do managers' perceptions of change match that of their direct reports? According to studies by Atwater and Yammarino (1992, 1997), individuals who are more self-aware are considered to be more: committed to their jobs, satisfied, and effective leaders and managers. The findings of this research suggested that managers were not as self-aware of their leadership behavior after the program as one might expect. Independent samples t-tests revealed that managers and direct reports mean scores posttraining were statistically different on all transformational dimensions except for Idealized Influence-- Attributed (IIA). The managers' self-awareness of their IIA behaviors was the same as their direct reports. Additionally, after the training, female managers felt they were more transactional than male managers. However, direct reports felt differently. The direct reports viewed male managers as more transactional after the program than female managers. 


\section{Data Analysis for Research Question 3}

Research question three addressed the extent to which personality types and select demographic measures help explain variation in the change in an individual's transformational and transactional leadership behavior. Managers who participated in the LDS completed the Myers Briggs Type Indicator (MBTI) prior to attending the program and were given their results during the five day training. The post-assessment Multifactor Leadership Questionnaire (MLQ) included a question asking managers to provide their MBTI results. Forty-four out of the fifty managers answered this question. Table 11 provides the breakdown of the managers' personality types.

Table 11. MBTI Characteristics of Managers $(n=44)$ MBTI Type

\section{Sample}

n

ISTJ

INTJ

ISTP

ISFP

INFP

INTP

ESTP

ESFP

ENFP

ESTJ

ENTP

ENFJ

ENTJ

7

7

4

1

1

2

2

1

1

3

13

5

2

2
Percent

15.9

9.1

2.3

2.3

4.5

4.5

2.3

2.3

6.8

29.5

11.4

4.5

4.5

Table 11 shows that $45.4 \%$ of the managers that participated in the Leader Development Simulation can be characterized as sensing, thinking, judging (STJ) individuals with a smaller proportion (15.9\%) being introverts rather than extroverts 
(29.5\%). The large percentage of STJ managers in this study are consistent with the metaanalysis performed by Gardner \& Martinko (1990) using the MBTI to study managers. Gardner \& Martinko found that managers favored thinking and judgment in 97 to 100 percent of the samples they studied (p. 59). MBTI theory describes thinking, judging individuals as the "logical decision makers" (Myers \& McCaulley, 1985) and suggests that they may be more prone to taking on management positions. Additionally, based on type theory, sensing individuals prefer concrete data where intuitive individuals have a greater penchant for the abstract and symbolic.

Analyses were performed to identify if any relationships existed between personality types and the dimensions of transformational and transactional leadership behavior. Personality type theory proposes that people have preferred ways of perceiving (sensing/intuition), judging (thinking/feeling), orienting to the external environment (judging/perceiving), and ways of obtaining energy (extraversion/introversion) (Gardner \& Martinko, 1996). Table 12 presents the mean MLQ score based on the postassessment scores from the direct reports' perspective. Each of the four dominant personality types are presented in pairs and their means provided in Table 12, e.g., I/E relates to the Introvert/Extrovert pairing.

There were no statistically significant differences between the thinking/feeling types or the sensing/intuition types. For the extrovert/introvert type, only laissez-faire was statistically significant $(\mathrm{p}<.05)$ showing that direct reports thought that the extroverted managers exhibited more laissez-faire behaviors than did the introverted managers. This is counter-intuitive because one would expect the introverts to have less social interaction with their direct reports. The judging/perceiving types exhibited the 
most significant differences. Perceiving managers were seen by their direct reports as displaying more frequent idealized influence - behaviors $(p<.05)$, inspirational motivation $(\mathrm{p}<.05)$, and contingent reward leadership behaviors $(\mathrm{p}<.01)$. Judging managers exhibited more management-by-exception active behaviors $(\mathrm{p}<.05)$.

Table 12. MBTI Preferences and Mean Scores for the Leadership Dimensions ( $\mathrm{n}=40)$

\begin{tabular}{lllll}
\hline Variable & $\mathrm{I} / \mathrm{E}$ & $\mathrm{S} / \mathrm{N}$ & $\mathrm{T} / \mathrm{F}$ & $\mathrm{J} / \mathrm{P}$ \\
\hline Idealized Influence - Active & $3.15 / 3.07$ & $3.11 / 3.12$ & $2.86 / 3.04$ & $2.98 / 3.40$ \\
Idealized Influence - Behavior & $2.88 / 2.80$ & $2.83 / 2.80$ & $2.86 / 2.78$ & $2.71 / 3.12^{*}$ \\
Inspirational Motivation & $3.21 / 2.89$ & $2.98 / 3.01$ & $3.18 / 2.91$ & $2.84 / 3.44 *$ \\
Intellectual Stimulation & $2.88 / 2.77$ & $2.81 / 2.75$ & $2.90 / 2.70$ & $2.75 / 2.96$ \\
Individualized Consideration & $3.12 / 2.81$ & $2.93 / 2.88$ & $2.96 / 2.87$ & $2.85 / 3.11$ \\
Contingent Reward & $3.12 / 2.87$ & $2.96 / 3.01$ & $2.99 / 2.99$ & $2.79 / 3.39 * *$ \\
Management-by-exception Active & $1.32 / 1.64$ & $1.60 / 1.45$ & $1.52 / 1.53$ & $1.75 / 0.96 *$ \\
Management-by-exception Passive & $0.70 / 0.79$ & $0.61 / 0.95$ & $0.83 / 0.73$ & $0.76 / 0.74$ \\
Laissez-faire & $0.18 / 0.51 *$ & $0.38 / 0.40$ & $0.31 / 0.45$ & $0.46 / 0.21$ \\
\hline
\end{tabular}

Notes: **Significant at the 0.01 level (2-tailed)

* Significant at the 0.05 level (2-tailed)

To further answer the third research question, analyses were conducted to help explain variation in the change in individuals' transformational and transactional leadership behavior as a function of select demographic measures. Hierarchical regressions were performed to answer this question and six regression models were used. Two models involved the determinants for changes in the manager's transformational and transactional behavior, two models included the determinants for changes according to the direct reports' perceptions in the manager's transformational and transactional 
behavior, and two models compared the managers' scores with their direct reports in regard to transformational and transactional behavior. The dependent variable was the change in a manager's behavior as measured by the difference between pre and post leadership behavior scores on each of the dimensions of transformational and transactional behaviors.

Table 13 presents the results of the analyses for the first regression model demonstrating the relationship between changes in the manager's transformational leadership behavior (self-rating) and select demographic measures. Model 1 reveals that four measures; whether the manager had a masters or doctorate degree, gender, number of years of supervisorial experience, and the managers post-transformational leadership self-rating were all statistically significant. This model explains 69.2 percent of the variance in the change in transformational leadership behavior and was significant $(\mathrm{p}<$ $.01)$.

Table 13. Hierarchical regression between changes in transformational leadership (CTFORM) and demographic variables - Model 1

CTFORM (Managers)
Estimated Coefficient p-value

.00

.01

.00

Post-transformational leadership

R-square .69

The estimated coefficient for the type of education $(-0.46)$ shows that managers with a doctorate changed less $(0.15)$ than managers with a masters education $(0.48)$. 
Upon further discovery, managers with a doctoral degree felt they were more transformational than masters educated managers prior to participating in the program as shown in Table 14.

Table 14. Demographic Measures and Change in Transformational Leadership Behavior

\begin{tabular}{llll}
\hline Variable & Pre & Post & Change
\end{tabular}

Education

Masters

2.89

3.37

0.48

Doctorate

3.21

3.36

0.15

Gender

Male

3.30

0.30

Female

3.01

3.26

0.25

Number of Years of Supervisorial

Experience

$\begin{array}{llll}<4 \text { years } & 2.77 & 3.30 & 0.53 \\ 4 \text { or more years } & 3.10 & 3.28 & 0.18\end{array}$

Managers with fewer than four years of supervisorial experience rated themselves less transformational than those managers with four or more years of experience before the training (2.77 and 3.10 respectively) and slightly more transformational (3.30 and 3.28 respectively) than the more experienced managers after the training. Furthermore, managers with less supervisorial experience believe they changed more in terms of their transformational leadership behavior than did those managers with more supervisory experience. 
The second regression model analyzed the relationship between additional select demographic measures and changes in transformational leadership behavior according to self-ratings. Table 15 displays the results for the model.

Table 15. Hierarchical regression between changes in transformational leadership (CTFORM) and demographic variables - Model 2

$\begin{array}{lll}\text { CTFORM } & \text { Estimated } & \text { p-value } \\ \text { (Managers) } & \text { Coefficient } & \end{array}$

$\begin{array}{lll}\text { MBTI } & -0.03 & 0.88\end{array}$

$\begin{array}{lll}\text { Organizational Level } & 0.09 & 0.61\end{array}$

$\begin{array}{lll}\text { Willingness to change } & -0.02 & 0.90\end{array}$

$\begin{array}{lll}\text { Self-Other Agreement } & 0.56 & 0.00^{* *}\end{array}$

$\begin{array}{lll}\text { Age } & 0.05 & 0.80\end{array}$

Pre-Transformational Leadership

Behavior

$-0.19$

0.33

Notes: R-square $.17,{ }^{* *}$ Significant at the 0.01 level (2-tailed)

The results of the regression analysis for Model 2 indicates a lower R-square value (0.17) than does Model $1(0.69)$ with only one significant factor in the model-- selfother agreement. Under-raters reported a decrease in the change in transformational leadership (-0.02), those in-agreement reported a positive change $(0.28)$, while over-raters reported the highest increase in change $(0.56)$.

The third regression model represents the change in transactional leadership behavior. According to Bass and Avolio (1997), managers should work to improve their transformational leadership behavior and decrease their transactional leadership behavior. 
Therefore, the results should show a decrease from pre- and post-assessment scores of transactional behavior. The results are presented in Table 16 . The model explained $12 \%$ of the variance in transactional leadership behavior with change in the manager's transformational leadership behavior (self-rated) as the only variable showing significance $(\mathrm{p}<.05)$. Using Stepwise Regression, the change in transformational leadership from the manager's perspective as the sole variable in the model explained $19.8 \%$ of the variance in transactional leadership behavior $(\mathrm{p}<.05)$.

Table 16. Hierarchical regression between changes in transactional leadership (CTACT) and demographic variables - Model 3 Managers

$\begin{array}{lll}\text { CTACT } & \text { Estimated } & \text { p-value } \\ \text { (Managers) } & \text { Coefficient } & \end{array}$

Gender (Manager)

Number of years of supervisorial exp.

$-0.91$

Masters and Doctorate

$-0.25$

.320

Change in transformational leadership

$-0.66$

$0.04^{*}$

Notes: R-square $.12 *$ Significant at the 0.05 level (2-tailed)

Further analyses were performed to understand the changes in transactional leadership behavior. Understanding that $45.5 \%$ of the sample was sensing, thinking, judging (STJ) personality types, a variable was created that grouped all STJ managers into one category and the remaining personality types into another category. Regression was run using just this variable and the results are presented in Table 17. 
Table 17. Model 4 Changes in Transactional Leadership Behavior

$\begin{array}{lll}\begin{array}{l}\text { CTRANSACT } \\ \text { (Managers) }\end{array} & \begin{array}{l}\text { Estimated } \\ \text { Coefficient }\end{array} & \text { p-value }\end{array}$

$\begin{array}{lll}\text { STJ Personality Type } & 0.38 & 0.03 *\end{array}$

Notes: R-square .12 *Significant at the 0.05 level (2-tailed)

Managers with the STJ type rated themselves less transactional after the training with a decrease of 0.15 while non-STJ types showed a slight increase in transactional leadership behavior after the training (0.09). STJ types also had a slightly higher mean score in transactional leadership behavior (1.90) than did non-STJ types (1.86) prior to participating in the training. Post-assessment scores revealed that STJ types had a lower mean score (1.75) after the training than did non-STJ types (1.95). Sensing types are said to focus on the small things more than intuitive people (Hautala, 2005). Thinking individuals tend to make decisions using logic while judging types prefer order and closure. These types may lend themselves more closely to transactional types of leadership behavior such as contingent reward. Contingent reward is characterized as an exchange- if you do this, you'll get this. Sensing types are consistent with managementby-exception behaviors that are focused on the present and direct attention to mistakes and failures. Judging types tend to prefer order and closure; 'if it ain't broke, don't fix it."

The next level of analyses identified the changes in transformational and transactional leadership behavior according to the managers' direct reports. Change in both leadership behaviors were measured as the post-assessment scores minus the pre- 
assessment scores. Table 18 presents the results for changes in transformational leadership behavior.

Table 18. Hierarchical regression between changes in transformational leadership (CTFORM) and demographic variables - Model 1 Direct Reports

CTFORM

(Direct Reports)
Estimated

Coefficient

$$
\text { p-value }
$$

\begin{tabular}{llc}
\hline Gender (Manager) & 0.05 & 0.71 \\
In-agreement & 0.01 & 0.92 \\
Months reporting to manager & 0.05 & 0.70 \\
Usual Interaction & 0.10 & 0.33 \\
Post Leadership Effectiveness & 0.56 & $0.01^{* *}$ \\
Post Extra Effort & 0.16 & 0.32 \\
Post Satisfaction with the manager & 0.11 & 0.57 \\
Pre-transformational leadership & -0.90 & $0.00^{* *}$ \\
MBTI & 0.04 & 0.69 \\
\hline
\end{tabular}

Notes: R-square . $74,{ }^{* *}$ Significant at the 0.01 level (2-tailed)

The results from Table 18 show that post-leadership effectiveness was positive and significant. The only other variable of significance was the pre-transformational leadership scores according to the direct reports which were negatively related. The higher the manager's pre-transformational leadership score, the less they gained in their post-assessment scores. This is not surprising, since the more transformational a manager is coming into the training program, the less room there is to grow after the program. 
Stepwise regression analysis was used to determine which variables had the most impact on the change in transformational leadership behavior according to the direct reports. The first model showed that the pre-transformational leadership behavior explained $30.4 \%$ of the variation with a negative standardized beta coefficient of -0.57 and this was significant $(\mathrm{p}<.01)$. The second model showed that both pretransformational leadership behavior and post-effectiveness according to the direct reports, explained $75.9 \%$ of the variation and was significant $(p<.01)$. The standardized beta coefficient for the pre-transformational leadership behavior was again negative ($0.87)$ and post-effectiveness had a positive coefficient $(0.73)$.

Additional analyses were performed to understand the relationship between the changes in transactional leadership behavior and select demographic measures according to the direct reports. Table 19 presents the findings. The only variable of significance in the model was the usual interaction the direct report had with their manager $(\mathrm{p}<.05)$. Furthermore, with all variables considered the model explained only $10 \%$ of the change in transactional leadership behavior. 
Table 19. Hierarchical regression between changes in transactional leadership (CTACT) and demographic variables - Model 2 Direct Reports

$\begin{array}{lll}\text { CTACT } & \text { Estimated } & \text { p-value } \\ \text { (Direct Reports) } & \text { Coefficient } & \end{array}$

$\begin{array}{lrl}\text { Gender (Manager) } & 0.12 & 0.58 \\ \text { In-agreement } & 0.07 & 0.70 \\ \text { Months reporting to manager } & -0.19 & 0.35 \\ \text { Usual Interaction } & -0.42 & 0.04^{*} \\ \text { Post Leadership Effectiveness } & 0.24 & 0.49 \\ \text { Post Extra Effort } & -0.45 & 0.15 \\ \text { Post Satisfaction with the manager } & -0.22 & 0.54 \\ \text { Pre-transactional leadership } & -0.28 & 0.14 \\ \text { MBTI } & 0.09 & 0.65\end{array}$

Notes: R-square .10 *Significant at the 0.05 level (2-tailed)

Mean scores for the pre-assessment of transactional leadership behavior according to the direct reports (2.58) were not significantly different from post-assessment mean scores (2.50). A stepwise regression was conducted to understand the impact of the select variables. Post-extra effort was the only variable of significance $(p<.05)$ explaining $11.1 \%$ of the variation in the change in transactional leadership behavior. Extra effort items on the MLQ were; increases my willingness to try harder, heightens my desire to succeed, and gets me to do more than I expected to do

The next two regression models analyze the difference scores between managers and their direct reports. Differences were calculated as the difference between the managers' and direct reports' ratings, i.e. Pre-transformation score Manager minus Pretransformation score Direct Report. The differences were then calculated as the postdifference scores minus the pre-difference scores for both transformational and 
transactional leadership behaviors. Table 20 provides the results for the difference scores for transformational leadership behavior. The length of time that the direct report worked for the organization was significant $(p<.05)$ and positive. The longer the direct report worked for the organization, the greater the difference between the direct reports' perceptions and the managers' perceptions with reference to the managers' transformational leadership behavior. The only other variable that showed minor significance $(\mathrm{p}<.07)$ was the usual interaction the direct report had with their manager. The results show that the less interaction with the manager, weekly rather than daily, the greater the difference in transformational leadership scores.

Table 20. Hierarchical regression differences in the differences Model 1 Transformational Leadership

$\begin{array}{ll}\text { DIFFTRANSFORM } & \begin{array}{l}\text { Estimated } \\ \text { Coefficient }\end{array}\end{array}$

Gender (Manager)

Months reporting to manager

Usual Interaction

Age of direct report

Open to change

Manager level in the organization

Manager length in current position

STJ Myers Briggs

Age of manager

Degree of manager

Years of supervisory experience

Length of time direct report working in the organization
$-0.11$

$-0.01$

0.31

0.18

0.11

$-0.18$

0.04

$-0.18$

$-0.16$

$-0.10$

$-0.04$

0.40
0.53

0.97

0.07

0.30

0.55

0.29

0.84

0.32

0.37

0.58

0.84

$0.03 *$

Notes: R-square .13 *Significant at the 0.05 level (2-tailed)

Stepwise regression analysis was conducted to provide insights to the relationship between two variables; length working in the organization and usual interaction. Usual 
interaction was assessed by how often the direct report interacted with their manager, ranging from multiple times in a day to bi-monthly. The regression model showed a significant relationship $(\mathrm{p}<.05)$ concerning the time the direct report had been working for the organization and the usual interaction between the direct report and their manager. These two variables explained $18.5 \%$ variation in the differences among direct reports and their managers for transformational leadership behavior.

Regression analyses were conducted to understand changes in transactional leadership behavior. Stepwise regression revealed that the age of the direct report $(p<.01)$ and the gender of the manager $(p<.05)$ explained $39.4 \%$ of the variance between the transactional difference scores. Both variables had negative coefficients illustrating that the younger the direct report the greater the differences between scores. Additionally, if the direct report's manager was a man the differences in transactional leadership scores tended to be higher.

\section{Concluding Remarks on Research Question 3}

Research question three explored the relationships between personality type and other demographic variables to help explain the variation for changes in transformational and transactional leadership behavior. The first two regression models were from the perspective of the managers. The model that explained the most variation $(69.2 \%)$ for changes in transformational leadership behavior were; whether the manager had a masters or doctorate degree, gender, the number of years of supervisory experience, and their post-transformational leadership scores $(\mathrm{p}<.01)$. The model that explained the most variation (12\%) for changes in transactional leadership behavior was personality type and changes in their transformational leadership behavior $(\mathrm{p}<.05)$. 
The next two regression models were from the perspective of the direct reports. The managers' pre-transformational leadership scores and the post-leadership effectiveness scores explained 75.9 percent of the change in transformational leadership behavior $(\mathrm{p}<.01)$. The model that explained the most variation $(11.1 \%)$ for changes in transactional leadership behavior was the post-extra effort scores $(\mathrm{p}<.05)$.

The final two regression models explored the relationship between the differences in the managers' and direct reports' leadership behavior scores. The first model examined the relationship between the differences in transformational leadership behavior scores. The length of time that the direct report worked for the organization and the usual interaction between the manager and direct report explained $18.5 \%$ of the variance in the transformational leadership differences $(\mathrm{p}<.05)$. The last model analyzed the relationship between the differences in transactional leadership behavior and revealed that the age of the direct report $(\mathrm{p}<.01)$ and the gender of the manager $(\mathrm{p}<.05)$ explained $39.4 \%$ of the variance between the transactional difference scores.

\section{Data Analysis Results for Research Question 4}

The fourth research question for this study sought to understand factors associated with those that changed the most and those that changed the least. Specifically, the research question asked, to what extent are there any identifiable themes between those who changed the most and those who changed the least? Change was defined as the manager's post-transformational scores minus their pre-transformational scores according to their direct reports. Items on the MLQ were rated on a 5-point scale ranging from not at all (0) to frequently, if not always (4). The mean change in transformational leadership 
behavior according to the direct reports was 0.10 with a standard deviation (SD) of 0.50 and the range was -1.00 to 1.65 .

Looking at the distribution of change scores as shown in Figure 1, there were clearly two outliers for those that changed the most, 1.65 and 1.55. Consequently two outliers for those that changed the least, -1.00 and -0.88 were included to equate the two groups. Analyses were performed to assess the relationships, if any, between the two groups, most changed and least changed.

Figure 2. Normal Distribution Curve - Change in Transformational Leadership Behavior as Perceived by the Direct Reports

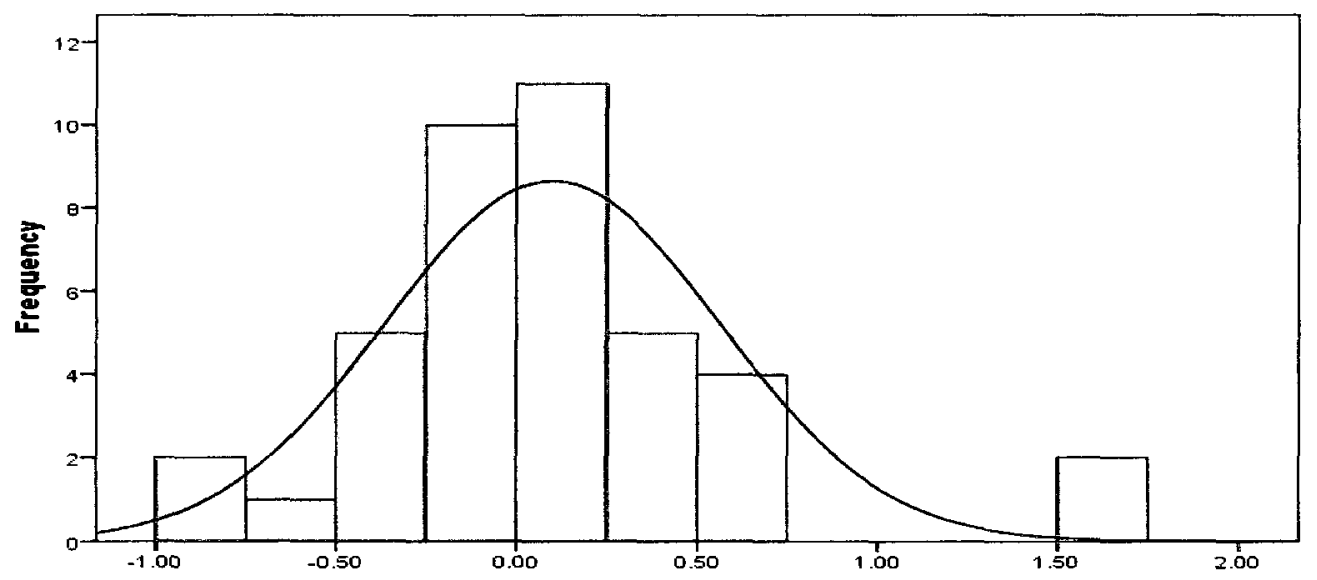

Prior to participating in the program, managers were asked how open they were to changing their leadership behavior on a 7-point scale ranging from not at all open (1) to extremely open (7). The mean scores for both groups were six, indicating that all individuals were very open to changing their leadership behavior whether they were perceived as changing the most or least. Table 21 provides the demographic data for these two groups. 
Table 21. Demographic Characteristics of the Most and Least Changed

\begin{tabular}{|c|c|c|}
\hline Characteristic & Least Changed & Most Changed \\
\hline$\overline{\text { Male }}$ & 1 & 0 \\
\hline Female & 1 & 2 \\
\hline \multicolumn{3}{|l|}{ Age } \\
\hline $31-40$ & 1 & 0 \\
\hline $41-50$ & 1 & 0 \\
\hline $51-60$ & 0 & 2 \\
\hline \multicolumn{3}{|l|}{ Degree } \\
\hline 4 year college & 1 & 0 \\
\hline Doctorate & 1 & 2 \\
\hline \multicolumn{3}{|c|}{ Years of supervisorial experience } \\
\hline $1-3$ years & 0 & 1 \\
\hline 10 or more years & 2 & 1 \\
\hline \multicolumn{3}{|l|}{ Organizational level } \\
\hline Middle Manager & 1 & 0 \\
\hline Upper Middle Manager & 0 & 2 \\
\hline Executive/Top Level & 1 & 0 \\
\hline \multicolumn{3}{|l|}{ MBTI } \\
\hline ESTP & 1 & 0 \\
\hline ESTJ & 1 & 1 \\
\hline ENTJ & 0 & 1 \\
\hline
\end{tabular}

Table 21 shows that the two individuals who changed the most in their transformational leadership behavior according to their direct reports were older (51-60 years) females, highly educated (doctorates), upper-middle level managers with one having the least amount of supervisorial experience (1-3 years) and the other having the highest number of years (10 or more). The two individuals who changed the least were more diverse; one male, one female; one between 31-40 years of age and the other between 41-50 years of age; one with a 4 year college degree and one with a doctorate; 
one was a middle manager and one was in an executive level position, and lastly, both had 10 or more years of supervisorial experience. According to their MBTI results, all four individuals are extroverted thinking individuals, however the least changed managers are sensing rather than intuitive people and the most changed individuals are more judging than they are perceiving.

Analyses were also performed to assess the ratings of these managers in regards to their leadership outcome measures of effectiveness, extra effort and satisfaction as perceived by their direct reports two months after their managers participated in the Leader Development Simulation. Table 22 presents the mean and standard deviation values for each of these outcomes. The two individuals who changed the most were rated significantly higher in terms of leadership effectiveness $(p<.05)$ than the two individuals who changed the least and higher overall in the other two areas.

Table 22. Leadership Outcome Measures

\begin{tabular}{lccccc}
\hline \multirow{2}{*}{ Leadership Outcome } & \multicolumn{2}{c}{ Least Changed } & \multicolumn{2}{c}{ Most Changed } \\
& Mean & SD & Mean & SD \\
& & & & & \\
\hline Leadership Effectiveness & 2.31 & 0.27 & $4.00^{*}$ & 0.00 \\
Extra Effort & 3.00 & 0.94 & 3.67 & 0.00 \\
Satisfaction & 2.63 & 1.24 & 4.00 & 0.00 \\
\hline
\end{tabular}

Notes: $*$ Significant at the 0.05 level (2-tailed)

The next level of analyses performed were to identify what dimensions of transformational, transactional, and laissez-faire leadership behaviors changed significantly for these two groups. Table 23 provides the means and standard deviations 
for the changes in the leadership behavior dimensions. Change was measured by subtracting post-assessment scores from pre-assessment scores.

Table 23. Changes in the Dimensions of Transformational, Transactional, and LaissezFaire Leadership Behavior - Direct Reports

\begin{tabular}{|c|c|c|c|c|}
\hline \multirow[t]{2}{*}{ Leadership Dimension } & \multicolumn{2}{|c|}{ Least Changed } & \multicolumn{2}{|c|}{ Most Changed } \\
\hline & Mean & SD & Mean & SD \\
\hline \multicolumn{5}{|l|}{ Idealized Influence } \\
\hline Attributed & -0.88 & 0.18 & $1.50^{* *}$ & 0.00 \\
\hline Behavioral & -0.63 & 0.18 & $2.00^{* *}$ & 0.00 \\
\hline Inspirational Motivation & -1.31 & 0.09 & $2.13^{*}$ & 0.88 \\
\hline Intellectual Stimulation & -0.81 & 0.27 & 1.00 & 0.71 \\
\hline Individualized Consideration & -1.06 & 0.27 & $1.38^{* *}$ & 0.18 \\
\hline Contingent Reward & -0.81 & 0.27 & $2.00^{*}$ & 0.35 \\
\hline \multicolumn{5}{|l|}{ Management-by-Exception } \\
\hline Active & 0.63 & 0.53 & 0.13 & 0.53 \\
\hline Passive & 1.25 & 0.53 & $-1.63^{*}$ & 0.18 \\
\hline Laissez-Faire & 0.06 & 0.09 & $-2.00 *$ & 0.35 \\
\hline
\end{tabular}

Notes:**Significant at the 0.01 level (2-tailed)

* Significant at the 0.05 level (2-tailed)

Performing analysis on the two managers that changed the most and two managers that changed the least according to their direct reports, Table 23 shows that all the dimensions of transformational leadership behavior were significantly different between the two groups except for intellectual stimulation. Additionally, the management-by-exception passive and laissez-faire leadership dimensions also showed a significant difference. The one dimension that seems to be contradictory is contingent 
reward. According to Bass \& Avolio (2004), one would want to show a decrease in a transactional leadership behavior dimension rather than an increase. In the case of this study, the two managers that changed the most showed a positive 2.00 point change in their contingent reward behavior while the two that changed the least showed a decrease in the behavior.

While the findings for those that changed the most and those that changed the least was important to explore, pre- and post-assessments for each manager was only provided by one direct report. Therefore, additional analyses were conducted to identify the differences between those managers who showed a decline in their transformational leadership behavior (negative change) and those that showed an increase in their transformational leadership behavior (positive change). Change was measured as the direct report ratings of their managers' transformational leadership behavior after the program minus the direct reports' pre-assessment scores. All managers who had direct report ratings showed either positive $(n=22)$ or negative change $(n=18)$. The mean change was 0.10 , standard deviation 0.50 and the range of change was -1.00 to 1.65 .

Table 24 presents a demographic analysis of the managers. Understanding that the sample size for each group is low, the table displays the actual number of responses for individual categories and the percent of responses for each individual category. As Table 24 indicates, there are some differences in the groups. More women (10) showed a positive change than a negative change (6). Further, more men improved their transformational leadership behavior (54.5\%) than did women (45.5\%). However, women had a greater percentage increase in their transformational leadership scores (0.54) than did men (0.32) and women were rated higher (3.18) than men (2.86) in their 
post-assessment transformational leadership scores according to their direct reports. The managers who showed a positive change were more educated $(67.3 \%)$ with a masters or doctorate level of education than were those showing a decline in their transformational behavior $(38.9 \%)$.

The years of supervisory experience were also different for the two groups. A majority of managers who reflected a decline in their leadership behavior had ten or more years of supervisory experience $(61.1 \%)$ compared to those with the same amount of experience showing a positive increase in their behavior (45.5\%). Additionally, the positive change group had more managers with four to nine years of experience $(45.4 \%)$ compared to those that declined $(16.7 \%)$. The level within the organization revealed only minor distinctions between the two groups with slightly more upper middle and executive managers showing increases $(70 \%)$ compared to those showing declines $(66.6 \%)$ in their behavior. The time these managers have been in their current position did differ between the groups. More managers in the negative change group $(50 \%)$ had been in their positions greater than three years compared to those showing positive change $(36.4 \%)$. 
Table 24. Demographic Characteristics of those with Negative and Positive Change

\begin{tabular}{|c|c|c|c|c|}
\hline \multirow[t]{2}{*}{ Characteristic } & \multicolumn{2}{|c|}{ Negative Change $(n=18)$} & \multicolumn{2}{|c|}{ Positive Changed $(n=22)$} \\
\hline & $\mathrm{n}$ & Percent & $\mathbf{n}$ & Percent \\
\hline Male & 12 & 66.7 & 12 & 54.5 \\
\hline Female & 6 & 33.3 & 10 & 45.5 \\
\hline \multicolumn{5}{|l|}{ Age } \\
\hline $20-30$ & 2 & 11.1 & 1 & 4.5 \\
\hline $31-40$ & 6 & 33.3 & 7 & 31.8 \\
\hline $41-50$ & 8 & 44.4 & 11 & 50.0 \\
\hline $51-60$ & 2 & 11.1 & 3 & 13.6 \\
\hline \multicolumn{5}{|l|}{ Degree } \\
\hline 4 year college & 11 & 61.1 & 5 & 22.7 \\
\hline Masters & 5 & 27.8 & 11 & 50.0 \\
\hline Doctorate & 2 & 11.1 & 6 & 27.3 \\
\hline \multicolumn{5}{|c|}{ Years of supervisorial experience } \\
\hline $1-3$ years & 4 & 22.2 & 2 & 9.1 \\
\hline $4-6$ years & 1 & 5.6 & 5 & 22.7 \\
\hline $7-9$ years & 2 & 11.1 & 5 & 22.7 \\
\hline 10 or more years & 11 & 61.1 & 10 & 45.5 \\
\hline \multicolumn{5}{|l|}{ Organizational level* } \\
\hline First Level/Hourly & 1 & 5.6 & 2 & 10.0 \\
\hline Middle Manager & 5 & 27.8 & 4 & 20.0 \\
\hline Upper Middle Manager & 8 & 44.4 & 8 & 40.0 \\
\hline Executive/Top Level & 4 & 22.2 & 6 & 30.0 \\
\hline \multicolumn{5}{|l|}{ Length in current position } \\
\hline$<6$ months & 1 & 5.6 & 2 & 9.1 \\
\hline $6-12$ months & 1 & 5.6 & 1 & 4.5 \\
\hline 13-24 months & 4 & 22.2 & 8 & 36.4 \\
\hline $25-36$ months & 3 & 16.7 & 3 & 13.6 \\
\hline$>3$ years & 9 & 50.0 & 8 & 36.4 \\
\hline
\end{tabular}

Notes: *Only 20 of 22 respondents provided their organizational level

Analyses were also performed to assess the change in the managers' leadership behaviors for each leadership dimension, as well as the outcome measures of 
effectiveness, extra effort, and satisfaction. Change was measured as the post-assessment scores minus the pre-assessment scores. Table 25 presents the mean and standard deviation values for each of the leadership dimensions.

Table 25. Leadership Outcome Measures

\begin{tabular}{llcll}
\hline Leadership Outcome & $\begin{array}{l}\text { Declined } \\
\text { Mean }\end{array}$ & SD & $\begin{array}{l}\text { Improved } \\
\text { Mean }\end{array}$ & SD \\
\hline IIA change & -0.21 & 0.33 & $0.35^{* *}$ & 0.50 \\
IIB change & -0.30 & 0.39 & $0.47^{* *}$ & 0.59 \\
IM change & -0.38 & 0.47 & $0.43^{* *}$ & 0.68 \\
IS change & -0.39 & 0.50 & $0.33^{* *}$ & 0.45 \\
IC change & -0.15 & 0.56 & $0.51^{* *}$ & 0.52 \\
CR change & -0.21 & 0.47 & $0.41^{* *}$ & 0.66 \\
MBEA change & 0.25 & 0.60 & $-0.21^{*}$ & 0.59 \\
MBEP change & 0.28 & 0.75 & $-0.32^{* *}$ & 0.58 \\
LF change & 0.02 & 0.49 & $-0.37^{*}$ & 0.62 \\
Leadership Effectiveness change & -0.07 & 0.57 & $0.52^{* *}$ & 0.63 \\
Extra Effort change & -0.30 & 0.50 & $0.40^{* *}$ & 0.76 \\
Satisfaction change & -0.17 & 0.55 & $0.56^{* *}$ & 0.71 \\
& & & & \\
\hline N & & & &
\end{tabular}

Notes: ${ }^{* *}$ Significant at the 0.01 level (2-tailed)

* Significant at the 0.05 level (2-tailed)

As shown in Table 25, the differences between the groups were significant at either the 0.01 or 0.05 level. All changes in the dimensions of transformational leadership were significant $(p<.01)$. Furthermore, the change in contingent reward was significant, however managers displaying an increase in their overall transformational leadership behavior also showed an increase in their contingent reward behavior $(0.41)$. The other two transactional dimensions, management-by-exception active and passive decreased for those that displayed improvements in their transformational behavior. According to Bass $\&$ Avolio, (1997), it is preferable to improve your transformational behavior and decrease your transactional behavior most of the time. Some exceptions for an increase in your 
transactional behavior would be for those positions requiring minimal mistakes, i.e. surgical positions, highly technical positions, etc.

\section{Concluding Remarks on Research Question 4}

Research question four explored identifiable themes between those managers that changed the most and those that changed the least. The first level of analyses focused on two individuals that changed the most and two that changed the least. While there were differences between the groups, only one direct report provided pre- and postassessments for each of the four individuals. Further analyses explored the themes between managers who declined in their transformational leadership behavior after the training program and managers who increased their leadership behavior.

More female managers showed a positive change in their transformational leadership behavior, had a greater percentage increase in their transformational leadership scores, and were rated higher in their post-assessment transformational leadership scores than men. Managers who had ten or more years of supervisory experience showed more of a decline in their behaviors than did managers with fewer years of experience. Additionally, direct reports were more satisfied with their managers, believed their managers were more effective as leaders, and were willing to give more effort in their jobs for the managers that showed a positive change in their transformational leadership behaviors.

\section{Conclusion}

The data collected for this study revealed several statistically significant findings. The chapter began with a review and discussion of the sample participants and their direct reports followed by descriptive statistics to help inform the analyses. The results of 
the analyses were provided to answer the four research questions and provided support for the impact of short-term leader development programs. Specifically, and perhaps most importantly, the findings suggest that while managers perceived significant and positive changes in all of their transformational leadership behaviors and reductions in their transactional and laissez-faire behaviors, their direct reports perceived significant changes $(p<.05)$ in only one dimension of their manager's transformational leadership behavior, individualized consideration. Additionally, the direct reports did believe that their manager's had become more effective in their leadership behavior $(\mathrm{p}<.05)$ and they were more satisfied with their manager overall $(\mathrm{p}<.05)$ two months after the manager had participated in the leader development program. These and selected other findings presented in this chapter will be discussed further in Chapter Five where the implications of the study will be discussed. 


\section{CHAPTER FIVE}

\section{DISCUSSION OF FINDINGS AND CONCLUSIONS}

The purpose of this study was to determine the impact of a simulation-based leader training program (Leader Development simulation) on transformational and transactional leadership behavior as measured by the Multi-factor Leadership Questionnaire Form 5x (MLQ). Impact was measured in this study as the improvement of a manager's transformational leadership behaviors and reductions in the manager's transactional leadership behaviors according to the managers and their direct reports. Past research, summarized in Chapter Two, established that effective leadership is a crucial means to organizational growth, change, and revitalization in turbulent times. In addition, research has established that the dimensions encompassing transformational leadership positively influence essential organizational attitudes and results (Avolio, 1999; Conger \& Kanungo, 1987; Dvir, Eden, Avolio, \& Shamir, 2002).

Conger \& Benjamin (1999) observed that organizations are concerned about leadership and are committed to training that enhances leadership skills in their employees despite the fact that they do not know whether such development interventions are effective. Some organizations do not have the time or resources to send their employees off for lengthy leader development training programs and this has contributed to the growing popularity of short-term training programs. Researchers called for empirical studies that examine these programs, yet such requests remain largely disregarded (Day, 2000, Parry \& Sinha, 2005).

Determining the exact changes that result from leader development training and the cause of those changes remains a methodological challenge for researchers. For 
instance, we are left to question whether development occurred because the individual participating in the training became aware of a new model of leadership. Did change occur because the individual took what they learned and applied leadership in their workplace and life? Can we state that change occurred when the manager exhibited new behaviors that were observed by their direct reports? This study aimed to address how individuals were changed after participating in a well-established and widely regarded short-term leader development training program. Specifically, this dissertation attempted to address the concerns of researchers asking for more empirical studies to examine the impact of leader development programs.

The grand tour question that guided this study was: Do managers participating in a short-term leader development training program change their leadership behaviors? In order to answer this question, four research questions were formulated. These research questions were analyzed using data from the Multifactor Leadership Questionnaire (MLQ). Demographic data were also collected to provide additional information for this study.

This chapter begins by providing an examination of the study's methodology and a summary of the study's key findings. The next section presents the conclusions drawn from the results of the data analysis and discusses policy implications. The final section of this chapter concludes the dissertation by examining the relevance of these findings to the current state of evaluating leader development programs and to the development of managers in the Leadership Studies field. 


\section{Methodology and Findings of the Study \\ A Brief Review of the Study's Methodology}

The framework for this study was conducted using a quasi-experimental pre-test, post-test quantitative research design to explore the impact of the Leader Development Simulation (LDS) behavioral simulation on transformational and transactional leadership behavior. A pre-test was conducted one month before the managers engaged in the LDS and two months after the training. Both managers (self-ratings) and their direct reports (other-ratings) completed the MLQ 5x assessment instrument.

The MLQ 5x assessment was chosen as the survey instrument for this study due to its overall alignment to the LDS course objectives as well as its ease of use (see Appendix $\mathrm{C}$ for the MLQ and LDS outcome measurement assessments). The MLQ is a validated instrument with 36 leadership questions and nine outcome items using a five point Likert-scale based on a model developed by Bernard Bass and Bruce Avolio (1994). The model denotes a leader's performance on a range of leadership behaviors, from the least potent, laissez faire, to the most potent, idealized (charismatic) leadership (Bass \& Avolio, 2000). Select demographic data were also included in the MLQ 5x assessment.

Among the managers invited to participate in this study, 54 (29.7\%) completed the pre-assessment and $50(27.5 \%)$ completed the post-assessment. Managers participating in this study were mid- to upper-level managers within a diverse array of industries and organizations. Direct reports (81) participating in this study were chosen by the managers and defined as those who observe the manager's behavior at least weekly. Managers participating in this study were representative of the population of all 
managers who had participated in the Leader Development Simulation during the months data were collected. Responses were submitted confidentially through the SurveyMonkey website, downloaded into SPSS, and analyzed using an assortment of quantitative methods.

\section{Discussion of the Study's Key Findings}

This study produced a number of significant findings for both the leadership studies field and for those interested in the evaluation of leader development programs. The core research question asked whether managers changed their leadership behavior after participating in a relatively condensed leader development training experience. The findings indicate that the Leader Development Simulation program did significantly improve the managers' transformational and transactional leadership behavior according to self-ratings $(p<.05)$. However, the managers perceived the changes more significantly than did their direct reports. Self-ratings tended to be inflated and these findings are congruent with the literature (Atwater \& Yammarino, 1997; Bass \& Yammarino, 1991; Sosik \& Megerian, 1999).

According to the direct reports, there were three statistically significant changes in their managers' leadership behavior after participating in the LDS. After the training experience the managers' level of individualized consideration behaviors increased $(p<.05)$, and both leadership effectiveness $(p<.05)$, and satisfaction with the leader improved $(\mathrm{p}<.05)$. Individualized consideration is one of the four dimensions of transformational leadership. Individualized consideration was expressed on the MLQ 5x using the following statements: 1) spends time teaching and coaching; 2) treats others as individuals rather than just as a member of the group; 3) considers each individual as 
having different needs, abilities, and aspirations from others; and 4) helps others to develop their strengths.

Leadership effectiveness was expressed on the MLQ 5x using the following statements: 1) is effective in meeting my job-related needs; 2) is effective in representing me to higher authority; 3 ) is effective in meeting organizational requirements; and 4) leads a group that is effective.

Satisfaction with the leader was expressed on the MLQ 5x as: 1) uses methods of leadership that are satisfying and 2) works with me in a satisfactory way. Overall, direct reports were more satisfied with their managers after the program, perceived their managers as being more effective as leaders, and thought their managers were spending more time considering their individual needs after the training program. While other transformational and transactional leadership behaviors did show positive improvements from the perspective of the direct reports, the results were not significant.

According to Avolio (2004), "the beginning point of developing leadership in any individual starts with an enhanced set of awareness, which leads to behaviors or ways of thinking that are new, sustained over time, and become part of the individual's repertoire" (p. 82). Managers who participated in this training believed they changed their behaviors whether their direct reports perceived these changes or not. It is argued that beliefs are perceptions of, and can be separate from, genuine capabilities (Hannah, Avolio, Luthans, \& Harms, 2008). Attitudes, of course, are related to behavioral change (Atwater, Waldman, Atwater, \& Carrier, 2000) and awareness of one's capabilities is often perceived as the beginning point of change. Furthermore, while many of the leadership behaviors did not change according to the managers' direct reports, 
perspectives changed that might eventually lead to observed behavioral change in the long-term. Perspective differences were analyzed in this study and several interesting findings are discussed in the next section.

Self-Other Discrepancies

Self-ratings tend to be inflated and are not usually seen as desirable in evaluating the impact of leader development efforts (Atwater \& Yammarino, 1997). This study confirmed that managers as a whole tended to over-estimate changes in their leadership behaviors. Specifically, there were two transformational leadership dimensions that showed significant discrepancies between the managers' perspective and their direct reports' perspective; behavioral idealized influence and inspirational motivation. Managers believed that their idealized influence behavior was significantly higher than perceptions from their direct reports both before and after the training. The items on the MLQ 5x relating to idealized influence behavior include; 1) talks about his/her most important values and beliefs, 2) specifies the importance of having a strong purpose, 3) considers the moral and ethical consequences of decisions, and 4) emphasizes the importance of having a collective sense of mission.

The behavior aspect of idealized influence connects with the LDS learning outcome that reads "to gain self-awareness and obtain an accurate picture of the manager's strengths and weaknesses" (CCL, 2009). While the managers in this study believed they had gained greater self-awareness their direct reports did not report observing a significant behavioral change in this area. The discrepancy could stem from how the manager communicates with their direct report. If, for example, the manager tells their direct report about their most important values and beliefs or specifies the 
importance of having a strong purpose, the direct report may interpret it as something the boss wants them to do or believe without fully understanding the "why" behind the "what." In this case, the extent to which such an internalized change is communicated may well be a determining factor in how the behavior is perceived by others.

Inspirational motivation was the second transformational dimension that showed significant differences between the managers' perspective and their direct reports' perspective. The pre-assessment inspirational motivation scores from both the managers and their direct reports were similar. However, the scores were significantly different after the program. Managers believed they changed significantly for this dimension though their direct reports did not report significant improvements. Inspirational motivation was expressed on the MLQ $5 \mathrm{x}$ as; 1) talks optimistically about the future, 2) talks enthusiastically about what needs to be accomplished, 3) articulates a compelling vision of the future, and 4) expresses confidence that goals will be achieved.

After participating in the training program, managers may have been re-energized and motivated. It is possible that the energy and motivation were not fully realized in behavior that was discerned by their direct reports in the two months that the postassessment was conducted. Timing could also be an issue for the measurement of this dimension. Many organizations conduct their strategic planning or become engaged in some form of goal setting toward the end of the year and most data collected for this study was in the first half of the year. Whether the discrepancy in behavioral idealized influence and inspirational motivation was due to direct reports not seeing the full effect of the managers' beliefs in change or in the timing of the data collection, there were still significant differences $(p<.01$ and $p<.05)$ between managers and their direct reports' 
perspectives. Analyses were conducted to look at why some managers were more selfaware than others.

\section{Self-Other Agreement}

Most leadership research on self-awareness compares an individual's ratings on behaviors or skills to the ratings of others; including supervisors, peers, and direct reports (Atwater \& Yammarino, 1992, 1997; Moshavi, Brown, \& Dodd, 2003). Self-awareness for this study was similarly operationalized by comparing the manager's ratings of their transformational and transactional leadership behavior to ratings of the manager given by their direct reports. A manager whose ratings were statistically similar to their direct reports was considered to be self-aware or "in-agreement" with their rater. Managers whose ratings were statistically different to their direct reports were considered to be lessaware or "not in-agreement." Results from this study found that the managers who overestimated their transformational leadership scores were rated the lowest by their direct reports while the managers who under-estimated their scores were rated the highest by their direct reports. These findings suggest a link between humility and perceptions of transformational leadership behavior.

\section{Common Themes for Change}

Correlations were run to identify common themes between those LDS participants that changed the most and those that changed the least. While there were slight differences in some demographic variables, only the managers' level of education reflected a significant difference. A significantly larger percentage of managers who had advanced degrees, masters or doctorates, demonstrated positive improvements in their transformational leadership behaviors $(77.3 \%, \mathrm{p}<.01)$. The opposite was true for 
managers who had obtained only a four year college degree. The majority of managers (61.1\%) with only a four year college degree showed a decline in their transformational leadership behaviors. These findings imply that managers with advanced degrees improved their transformational leadership behaviors more than those who had obtained an undergraduate degree. The implications of this finding could lead us to consider the possibility that managers with advanced degrees are more open to self-improvement.

Additionally the group that showed improvements in transformational leadership behavior demonstrated declines in: contingent reward, management-by-exception active, management-by-exception passive, and laissez-faire behaviors. Managers that showed declines in transformational leadership behaviors exhibited a concurrent increase in all three of their transactional behaviors and in laissez-faire behaviors. When managers demonstrated increases in transformational behaviors, direct reports indicated that they were also more satisfied, willing to put forth greater extra-effort, and believed their managers were more effective.

Personality Type and Changes in Behavior

This study also explored the relationships between personality types and other select demographic measures to help explain changes in an individual's transformational and transactional leadership behavior. Managers participating in the LDS completed the Myers Briggs Type Indicator (MBTI). One of the advantages of using the MBTI instrument is the theory behind it based on Jung's (1921) work on psychological types and further developed by Myers and Briggs (1998). The MBTI has become one of the most widely used tools for defining personality types (Myers, McCaulley, Quenk, \& 
Hammer, 1998) and a common method for studying the relationship between leadership and personality (Gallen, 1997; McCarthy \& Garavan, 1999; Hautala, 2005).

Findings in this research suggested no significant differences between the thinking/feeling types or the sensing/intuiting types in the perceived expression of transformational leadership behaviors. However, managers characterized as perceiving were viewed significantly higher $(p<.05)$ than judging managers in two transformational leadership dimensions; idealized influence and inspirational motivation. Perceivers scored higher in behavioral idealized influence and inspirational motivation than any other personality type. Perceiving types were also rated significantly higher on the contingent reward dimension $(p<.05)$ and lower on the management-by-exception active scale $(\mathrm{p}<.05)$. Individuals with perceiving preferences are viewed as more adaptive, spontaneous, and open-minded (Roush \& Atwater, 1992).

Transformational leaders, by definition, develop their followers. Part of this development is the need to be adaptive and open-minded to an individual's unique needs and characteristics that are typical attributes for those with a perceiving personality type. Open-mindedness allows for multiple perspectives in solving complex problems. Leadership is most assuredly a complex phenomenon. These findings suggest that perceiving individuals have a set of preferences that convert to more transformational behaviors than other personality types. Most of the managers in this study were reported as having sensing, thinking, and judging personality types. While only ten individuals had a perceiving tendency, the impact on their direct reports was significant $(p<.05)$. Perceiving managers significantly exhibited more idealized influence and inspirational motivation behaviors than did judging managers $(\mathrm{p}<.05)$. 


\section{Leadership Effectiveness}

Post-test effectiveness was positively related to changes in transformational leadership behavior. The greater the change in transformational leadership behavior, according to direct reports, the higher the manager's post-leadership effectiveness scores. These findings suggest that as managers increase their transformational leadership behaviors the more effective they are in their leadership as observed by their direct reports. Effectiveness was measured as: 1) leads a group that is effective; 2) is effective in meeting organizational requirements; 3 ) is effective in representing me to higher authority; and 4) is effective in meeting my job-related needs.

Each of the findings presented in this section provided significant, desired, and timely information for the leader development community. The findings also contribute empirical support for the impact of a leader development program and demonstrate that individuals can change some of their leadership behaviors from participation in a shortterm training program. The implications for policy and practice as well as suggestions for future research will be discussed in the following sections.

$$
\text { Implications of the Study }
$$

\section{Specific Implications for Leader Development Policy and Practice}

The impact of leader development programs can be evaluated based on how the program influences positive changes in leader behavior. Research has shown that people who believe they have the skills and knowledge required to meet organizational challenges will, if supported over time, develop an improved response pattern (Hannah, Avolio, Luthans, \& Harms, 2008). With practice and frequency, challenging leadership situations can become less difficult to navigate. The more opportunities individuals have 
to develop their leadership skills and behaviors, the more adept they become as managers. The Leader Development Simulation provides such an opportunity and provides managers with a means to practice their leadership behaviors in a simulated environment.

Findings from this study suggest that self-awareness should be even more prominent in leader development programs. While managers participating in this study professed that almost all of their leadership behaviors changed for the positive, their direct reports did not have the same perceptions. While a 360-degree feedback instrument is a start to obtaining greater self-awareness and the Leader Development Simulation also provides its participants with faculty and peer feedback during the five day program, this may be insufficient for long-term change. According to Riggio (2008), "nearly every author mentions that leaders must develop awareness of their own leadership strengths and limitations to capitalize on strengths and overcome shortcomings" (p. 387).

The real issue may rest with receptivity to feedback rather than just selfawareness. Taking five minutes to reflect on feedback versus spending three hours reflecting on feedback may well be the difference between being open to hearing one's shortcomings and being a student wanting to learn more about one's behavior. Managers who participated in this study received extensive feedback from their supervisors, peers, and direct reports, yet the implications of this study clearly suggests that managers felt they were more transformational than did their direct reports. Recognizing the relationship between being self-aware and being a "reflective practitioner" should move administrators of leader development programs toward a more integrated approach. The relationship between self-awareness and being a reflective practitioner lies in questioning 
one's assumptions. Reflective practice begins with reframing problems, listening with a neutral ear, engaging in dialogue with others, and trying again to understand how one is perceived (Schon, 1983). When individuals learn how to expand their views and look at the underlying assumptions that drive actions, they begin to understand how they relate to others, the organization, and to a larger system.

Self-awareness also relates to adult development. Managers wanting to become more effective in their leadership move from being technically competent with business knowledge to acquiring greater self-awareness and attaining higher levels of adult development. Adult development is an integral piece of leader development and has been studied extensively (Kegan \& Lahey, 1984; Kuhnert \& Lewis, 1987; Rost, 1991; Zullo, 1997).

This study discovered that managers participating in the training felt they had changed more than did their direct reports. According to the constructive/development theory of adult development by Robert Kegan (1982), the managers in this study may be operating in Stage Two. Stage Two is where adults may say that they aspire to higher orders of development but they have not developed enough to understand mutual experiences and shared perceptions. An individual's self-awareness can progress at varying rates along the adult developmental curve (Axelrod, 2005). Understanding how an individual's level of adult development relates to leader development can be an effective tool for executives in their on-going efforts to be better individuals and to lead effectively. Results of this study provide support for this key point and for an increase in adult development as it relates to leader development. 
This study also revealed that managers who under-rated their transformational leadership behavior were seen as exhibiting the highest transformational scores compared to over-raters and those in-agreement. Although excessive humility may be seen as a weakness in some business settings, managers in this study who were more humble were also rated the most effective. Collins (2001) provided extensive research on the differences between a "good" organization and a "great" organization and provided evidence for the utility of humility in leadership. Humility may offer a new lens through which to understand and study the leader development process (Morris, Brotheridge, \& Urbanski, 2005).

Leader development is an on-going process (McCauley \& Van Velsor, 2004; Riggio, 2008) and should not be viewed as a one-time exercise. The managers in this study underwent extensive feedback, but the majority of them did not become accurately self-aware of their behaviors. Avolio, Gardner, \& Walumba, (2007) argue that there is sparse evidence in support of leader development initiatives:

For the most part, there are numerous players in the business of leadership development who cannot answer a simple and direct question, What evidence do you have that you have actually developed even one leader? That question was posed to one of the top consultants from a very well-known organization that profits from leadership development interventions around the globe and her response was, 'someone was examining that issue in another department.' We challenge all of those in the business of developing leaders to come up with a better answer-one that at least demonstrates they have actually developed just one leader! (xxii).

Transformational leadership theory attempts to advance both the leaders and followers to higher levels of development. One primary responsibility of a transformational leader is the development of others. The findings from this study show that the LDS, a relatively short-term training experience, did develop leaders in ways that 
were visible to their direct reports. Direct reports felt that their managers improved in considering their individual needs as a result of participating in this short-term training program and that very improvement was one of the core outcomes for the LDS. Participants in the LDS learned how to give developmental feedback. Direct reports felt that their managers spent more time teaching and coaching them, helped them to develop their strengths, and considered their individual needs more as a result of participating in the training program. Direct reports also saw improvements in leadership effectiveness and satisfaction with their managers.

Organizations facing a decline in their leadership bench because of retiring babyboomers should feel somewhat relieved that their managers can develop and be more effective after participating in a condensed leader development program. Not only did the managers benefit from the training program, their direct reports felt the benefits as well. The encouraging findings of this study provide support that the LDS leadership training does result in more effective leadership behavior and there is a "trickle-down" effect with others in the organization. The next section will address the concerns in the leadership development field regarding evaluating the efficacy of leader development training programs.

Specific Implications for Leader Development Evaluation Policy and Practice

This study addressed the concerns of several researchers in the field of leadership development, specifically the call for greater attention to evaluation of leader development programs. In an article by Ronald Riggio (2008) regarding the current state and future expectations of leadership development, he illustrates the underlying problem: 
In summary, those of us involved in efforts to develop leadership need to be very concerned about evaluation of our programs. We need to demonstrate the effectiveness of what we are doing and, in short, justify our existence. Organizations should be assured that their investment in leadership development does indeed pay off. Because of this, it is somewhat disheartening that there is not more attention to evaluation, both in the research literature and in practice (p. $389)$.

Evaluation of this program provided an opportunity to examine whether personal transformation occurred and whether the inner change lead to outer observable change. Kelloway and Barling (2000) argue that the intervention could only be deemed a success if the leaders' direct reports saw an increase in positive leadership behaviors. This study obtained not only the views of the managers participating in the training program, it also obtained their direct reports' perceptions and showed that individuals participating in a short-term leader development program can significantly change some of their transformational leadership behaviors, specifically the behaviors related to individualized consideration. The findings also suggest that other transformational leadership behaviors may have improved, although not significantly. However, this study confirmed results from previous studies which showed that self-ratings tend to be inflated. This lends itself to the need for multiple raters in the evaluation process.

Additionally, and perhaps just as important to evaluating leader development programs, is including a qualitative component to the evaluation plan. Researchers have argued that different types of organizational context can generate varying degrees of a need for leader development (Bass, 1998; Pawar, 2003). Gaining further information about the training program from the individuals who participated can provide more indepth information about the mechanisms of leader development training programs. In 
summary, in order to grasp the full extent of the impact of a leader development training program, both a quantitative and qualitative approach is warranted.

\section{Suggestions for Future Research}

The research for this dissertation provided results from 50 managers and 81 direct reports. Due to the limited sample size it is suggested that this study be replicated with a larger sample to provide greater opportunities for generalizability. A qualitative approach that examines the mechanisms of leader development from the perspectives of participants should also be included. Future research might examine the impact of a leader development training program over a longer period to identify if changes in behavior were improved or sustained over time.

Self-awareness and humility were two primary areas of concern in this study. Further research could explore the impact that these two dimensions have on leader development. Data from the managers' peers and supervisor would also lend itself to a rich study evaluating these two constructs. The comparison of manager and rater responses would also enable researchers to determine if the direct reports' perceptions were similar to those of the peer and supervisor groups.

Training simulations have the ability to provide individuals with knowledge and the ability to apply that knowledge in controlled situations. A study that added more opportunities for reflection into its learning objectives (e.g., through journaling and focused interviews) would provide valuable insights.

\section{Conclusion}

A recent search for leader development programs on Google revealed over 17 million hits. Many of these sites profess to develop the next generation of leaders by 
following their "proven" leadership development methods. However, scholars in the leadership field (Bass \& Avolio, 1997; Day, 2000, Riggio, 2008) would likely agree that there is no one "proven" method. Instead, these scholars acknowledge the need for multiple pedagogies in training the next generation of leaders. These pedagogies include; 360-degree feedback, executive coaching, mentoring, and role-playing simulation exercises. Most Fortune 500 companies offer some form of leader development training for their employees and many of these programs include the more popular training pedagogies.

Organizations are not only facing a significant loss in their workforce due to the retirement of baby-boomers, they are also confronted with rapidly changing environments in the industries in which they compete. These organizations are devoting considerable resources to develop their employees' capacity for leadership because they believe that "leaders" are essential in the operations of their organizations (Riggio, 2008). Transformational leadership is one of the most studied theories of leadership. Transforming leadership theory was first described by James MacGregor Burns (1978) and later operationalized by Bernard Bass (1985). Transformational leadership occurs when leaders and followers raise one another to higher levels of motivation and morality. Research has established the positive impact of transformational leadership on individual, direct report, and organizational performance (Bass, Avolio, Jung, \& Berson, 2000; Dvir, Eden, Avolio, \& Shamir, 2002; Lowe \& Galen, 1996). Conger (1999) reviewed 15 years of research and found that transformational leadership may be traceable to companies wanting to change and reinvent themselves. However, few studies have empirically 
examined whether managers actually change their behaviors after participating in a shortterm leader development program.

This dissertation has demonstrated that managers can change some of their transformational leadership behaviors after participating in a short-term leader development training program. Direct reports perceived significant changes in their managers' individualized consideration behaviors. These behaviors are consistent with the LDS learning outcome that emphasizes the need for managers to learn how to give and receive developmental feedback. Direct reports felt that after the training event their managers were spending more time teaching and coaching them and helping them to develop as individuals. Organizations should feel somewhat encouraged that the resources they put into developing their managers not only improved those who participated in the training, it also trickled-down to others in their organization, yielding an even higher return on their investment.

This study also adds empirical support for the justification of leader development training efforts. Even short-term leader development initiatives can change leadership behavior. However, the development of leadership is an on-going process and not something that happens once in someone's career. While managers can change their behaviors in a short amount of time, left unanswered is the extent to which such short term changes translate to long-term growth and development.

It is my hope that this dissertation will serve the field of leader development training and evaluation by showing that even short-term developmental experiences can result in increases in transformational leadership behavior that takes leaders and 
followers to higher levels. Leaders who improve in some of the measures of transformational leadership behaviors have a positive impact on their direct reports. 


\section{REFERENCES}

Alimo-Metcalfe, B and Alban-Metcalfe, R. (2002). Leadership, in Warr, P. (Ed.), Psychology at Work, Penguin, London.

Alimo-Metcalfe, B. \& Lawler, J. (2001). Leadership development in UK companies at the beginning of the twenty-first century - lessons for the NHS?, Journal of Management in Medicine, 15 (5), 387-404.

Allio, R. (2005). Leadership development: teaching versus learning. Management Decision, 43(7/8), 1071-1077.

Anderson, J. (2005, Fall). The relationship between student perceptions of team dynamics and simulation game outcomes: An individual-level analysis. Journal of Education for Business, 85-90.

Anderson, P., \& Lawton, L. (1997). Demonstrating the learning effectiveness of simulations: Where we are and where we need to go. Developments in Business Simulation \& Experiential Learning, 24, 68-73.

Antonakis, J., Avolio, B. \& Aivasubramaniam, N. (2003). Context and leadership: An examination of the nine full-range leadership theory using the multifactor leadership questionnaire. Leadership Quarterly, 14, 261-295.

Antonovsky, A. (1987). Unraveling the Mystery of Health: How People Manage Stress and Stay Well. Jossey-Bass, San Francisco, CA.

Atwater, L.E. and Yammarino, F.J. (1992). Does self-other agreement on leadership perceptions moderate the validity of leadership and performance predictions? Personnel Psychology, 45, 141-64.

Atwater, L.E. and Yammarino, F.J. (1997). Self-other rating agreement: a review and model. Research in Personnel and Human Resources Management, 15, 121-74.

Avolio, B. (1994). The "natural" leader: Some antecedents to transformational leadership. International Journal of Public Administration, 17, 1559-1581.

Avolio, B. (1999). Full Leadership Development: Building the Vital Forces in Organizations. Sage Publications, Thousand Oaks, CA.

Avolio, B. \& Bass, B. (1988a). Charisma and beyond. In J.G. Hunt, B.R. Baliga, H.P. Dachler, \& C.A. Schriesheim (Eds.), Emerging Leadership Vistas, Lexington Books, Boston: MA.

Avolio, B. \& Bass, B. (1998). You can drag a horse to water but you can't make it drink unless it is thirsty. The Journal of Leadership Studies, 4(1), 393-399. 
Avolio, B. \& Bass, B. (2002). Developing Potential Across a Full Range of Leadership: Cases on Transactional and Transformational Leadership. Lawrence Erlbaum Associates, Inc., Mahwah, NJ.

Avolio, B., Bass, B. \& Yammarino, F. (1991). Identifying common methods variance with data collected from a single source: An unresolved sticky issue. Journal of Management, 173, 571-587.

Avolio, B., Gardner, W., \& Walumbwa, F. (2007). Authentic Leadership Questionnaire $(A L Q)$. Redwood City, CA: Mind Garden.

Avolio, B, \& Hannah, S. (2008). Developmental readiness: Accelerating leader development. Consulting Psychology Journal: Practice and Research 60(4), 331347.

Avolio, B. Waldman, D. \& Yammarino, F. (1991). Leading in the 1990s: The four I's of transformational leadership. Journal of European Industrial Training, 15(4), 9-16.

Atwater, L., Waldman, D., Atwater, D. \& Carrier, P. (2000). An upward feedback field experiement: Supervisors' cynicism, reactions, and commitment to subordinates. Personnel Psychology, 53, 275-297.

Atwater, L. \& Yammarino, F. (1992). Does self-other agreement on leadership perceptions moderate the validity of leadership and performance predictions? Personnel Psychology, 45, 141-164.

Atwater, L. \& Yammarino, R. (1997). Self-other rating agreement: A review and model. Research in Personnel and Human Resources Management, 15, 121-174.

Axelrod, S. (2005). Executive growth along the adult development curve. Consulting Psychology Journal: Practice and Research 57(2), 118-125.

Azriel, J., Erthal, M., \& Starr, E. (2005, Fall). Answers, Questions, and Deceptions: What is the role of games in business education? Journal of Education for Business, 913.

Bandura, A. (Ed.) (1995). Self-Efficacy in Changing Societies, Cambridge Press, New York, NY.

Barling, J., Loughlin, C., \& Kelloway, E. (2002). Development and test of a model linking safety-specific transformational leadership and occupational safety. Journal of Applied Psychology, 87,488-496. 
Barling, J., Weber, T., \& Kelloway, E. (1996). Effects of transformational leadership training on attitudinal and financial outcomes: A field experiment. Journal of Applied Psychology, 81, 827-832.

Bass, B. (1985). Leadership and Performance beyond Expectations, Free Press, New York, NY.

Bass, B. (1999). Two decades of research and development in transformational leadership. European Journal of Work and Organizational Psychology, 8(1), 932.

Bass, B. \& Avolio, B. (1990). Multifactor Leadership Questionnaire Manual. Consulting Psychologists Press, Palo Alto, CA.

Bass, B. \& Avolio, B. (1993). Training and development of transformational leaders: Looking to 1992 and beyond. Journal of European Industrial Training,

Bass, B. \& Avolio, B. (1994). Improving Organizational Effectiveness Through Transformational Leadership. Sage, London.

Bass, B. \& Avolio, B. (2004). Multifactor Leadership Questionnaire Manual, Mind Garden, Inc., www.mindgarden.com.

Bass, B., Avolio, B. \& Atwater, L. (1996). The transformational and transactional leadership of men and women. Applied Psychology: An International Review, $45(1), 5-34$.

Bass, B., Avolio, B. \& Goodheim, L. (1987). Quantitative description of world-class industrial, political, and military leaders. Journal of Management, 13, 7-19.

Bass, B., Avolio, B., Jung, D., \& Berson, Y. (2000). Predicting unit performance by assessing transformational and transactional leadership. Journal of Applied Psychology, 88(2), 207-218.

Bass, B., \& Riggio, R. (2006). Transformational Leadership. New Jersey: Lawrence Erlbaum Associates.

Bass, B. \& Stogdill, R. (1990). Bass \& Stogdill's Handbook of Leadership. New York: Free Press.

Bass, B. \& Yammarino, F. (1991). Congruence of self and others' leadership ratings of naval officers for understanding successful performance. Applied Psychology: An International Review, 40, 437-454. 
Bennett, T. (2009). The relationship between the subordinates's perception of the leadership style of IT managers and the subordinate's perceptions of IT manager's ability to inspire extra effort, to be effective, and to enhance satisfaction with management in an information technology environment. (Doctoral dissertation, Nova Southeastern University). Dissertation Abstracts International, AATT3352391.

Bennis, W. (1989). On Becoming A Leader. New York: Harper \& Row.

Binard, C. and Brungardt, C. (1997). Learning leadership: Assessing students at the community college of Denver, Journal of Leadership and Organizational Studies, $4,(4), 128-140$.

Bloom, B. (1956). A Taxonomy of Educational Objectives: The Classification of Educational Goals, Handbook 1: Cognitive Domain, New York: David McKay Co Inc.

Boaden, R. (2005). Leadership development: Does it make a difference? Leadership \& Organization Development Journal 27(1), 5-27.

Bryman, A. (1993). Charismatic leadership in business organizations: some neglected issues. Leadership Quarterly, 4, 289-304.

Bullis, R., Kane, T., \& Tremble, T. (1997). The factor structure of the multifactor leadership questionnaire: An investigation across organizational levels. Paper presented at the annual meeting of the Academy of Management, Boston, MA.

Burns, J.M. (1978). Leadership. New York: Harper and Row.

Bycio, P., Hackett, R., \& Allen, J. (1995). Further assessments of the Bass (1985) conceptualization of transactional and transformational leadership. Journal of Applied Psychology, 80, 468-478.

Cacioppe, R. (1998). An integrated model and approach for the design of effective leadership development programs. Leadership \& Organization Development Journal, 19(1), 44-53.

Campbell, D., \& Stanley, J. (1963). Experimental and Quasi-Experimental Designs for Research. Boston: Houghton Mifflin Company.

Cannon, H., \& Schwaiger, M. (2005). The role of company reputation in business simulations. Simulation \& Gaming, 36(2), 188-202.

Collins, D. (2001). Organizational performance: The future focus of leadership development programs. The Journal of Leadership Studies, 7(4), 43-54. 
Collins, J. (2001). Good to Great: Why Some Companies Make the Leap and Others Don't. Harper Business, New York.

Conger, J. (1999). Charismatic and transformational leadership in organizations: An insider's perspective on these developing streams of research. Leadership Quarterly, 10(2), 145-179.

Conger, J. \& Benjamin, B. (1999). Building Leaders: How Successful Companies Develop the Next Generation, Jossey-Bass, San Francisco, CA.

Conger, J. and Kanungo, R. (1987). Toward a behavioral theory of charismatic leadership in organizational settings. Academy of Management Review, 12(4), 637-47.

Corrigan, P., Lickey, S., Campion, J. \& Rishad. F. (2000). A short course in leadership skills for the rehabilitation team. Journal of Rehabilitation, 66(2), 56-58.

Cunningham, G. \& Kitson, A. (2000). An evaluation of the RCN Clinical Leadership Development Programme: Part 1. Nursing Standard 15(12), 34-37.

Danserau, R., Alutto, J. and Yammarino, F. (1984). Theory Testing in Organizational Behavior: The Varient Approach. Prentice-Hall, Englewood Cliffs, N.J.

Day, D. (2000). Leadership development: A review in context. The Leadership Quarterly, 11(4), 581-613.

Day, D. \& Halpin, S. (2004). Growing leaders for tomorrow: An introduction. In D.V. Day, S.J. Zaccaro, \& S.M. Halpin (eds.), Leader Development for Transforming Organizations: Growing Leaders for Tomorrow, Mahwah, NJ: Erlbaum.

De Cremer, D., \& Van Knippenberg, D. (2002). How do leaders promote cooperation? The effects of charisma and procedural justice. Journal of Applied Psychology, $87,858-866$.

Dewey, J. (1938). Experience and education. New York: Simon and Schuster.

Dohm, A. (2000). Gauging the labor force effects of retiring baby boomer. Monthly Labor Review, 123 (7), 17-25.

Dumblekar, V. (2003). Management simulations: tests of effectiveness. In U. Dhar, S. Dhar and R. Agrawal, (Eds.) Changing trends in management: challenges and opportunities (pp. 104-113). New Delhi: Excel Books. 
Dum dum, U., Lowe, K., \& Avolio, B. (2002). A meta-analysis of transformational and transactional leadership correlates of effectiveness and satisfaction: An update and extension. In B.J. Avolio \& F.J. Yammarino (Eds.), Transformational and charismatic leadership: The road ahead (vol. 2, pp 35-66). Oxford, U.D: Elsevier Science.

Dvir, T., Eden, D, Avolio, B, \& Shamir, B. (2002). Impact of transformational leadership on follower development and performance: A field experiment. Academy of Management Journal, 45(4), 735-744.

Dvir, T. \& Shamir, B. (2003). Follower developmental characteristics as predicting transformational leadership: A longitudinal field study. Leadership Quarterly, 14, 327-344.

Dvir, T., Eden, D., Avolio, B. \& Shamir, B. (2002). Impact of transformational leadership on follower development and performance: A field experiment. Academy of Management Journal, 45, 735-744.

Eagly, A.H., Johannesen-Schmidt, M.C., \& Van Engen, M.L., (2003). Transformational, transactional, and laissez-faire leadership styles: A meta-analysis comparing men and women. Psychological Bulletin, 129, 569-591.

Eagly, A.H. \& Johnson, B.T. (1990). Gender and leadership style: A meta-analysis. Psychological Bulletin, 108, 233-256.

Eagly, A.H. \& Karu, S.S. (1991). Gender and the emergence of leaders: A meta-analysis. Personality and Social Psychology Bulletin, 15, 543-558.

Edwards, J. (1994). The study of congruence in organizational behavior research: critique and a proposed alternative. Organizational Behavior and Human Decision Processes, 58, 51-100.

Elenkov, D. (2000). Effects of leadership on organizational performance in Russian companies. Journal of Business Research, 55(6), 467-480.

Erikson, E. (1950). Childhood and Society. Norton, New York, NY.

Erikson, E. (1958). Young Man Luther. Norton, New York, NY.

Erikson, E. (1968). Identity: Youth and Crisis. Norton, New York, NY.

Faria, A. (2001). The changing nature of business simulation/gaming research: A brief history. Simulation \& Gaming, 32(1), 97-110.

Feinstein, A., \& Cannon, H. (2002). Constructs of simulation evaluation. Simulation \& Gaming, 33(4), 425-440. 
Fulmer, R. \& Conger, J. (2004). Developing leaders with 2020 vision. Financial Executive, 20(5), 38.

Gallen, T. (1997). The cognitive style and strategic decisions of managers. Management Decision, 35(7), 541-551.

Gardner, W., Avolio, B., Walumbwa, F. (2005). Preface, Authentic Leadership Theory and Practice: Origins, Effects and Development: Monographs in Leadership and Management Volume 3. Elsevier: London.

Gardner, W. \& Martinko, M. (1990). The relationship between psychological type, managerial behavior, and managerial effectiveness: An empirical study. Journal of Psychological Type, 19, 35-43.

Gardner, W. \& Martinko, M. (1996). Using the Myers-Briggs Type Indicator to study managers: A literature review and research agenda. Journal of Management, $22(1), 45-83$.

Giber, D., Carter, L. \& Goldsmith, M. (2000). Linkage Inc. 's Best Practices in Leadership Development Handbook, Jossey-Bass/Pfeiffer, San Francisco, CA.

Gilligan, C. (1982). In a different voice. Cambridge, MA: Harvard University Press.

Goleman, D. (1998). Working with Emotional Intelligence. Bantam Dell, New York.

Goleman, D. (2004). What makes a leader. Inside the Mind of the Leader, Harvard Business Review, January.

Gosen, J., \& Washbush, J. (1997). Antecedents of learning in simulations. Simulation \& Gaming, 24, 60-67.

Gosen, J., \& Washbush, J. (2004). A review of scholarship on assessing experiential learning effectiveness. Simulation \& Gaming, 35(2), 270-293.

Goosen, K., Jensen, R., \& Wells, R. (2001). Purpose and learning benefits of simulations: A design and development perspective. Simulation \& Gaming, 32, 21-39.

Gosenpud, J., \& Washbush, J. (1994). Simulation performance and learning revisited. Developments in Business Simulation \& Experiential Exercises, 21, 83-86.

Gould, R. L. (1972). The phases of adult life: A study in developmental psychology. American Journal of Psychiatry, 129, 521-531.

Hackett, G. and Betz, N.E. (1995). Self-efficacy and career choice and development, in Maddux, J.E. (Ed.). Self-efficacy, Adaptation and Adjustment: Theory, Research and Application. Plenum Press, New York, N.Y. 
Hannah, S., Avolio, B., Luthans, F. \& Harms, P. (2008). Leadership efficacy: Review and future directions. The Leadership Quarterly, 19, 669-692.

Harris, M. \& Schaubroeck, J. (1988). A meta-analysis of self-supervisor, self-peer, and peer-supervisor ratings. Personnel Psychology, 41, 43-62.

Hasegawa, B. (2003). The teacher leader role shift: A constructive-developmental study of teacher leaders' experiences of role transition and authority relationships. (Doctoral dissertation, Harvard University). Dissertation Abstracts International, AATT-3100144.

Hater, J. \& Bass, B. (1988). Superiors' evaluations and subordinates' perceptions of transformational and transactional leadership. Journal of Applied Psychology, $73(4), 695-702$.

Hautala, T. (2005) The relationship between personality and transformational leadership. Journal of Management Development, 25(8), 777-794.

Hemmasi, M., \& Graf, L. (1991). Educational effectiveness of business simulation gaming: A comparative study of student and practitioner perspectives. Developments in Business Simulation \& Experiential Exercises, 18, 53-61.

Hernez-Broome, G. \& Hughes, R. (2004). Leadership development: Past, present, and future. Human Resource Planning, 27(1), 24-32.

House, R. (1995). Leadership in the twenty-first century: A speculative inquiry. In A. Howard (Ed.), The Changing Nature of Work. Jossey-Bass, San Francisco.

Howe, N. \& Strauss, W. (1993). $13^{\text {th }}$ Generation: Abort, Retry, Ignore, Fail? New York: Vintage Books.

Howell, J. \& Avolio, B. (1993). Transformational leadership, transactional leadership, locus of control, and support for innovation: Key predictors of consolidatedbusiness-unit performance. Journal of Applied Psychology, 78(6), 891-902.

Howell, J. \& Frost, P. (1989). A laboratory study of charismatic leadership. Organizational Behavior and Human Decision Process, 43(2), 243-269.

Howell, J. \& Hall-Merenda, K. (1999). The ties that bind: The impact of leader-member exchange, transformational and transactional leadership, and distance on predicting follower performance. Journal of Applied Psychology, 84(5), 680-694.

Humphreys, J. (2002). Transformational leader behavior, proximity and successful services marketing. Journal of Services Marketing, 16(6), 487-502. 
Humphreys, J. \& Einstein, W. (2003). Nothing new under the sun: transformational leadership from a historical perspective. Management Decision, 4l(1), 85-95.

Hunsaker, P., Mudgett, W. \& Wynne, B. (1975). Assessing and developing administrators for turbulent environments. Administration and Society, 17, 312327.

Judge, T. \& Piccolo, R. (2004). Transformational and transactional leadership: A metaanalytic test of their validity. Journal of Applied Psychology, 71(5), 755-768.

Jung, C. (1921). Psychological Types, Routledge \& Kegan Paul, London.

Kegan, R. (1994). The Evolving Self. Cambridge: Harvard University Press.

Kegan, R. \& Lahey, L. (1984). Adult leadership and adult development: A constructivists view, In B. Kelleman (Ed.), Leadership: Multidisciplinary Perspectives, (pp. 200230), Englewood Cliffs, NJ: Prentice-Hall.

Kelloway, E. K. \& Barling, J. (2000) What we have learned about developing transformational leaders. Leadership \& Organization Development Journal , $21(7), 355-362$.

Kelloway, E. K., Barling, J., \& Helleur, J. (2000). Enhancing transformational leadership: The roles of training and feedback. Leadership \& Organization Development Journal, 21(3), 145-149.

Kessler, T. (1993). The relationship between transformational, transactional, and laissezfaire leadership behaviors and job satisfaction in a research environment. Dissertation, Nova University, Florida.

Keys, B., \& Wolfe, J. (1990). The role of management games and simulations in education and research. Journal of Management, 16, 307-336.

Kohlberg, L. (1984). Essays on moral development. Volume two: The philosophy of moral development: The nature and validity of moral stages. San Francisco: Harper \& Row.

Kirkbride, P. (2006). Developing transformational leaders: the full range leadership model in action. Industrial and Commercial Training, 38(1), 23-32.

Kirkpatrick, S. \& Locke, E. (1996). Direct and indirect effects of three core charismatic leadership components on performance and attitudes. Journal of Applied psychology, 81, 36-51.

Knotts, U., Jr., \& Keys, J. (1997). Teaching strategic management with a business game. Simulation \& Gaming, 28, 377-394. 
Kolb, D. \& Fry, R. (1975). Toward an applied theory of experiential learning; in C. Cooper (ed.) Theories of Group Process, London: John Wiley.

Kotter, J. (1988). The Leadership Factor. Free Press, New York, N.Y.

Kotter, J. (1990). A Force for Change. How Leadership Differs from Management, Free Press, New York, NY.

Kouzes, J. \& Posner, B. (1987). The Leadership Challenge. Jossey-Bass, San Francisco.

Krishnan, V. (2003). Power and moral leadership: role of self-other agreement. Leadership \& Organization Development Journal, 24(6), 345-351.

Kuhnert, K. \& Lewis, P. (1987). Transactional and Transformational Leadership: A constructive/developmental analysis. The Academy of Management Review, 12(4), p. 648-657.

Leonard, T., \& Leonard, N. (1995). Graduates views on the use of computer simulation games vs. cases as pedagogical tools. Developments in Business Simulation \& Experiential Exercises, 22, 83-87.

Leskiw, S. \& Singh, P. (2007). Leadership development: Learning from best practices. Leadership \& Organization Development Journal, 28(5), 444-464.

Lipmen-Blumen, J. (2000). Connective Leadership: Managing in a Changing World. Oxford: Oxford University Press.

Lewin, K. (1958). Group decision and social change. In E. Maccoby (Ed.), Readings in Social Psychology, 197-211. Holt, Rinehart \& Winston, New York, N.Y.

Lord, R. \& Hall, R. 2005. Identity, deep structure and the development of leadership skill. The Leadership Quarterly, 16, 591-615.

Lowe, K., Kroeck, K. \& Sivasubramaniam, N. (1996). Effectiveness correlates of transformational and transactional leadership: A meta-analytic review of the MLQ literature. Leadership Quarterly, 7(3), 385-425.

Lynham, S. (2000). Leadership development: A review of the theory and literature, in: P. Kuchinke (Ed.). Proceedings of the 2000 Academy of Human Resource Development Annual Meeting (Baton Rouge, LA: Academy of Human Resource Development.

Mabe, P. \& West, S. (1982). Validity of self-evaluation of ability: a review and metaanalysis. Journal of Applied Psychology, 67(3), 280-296. 
Maddux, J.E. (Ed.) (1995). Self-Efficacy, Adaptation, and Adjustment: Theory, Research, and Application. Plenum Press, New York, N.Y.

McCall, M. (1998). High Flyers: Developing the Next Generation of Leaders. Boston: Harvard Business School.

McCall, M. \& Lombardo, M. (1982). Using simulation for leadership and management research: Through the looking glass. Management Science, 28 (5), 533-549.

McCarthy, A. \& Garavan, T. (1999). Developing self-awareness in the managerial career development process: The value of 360-degree feedback and the MBTI. Journal of European Industrial Training, 23(9), 437-445.

McCauley, C.D. \& Hughes-James, M.W. (1994). An Evaluation of the Outcomes of a Leadership Development Program, The Institute, Greensboro, NC.

McCauley, C. \& Van Velsor, E. (Eds.). (2004). Handbook of Leadership Development. San Francisco, CA: Jossey-Bass.

McColl-Kennedy, J. \& Anderson, R. (2002). Impact of leadership style and emotions on subordinate performance. The Leadership Quarterly, 13, 545-559.

McDevitt, P. (1997). Measuring student learning using business simulations: A theory based perspective. Developments in Business Simulation \& Experiential Exercises, 24, 247-252.

McManus, A., \& Feinstein, A. (2006). Narratology and ludology: Competing paradigms or complementary theories in simulations. Developments in Business Simulation \& Experiential Exercises, 33, 363-372.

Megerian, L.E. and Sosik, J.J. (1996). An affair of the heart: Emotional intelligence and transformational leadership. Journal of Leadership Studies, 3, 31-48.

Middleton, K. (1980). Collegiate introduction to business: A computer-assisted simulation. Unpublished doctoral dissertation. Arizona State University.

Miller, D., Umble, K., Frederick, S., \& Dinkin, D. (2007). Linking learning methods to outcomes in public health leadership development. Leadership in Health Services, 20(2), 97-123.

Mitchell, C. (2005). The use of simulation in the development of future leaders: An approach for Canadian forces health services 2020. (Doctoral dissertation, Royal Roads University, 2005). Dissertation Abstracts International, AAT 978-0-49430663-5. 
Mitchell, R. (2004, Spring). Combining cases and computer simulations in strategic management courses. Journal of Education for Business, 79, 198-204.

Morris, J., Brotheridge, C. \& Urbanski, J. (2005). Bringing humility to leadership: Antecedents and consequences of leader humility. Human Relations, 58(10), 1323-1350.

Moshavi, D., Brown, F. W., \& Dodd, N. (2003). Leader self-awareness and its relationship to subordinate attitudes and performance. Leadership \& Organization Development Journal, 24(7), 407-418.

Murphy, S. (2004). A 360-degree feedback follow-up study: Effort to change is key. (Doctoral dissertation, University of Minnesota, 2004). Dissertation Abstracts International, AAT 3134593.

Myers, I., McCaulley, M., Quenk, N., \& Hammer, A. (1998). Manual: A Guide to the Development and Use of the Myers-Briggs Type Indicator, $3^{\text {rd }} \mathrm{ed}$., Consulting Psychologists Press, Palo Alto, CA.

Norris, D. \& Snyder, C. (1980). External validation of simulation games. Simulation \& Games, 13, 73-85.

Parente, D. (1995). A large-scale simulation for teaching business strategy. In. D. Grookal \& K. Arai (Eds.), Simulation and gaming across disciplines and cultures (pp. 75-82). Thousand Oaks, CA: Sage.

Parente, D., Brown, R., \& Warner, A. (2005). Review sessions and results: Competency testing in the capstone business class. Journal of Instructional Psychology, 32, 233-243.

Parry, K. \& Sinha, P. (2005). Researching the trainability of transformational organizational leadership. Human Resource Development International, 8(2), 165-183.

Pawar, B. (2003). Central conceptual issues in transformational leadership research. Leadership \& Organization Development Journal, 24(7), 397-406.

Payne, S., Whitfield, J.M. \& Flynn, J. (2002, Winter). Assessing the business capstone course through a method based on the SOTL and the stakeholder process. Journal of Education for Business, 69-73.

Podsakokk, P. \& Organ, D. (1986). Self-reports in organizational research: Problems and prospects. Journal of Management, 12, 531-544.

Popper, M. (2004). Main principles and practices in leader development. Leadership \& Organization Development Journal 26, (1), 62-75. 
Raia, A. (1966). A study of the educational value of management games. Journal of Business, 39, 339-352.

Riggio, R. (2008). Leadership development: The current state and future expectations. Consulting Psychology Journal: Practice and Research, 60(4), 383-392.

Rousch, P. \& Atwater, L. (1992). Using the MBTI to understand transformational leadership and self-perception accuracy. Military Psychology, 4(1), 17-34.

Romme, A. (2004). Perceptions of the value of microworld simulation: Research note. Simulation \& Gaming, 35(3), 427-436.

Rost, J. (1991). Leadership for the Twenty-First Century. Westport, CT: Greenwood Publishing Group, Inc.

Schein, E.H., \& Bennis, W. (1965). Personal and Organizational Change Via Group Methods. Wiley, New York, N.Y.

Scherpereel, C. (2003). The impact of business war games: Quantifying training effectiveness. Developments in Business Simulation \& Experiential Exercises, 30 , 69-82.

Scherpereel, C. (2005). Changing mental models: Business simulation exercises. Simulation \& Gaming. 36(5). 388-403.

Schon, D. (1983). The Reflective Practitioner How Professionals Think in Action. Basic Books, Inc. New York.

Selznick, P. (1957). Leadership in Administration: A Sociological Interpretation. California: Harper \& Row.

Senge, P. (1990). The Fifth Discipline: The Art and Practice of the Learning Organization. New York: Doubleday, 175-204.

Smith, P. (2001). Action learning and reflective practice in project environments that are related to leadership development. Management Learning, 32(1), 31-48.

Sonungro, O. (1997). Impact of training on leadership development: Lessons from a leadership-training program. Evaluation Review, 21(6), 713-737.

Spreitzer, G. \& Quinn, R. (1996). Empowering middle managers to be transformational leaders. Journal of Applied Behavioral Science, 32(3), 237-261. 
Stephen, J., Parente, D., \& Brown, R. (2002). Seeing the forest and the trees: Balancing functional and integrative knowledge using large scale simulations in capstone business classes. Journal of Management Education, 26, 164-193.

Stumpf, S. (1995). Applying new science theories in leadership development activities. Journal of Management Development, 14(5), 39-49.

Teach, R. (1993). What do we teach when we use games? In F. Percival, S. Lodge, \& D. Saunders (Eds.), The simulation and gaming yearbook 1993 (pp. 112-121). London: Kogan Page.

Teach, R., \& Govahi, G. (1988). The role of experiential learning and simulation in teaching management skills. Developments in Business Simulation \& Experiential Exercises, 15, 65-71.

Teach, R. \& Govahi, G. (1993). The role of classroom techniques in teaching management skills. Simulation \& Gaming, 24(4), 429-445.

Tejeda, M., Scandura, T., \& Pillai, R. (2001). The MLQ revisited: Psychometric properties and recommendations. The Leadership Quarterly, 12(1), 31-52.

Tekleab, A, Sims, Jr. H., Yun, S., Tesluk, P., and Cox, J. (2008). Effects of selfawareness of empowering and transformational leadership. Journal of Leadership \& Organizational Studies, 14(3), 185-201.

Tepper, B. \& Percy, P. (1994). Structural validity of the multifactor leadership questionnaire. Educational and Psychological Measurement, 54, 734-744.

Tichy, N. (1997). The Leadership Engine: How Winning Companies Build Leaders at Every Level. Harper Business, New York, NY.

Tompson, G., \& Dass, P. (2000). Improving students' self-efficacy in strategic management: The relative impact of cases and simulations. Simulation \& Gaming, $31(1), 22-41$.

Tonks, D., \& Armitage, S. (1997). A framework for understanding learning from management simulations. Journal of Computer Assisted Learning, 13, 48-58.

United States Department of Labor Statistics. Retrieved February 12, 2008 from http://www.bls.gov/cps/home.

Vaidyanathan, R., \& Rochford, L. (1998). An exploratory investigation of computer simulations, student preferences, and performance. Journal of Education for Business, 73, 144-149. 
Van Auken, S., \& Chrysler, E. (2005, Fall). The relative value of skills, knowledge, and teaching methods in explaining master of business administration program return on investment. Journal of Education for Business, 41-45.

VanDevender, J. \& Barker, J. (1999). Leadership and decision processing in twenty-first century technical organizations, in Hunt, J. \& Dodge, G. (Eds), Out-of-the-Box Leadership: Transforming the Twenty-First-Century Army and Other Top Performing Organizations: Monographs in Leadership and Management, 1, Elsevier Science/JAI Press, Amsterdam, 91-107.

Vicere, A. \& Fulmer, R. (1998). Leadership By Design, Harvard Business School Press, Boston, MA.

Waldman, D. Bass, B. \& Yammarino, F. (1990). Adding to contingent reward behavior: The augmenting effect of charismatic leadership. Group and Organizational Studies, 15, 381-394.

Waldman, D., \& Korbar, T. (2004). Student assessment center performance in the prediction of early career success. Academy of Management Learning \& Education, 3(2), 151-167.

Walinga, J. (2008). Toward a theory of change readiness: The roles of appraisal, focus, and perceived control. The Journal of Applied Behavioral Science, 44, 315-347.

Walters, B., \& Coalter, T. (1997). Simulation games in business policy courses: Is there....Journal of Education for Business, 72, 170-176.

Washbush, J. \& Gosen, J. (2001). Learning in total enterprise simulations. Simulation \& Gaming, 32, 281-296.

Wheatley, M. (1999). Leadership and the New Science. San Francisco, Berret-Koehler.

Weiss, D. \& Molinaro, V. (2006). Integrated leadership development. Industrial and Commercial Training, 38(1), 3-11.

Wheatley, W., Roberts, R., \& Einbecker, R. (1990). A complex simulation and community involvement yield an award-winning capstone experience. Simulation \& Gaming, 21(2), 181-189.

Wilber, K. (2000). A Theory of Everything. Shambala Publications, Boston, Mass.

Wilson, R. (2006). The effects of one leadership training program on behavioral and skill change in community college division chairs and other organizational leaders. Dissertation Abstracts International.UMI 3216359. 
Wolfe, J. (1997). The effectiveness of business games in strategic management course work. Simulation \& Gaming, 28(4), 360-376.

Wolfe, J., \& Roberts, C. (1986). The external validity of a business management game: A five-year longitudinal study. Simulation \& Gaming, 17, 45-59.

Wolfe, J., \& Roberts, C. (1993). A further study of the external validity of business games: Five year peer group indicators. Simulation \& Gaming, 24(1), 21-33.

Wolfe, J., \& Roge, J. (1997). Computerized general management games as strategic management learning environments. Simulation \& Gaming, 28, 423-441.

Wolfe, J., \& Crookall, D. (1998). Developing a scientific knowledge of simulation gaming. Simulation \& Gaming, 29, 7-19.

Wolfe, J., \& Luethge, D. (2003, Winter). The impact of involvement on performance in business simulations: An examination of Goosen's "Know Little" decision making thesis. Journal of Education for Business, 69-74.

Yammarino, R. \& Atwater, L. (1997). Do managers see themselves as others see them? Implications of self-other rating agreement for human resources management. Organizational Dynamics, 25(4), 35-44.

Young, D.P. \& Dixon, N.M. (1996). Helping Leaders Take Effective Action: A Program Evaluation, Greensboro, NC.

Yukl, G. (1999). An evaluation of conceptual weaknesses in transformational and charismatic leadership theories. Leadership Quarterly, 10, 285-305.

Zaccaro, S. \& Klimoski, R. (2001). The nature of organizational leadership: An introduction. In S.J. Zaccaro, \& R. J. Klimoski (Eds), The Nature of Organizational Leadership: Understanding the Performance Imperatives Confronting Today's Leaders, Jossey-Bass, San Francisco, CA. (3-41).

Zantow, K., Knowlton, D., \& Sharp, D. (2005). More than fun and games: Reconsidering the virtues of strategic management simulations. Academy of Management Learning \& Education, 4, 451-458.

Zohar, D. (2002). The effects of leadership dimensions, safety climate, and assigned priorities on minor injuries in work groups. Journal of Organizational Behavior, $23,75-92$.

Zullo, J. (1997). Leadership and Adult Development: Postindustrial paradigms and parallels. The Journal of Leadership Studies, 4(4), p. 118-127. 
Appendix A

Multi-factor Leadership Questionnaire Form 5x 
For use by robin mccoy only. Received from Mind Garden. Inc. on April 3, 2008

\section{Multifactor Leadership Questionnaire Rater Form}

Name of Leader:

Date:

Organization ID \#:

Leader ID \#:

This questionnaire is used to describe the leadership style of the above-mentioned individual as you perceive it. Answer all items on this answer sheet. If an item is irrelevant, or if you are unsure or do not know the answer, leave the answer blank. Please answer this questionnaire anonymously.

Important (necessary for processing): Which best describes you?

I am at a higher organizational level than the person I am rating.

The person 1 am rating is at my organizational level.

I am at a lower organizational level than the person I am rating.

Other than the above.

Forty-five descriptive statements are listed on the following pages. Judge how frequently each statement fits the person you are describing. Use the following rating scale:

\begin{tabular}{|ccccc|}
\hline Not at all & $\begin{array}{c}\text { Once in a } \\
\text { while } \\
0\end{array}$ & Sometimes & Fairly often & $\begin{array}{c}\text { Frequently, } \\
\text { if not always } \\
4\end{array}$ \\
\hline
\end{tabular}

The Person I Am Rating. . .

l. Provides me with assistance in exchange for my efforts

2. Re-examines critical assumptions to question whether they are appropnate.

3. Fails to interfere until problems become serious

4. Focuses attention on irregularities, mistakes, exceptions, and deviations from starresards..

\$. Avoids getting involved when important issues arise.

6. Talks about his her most important values and beliefs

7 . Is absent when needed

8. Seeks differing perspectives when solving problems

9. Talks optimistically about the future....

10. Instills pride in me for bentg assodciateg with $\mathrm{h} m$ her.

11. Discusses in specific terms who is respohsible for achieving performance targets
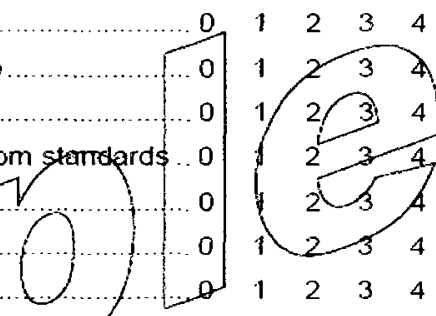

12. Waits for things torge befong befo takingaetion

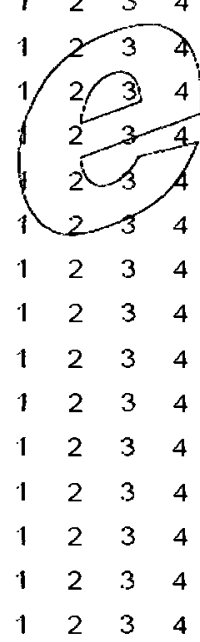

13. Talks enthusiastican abbut yhat needs to be accomplished

Continued $\rightarrow$ 
For use by robin mccoy only. Received from Mind Garden. Inc. on April 3, 2008

\begin{tabular}{|ccccc|}
\hline Not at all & Once in a while & Sometimes & Fairly often & $\begin{array}{c}\text { Frequently, } \\
\text { If not always } \\
0\end{array}$ \\
\hline
\end{tabular}

16. I make clear what one can expect to receive when performance goals are achieved ......... $0 \begin{array}{lllll}0 & 2 & 3 & 4\end{array}$

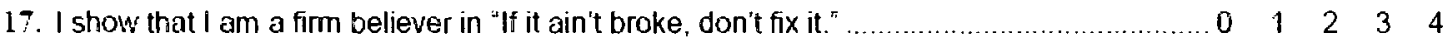

18. I go beyond self-interest for the good of the group .................................................. $0 \begin{array}{llllll}1 & 2 & 3 & 4\end{array}$

19. I treat others as individuals rather than just as a member of a group .............................. $0 \begin{array}{llllll}0 & 2 & 3 & 4\end{array}$

20. I demonstrate that problems must become chronic before I take action ......................... $0 \begin{array}{lllll}1 & 2 & 3 & 4\end{array}$

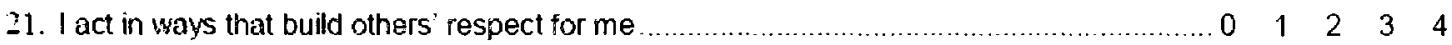

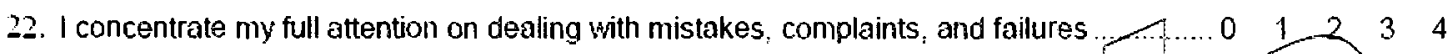

23. I consider the moral and ethical consequences of decisions

24. I keep track of all mistakes

25. I display a sense of power and confidence

26. I articulate a compelling vision of the future.

27. 1 direct my attention toward failures to meet standards

28. I avoid making decisions.

29. I consider an individual as havipg diffeyen needs, abilities, and aspirations from others.... $0 \begin{array}{llllll} & 1 & 2 & 3 & 4\end{array}$

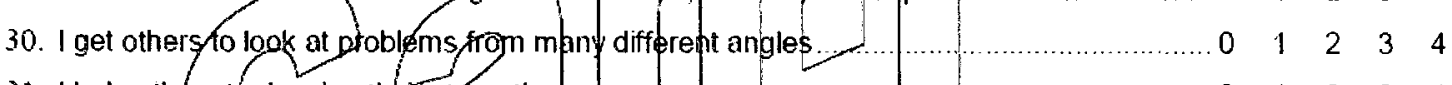

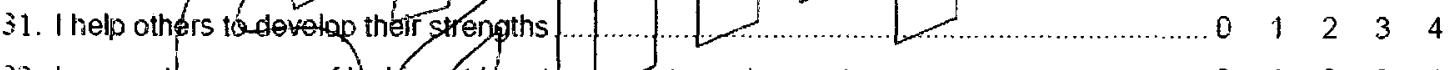

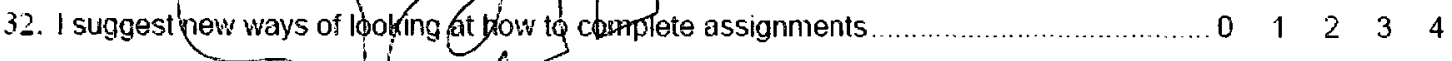

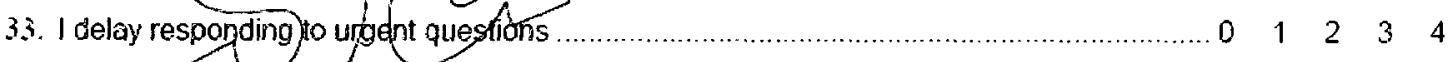

34. I emphasize the impgrtance of having a collective sense of mission ............................ $0 \begin{array}{llllll}2 & 1 & 3 & 4\end{array}$

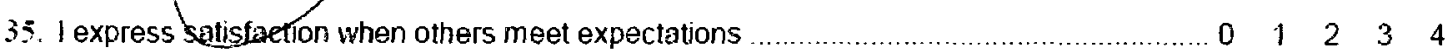

36. I express confidence that goals will be achieved …….............................................. 0

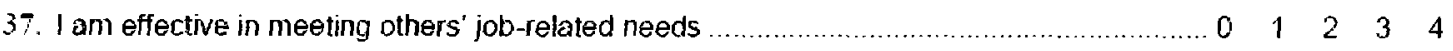

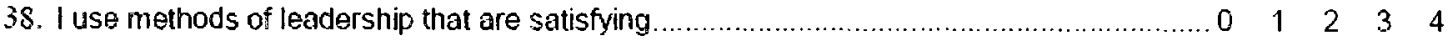

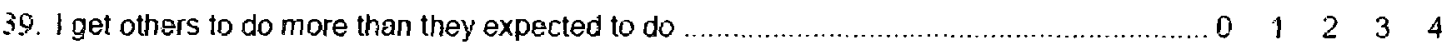

40. I am effective in representing others to higher authority ............................................ $0 \begin{array}{llllll}2 & 2 & 3 & 4\end{array}$

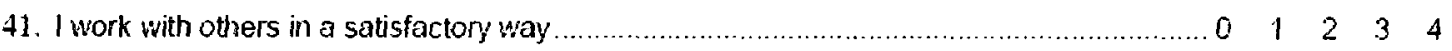

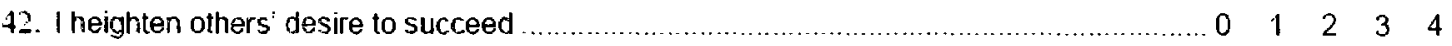

43. I am effective in meeting organizational requirements ............................................. $0 \begin{array}{llllll}2 & 2 & 3 & 4\end{array}$

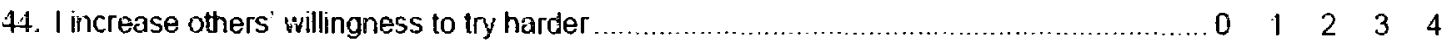

45. llead a group that is effective ................................................................................. 0

Copyright $\$ 1995$ by Bernard Bass and Bruce Avolio. All rights reserved.

It is your legal responsibility to compensate the copyright holder of this work for any reproduction in any medium. If you need to reproduce the MLQ, please contact Mind Garden www.mindgorden.com. Mind Garden is a registered trademark of Mind Gorden, Inc. 
For use by robin mccoy only. Received from Mind Garden, Inc. on April 3, 2008

\begin{tabular}{|ccccc|}
\hline Not at all & $\begin{array}{c}\text { Once in a } \\
\text { while }\end{array}$ & Sometimes & Fairly often & $\begin{array}{c}\text { Frequently, } \\
\text { if not always } \\
0\end{array}$ \\
1 & 2 & 3 & 4 \\
\hline
\end{tabular}

16. Makes clear what one can expect to receive when performance goals are achieved ......... $0 \quad 1 \quad 1 \quad 2 \quad 34$

17. Shows that heishe is a firm believer in "If it ain't broke, don't fix it." ............................ 0 1 2434

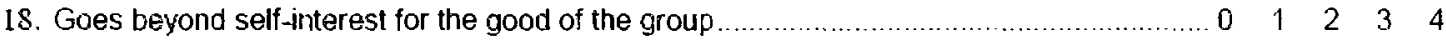

19. Treats $m e$ as an individual rather than just as a member of a group .......................... 0 1 2434

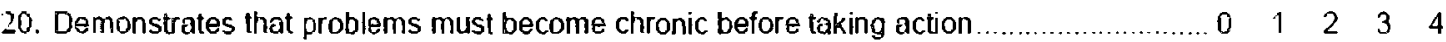

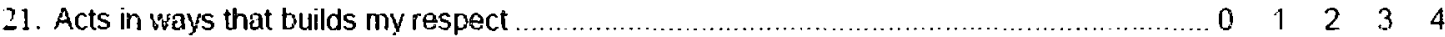

22. Concentrates his her full attention on dealing with mistakes, complaints, and failures ....... $0 \begin{array}{llllll}0 & 1 & 3 & 4\end{array}$

23. Considers the moral and ethical consequences of decisions

24. Keeps track of all mistakes

25. Displays a sense of power and confidence

26. Articulates a compelling vision of the future

27. Directs my attention toward failures to meet standards

2S. Avoids making decisions

29. Considers me as having different needs, abilities and aspirations from othets

30. Gets me to look at problems from many fifferent angres...

31. Helps me to develop my strengths.

32. Suggests new ways of looking at now to complete assidnments

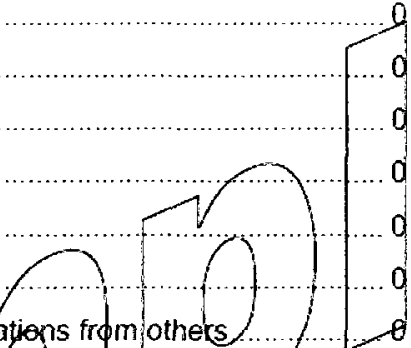

$\begin{array}{llll}1 & 2 & 3 & 4\end{array}$

33. Delays responding to urgent questiops.).

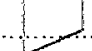

34. Emphasizes the importance of having akettective sense of mission .

35. Expresses satisfaction Aned I meet expectations

$12 \frac{3}{3}$

36. Expresses confidence that goals will be achieved

Is effective in meeting my job-related needs

3S. Uses methods of leadership that are satisfying

$\begin{array}{llll}1 & 2 & 3 & 4\end{array}$

39. Gets me to do more than I expected to do

40. Is effective in representing me to higher authority

41. Works with me in a satisfactory way

42. Heightens my desire to succeed

43. Is effective in meeting organizational requirements...

44. Increases my willingness to try harder

45. Leads a group that is effective

\section{Copyright 1995 by Bernard Bass and Bruce Avolio. All rights reserved.}

It is your legal responsibility to compensate the copyright holder of this work for any reproduction in any medium. If you need to reproduce the MLO, please contact Mind Garden wWw.mindgerden.com. Mind Garden is a registered trademark of Mind Garden, Inc. 
Appendix B

Invitation to Participate in a Research Study 


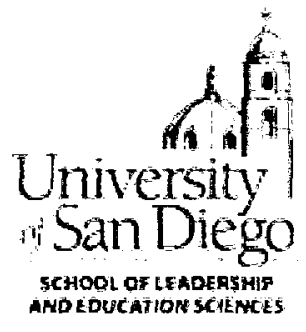

Dear

Robin McCoy is a doctoral student in Leadership Studies at the School of Leadership and Education Sciences at the University of San Diego. You are invited to voluntarily participate in a doctoral dissertation study she is conducting that explores the impact of the leader development program you will be participating in at the The Institute.

Participation entails completing an online survey two times over the course of seven months. The time required to complete the questionnaire is approximately 15 minutes and will be done using SurveyMonkey.com. A special encryption has been added to this survey to provide further security and ensure confidentiality of responses. The identity of those who choose to participate will be kept completely confidential and you will be provided with a unique identifier code. This code will only be known by you and the researcher. You will be provided with the results of the study.

If you are willing to participate in this study, please click on the following link: [link to survey will be provided here]. If you have any questions about this research or would like copies of the results of the study, please contact Robin McCoy at 619-2607774 or via email at rmccoy@sandiego.edu or Dr. Fred Galloway at 619-260-7435 or via email at Galloway@sandiego.edu at the University of San Diego. 
Appendix C

Learning Outcomes and MLQ Leadership Dimensions 


\begin{tabular}{|c|c|}
\hline $\begin{array}{l}\text { To gain self-awareness and obtain an } \\
\text { accurate picture of the manager's strengths } \\
\text { and weaknesses }\end{array}$ & $\begin{array}{l}\text { Idealized Behaviors (IB) - Items } 6,14,23,34 \\
\text { - Talk about my most important values and beliefs } \\
\text { - } \text { ppecify the importance of having a strong sense of } \\
\text { - Consider the moral and ethical consequences of decisions } \\
\text { - Emphasize the importance of having a collect sense of } \\
\text { mission } \\
\text { Management by Exception Passive (MBEP) - Items } 3,12,17,20 \\
\text { - Fails to interfere until problems become serious } \\
\text { - Waits for things to go wrong before taking action } \\
\text { - Show that he/she is a firm believer in "If it ain't broke, } \\
\text { don't fix it" } \\
\text { Laissez-faire (LF) - Items } 5,7,28,33 \\
\text { - } \text { Avoids getting involved when important issues arise } \\
\text { - Is absent when needed } \\
\text { - Avoids making decisions } \\
\text { - Delays responding to urgent questions } \\
\text { Management by Exception Active (MBEA) - Items } 4,22,24,27 \\
\text { - Focus attention on irregularities, mistakes, exceptions, } \\
\text { - } \text { and deviations from standards } \\
\text { - Concentrate my full attention on dealing with mistakes, } \\
\text { - Keep track of mistakes } \\
\text { - Direct my attention toward failures to meet standards }\end{array}$ \\
\hline $\begin{array}{l}\text { To learn how to give and receive } \\
\text { developmental feedback }\end{array}$ & $\begin{array}{l}\text { Individualized Consideration (IC) - Items } 15,19,29,31 \\
\text { - Spend time teaching and coaching } \\
\text { - Treat others as individuals rather than just as a member of } \\
\text { the group } \\
\text { - Consider each individual as having different needs, } \\
\text { abilities and aspirations from others } \\
\text { - Help others to develop their strengths } \\
\text { Satisfaction - Items } 38,41 \\
\text { - Use methods of leadership that are satisfying } \\
\text { - Work with others in a satisfactory way }\end{array}$ \\
\hline $\begin{array}{l}\text { To know how to influence across } \\
\text { boundaries and navigate complex leadership } \\
\text { issues }\end{array}$ & $\begin{array}{l}\text { Effectiveness - Items } 37,40,43,45 \\
\text { - Is effective in meeting my job-related needs } \\
\text { - Is effective in representing others to higher authority } \\
\text { - Is effective in meeting organizational requirements } \\
\text { - Leads a group that is effective } \\
\text { Idealized Influence Attributed - Items } 10,18,21,25 \\
\text { - Instills pride in others for being associated with me } \\
\text { - Goes beyond self-interest for the good of the group } \\
\text { - Acts in ways that build others' respect for me } \\
\text { - Displays a sense of power and confidence }\end{array}$ \\
\hline $\begin{array}{l}\text { To understand the impact they have on an } \\
\text { organization }\end{array}$ & $\begin{array}{l}\text { Intellectual Stimulation (IS) - Items } 2,8,30,32 \\
\text { - Re-examine critical assumptions to question whether they } \\
\text { are appropriate }\end{array}$ \\
\hline
\end{tabular}




\begin{tabular}{|c|c|}
\hline & $\begin{array}{l}\text { - } \quad \text { Seek differing perspectives when solving problems } \\
\text { angles } \\
\text { - Suggest new ways of looking at how to complete } \\
\text { assignments }\end{array}$ \\
\hline $\begin{array}{l}\text { To set strategy and direction for those they } \\
\text { lead understanding the balance between } \\
\text { tactical and strategic possibilities }\end{array}$ & $\begin{array}{l}\text { Inspirational Motivation (IM) - Items } 9,13,26,36 \\
\text { - Talk optimistically about the future } \\
\text { - Talk enthusiastically about what needs to be } \\
\text { accomplished } \\
\text { - Articulate a compelling vision of the future } \\
\text { - Express confidence that goals will be achieved }\end{array}$ \\
\hline $\begin{array}{l}\text { To communicate effectively and manage } \\
\text { personality differences more effectively }\end{array}$ & $\begin{array}{l}\text { Contingent Reward (CR) - Items } 1,11,16,35 \\
\text { - Provide others with assistance in exchange for their } \\
\text { efforts } \\
\text { - Discuss in specific terms who is responsible for achieving } \\
\text { performance targets } \\
\text { - Make clear what one can expect to receive when } \\
\text { - } \text { exformance goals are achieved } \\
\text { - Express satisfaction when others meet expectations }\end{array}$ \\
\hline
\end{tabular}




\section{Appendix D}

Permission to Use MLQ by MindGarden 
Dear Robin McCoy,

Thank you for your research with Multifactor Leadership Questionnaire. Mind Garden, Inc. has now registered your statement of your using this instrument in an electronic medium. Meeting these conditions provides you with our permission to move forward on your project.

Sincerely yours, Mind Garden, Inc.

www.mindgarden.com

***** Your statement to Mind Garden, Inc. was the following:

Name: Robin McCoy

Email address: robin.l.mccoy@gmail.com

Phone number: 858-775-6967

Company/Institution: University of San Diego

Order/Invoice number: 5410

Order Date: 7/29/08

Project Title: The Impact of a Leader Development Simulation on Transformational Leadership Behavior

Instrument Name: Multifactor Leadership Questionnaire

I will compensate Mind Garden, Inc. for every use of this web form.

I will put the instrument copyright on every page containing question items from this instrument.

I will remove this form from the Web at the conclusion of my data collection.

I will limit access to this web form and require a login or uniquely coded url. Once the login/code is used that evaluation will be closed to use.

The form will not be available to the open Web.

Method for Restricting Access:

I will be using an encrypted version of Survey Monkey

Electronically signed on 9/18/08 by Robin McCoy.

Reply Forward 
Appendix E

Normative Database for the MLQ 


\begin{tabular}{|l|l|l|}
\hline Countries & Number of Raters & Number of Leaders \\
\hline United States & 27,285 & 4,600 \\
\hline Europe & 8,025 & 1,070 \\
\hline Australia \& New Zealand & 13,350 & 1,306 \\
\hline South Africa & 7,324 & 1,018 \\
\hline Total & $\mathbf{5 5 , 9 8 4}$ & $\mathbf{7 , 9 9 4}$ \\
\hline
\end{tabular}


Appendix F

Leader Pre-Assessment Instrument 
You are invited to participate in a dissertation research study. The purpose of this study is to understand the impact of a leadership development simulation on transformational leadership behavior. Your participation will provide valuable information upon which administrators can improve and tailor future leadership training. Additionally, you will receive feed back that can provide results on whether you changed as a result of participating in this training. You are being asked to participate in this study because you will be completing the Center for Creative Leadership's Looking Glass Experience and wanting to improve your leadership abilities.

Your participation in this study is voluntary and you may refuse to participate in this study or in any part of this study at any time without prejudice to your relations with the University of San Diego or the Center for Creative Leadership. You are encouraged to ask questions about this study at the beginning or any time during the research study.

If you volunteer to participate in this study, you will be asked to fill out the Multi-factor Leadership Questionnaire assessment two times. Once before you start the program and one month after the program has been completed. The questionnaire consists of 2 open-ended questions and 45 Likert scaled questions which will take approximately 5 to 7 minutes to complete each time, for a total time investment of a little more than 15 minutes.

In addition, you will be asked to provide the names and email addresses of at least three subordinates who report to you. These subordinates will be asked to complete the questionnaire during the two phases as well. The results of your assessment both before and after the program will be shared with you, the researcher, and those directly related to the research. The results of your subordinates will be confidential and you will receive, in aggregate form, how they perceive your change in behavior.

One aspect of the research will be to explore if there are any relationships between changes in leadership behavior and certain demographic variables such as age, gender, and years in current position. Additionally, you will be given a personality test from the Center for Creative Leadership to assess your Myers-Briggs Type Indicator (MBTI). Since this ultimately may help explain changes in leadership behavior, after the Center has provided you with your MBTI, you will be asked (in an email) to provide this information to the researcher.

In addition to completing the questionnaire, you may be asked to participate in a 15 minute personal interview between you and the researcher six months after completing the leadership development program. All information gathered in this study will be kept completely confidential. No reference will be made in written or oral material that could link you to the study. All records will be stored in a locked facility for at least three years after completion of this study. After the storage time has elapsed, the information will be shredded.

There may or may not be direct benefits to you as a participant of this study. However, we hope to learn the impact of this leadership development program on a manager's transformational leadership abilities. There will not be any financial cost to you to participate in this study. If you have any questions or concerns about this study, you may contact Robin McCoy at 858-775-6967 or Dr. Fred Galloway at 619-260-7435.

Sincerely,

Robin McCoy

Researcher, PhD Candidate

Visiting Professor, University of San Diego

5998 Alcala Park, San Diego, CA 92

\section{Do you consent to participate in this Dissertation Research Study?}

Yes

No 


\section{McCoy Dissertation (Leader)}

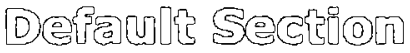

This questionnaire is to describe your leadership style as you perceive it. Please answer all items on this survey. If an item is irrelevant, or if you are unsure or do not know the answer, leave the answer blank.

3. Date of first day that you will attend the Looking Glass Experience with CCL:

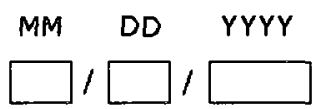

* 4. Please enter a Leader ID \# It should be the initials of your name \& month and day that you were born, e.g. My initials are RLM and I was born on July 19 - RLMO719

\section{Position Title}

6. How long have you been working within your current position title?

O $<6$ months

O 6-12 months

O 13-24 months

O) 25-36 months

O $>3$ years 


\section{McCoy Dissertation (Leader)}

7. As you enter into this leadership development experience, how open are you to changing your leadership behavior? 8. In just a few words, why did you choose to participate in The Leader Development Simulation? * 


\section{McCoy Dissertation (Leader)}

MLQ, Copyright 1995, 2000, 2004 by Bernard Bass and Bruce Avolio. All rights reserved. Published by Mind Garden, Inc. www. mindgarden.com

\section{The following questions are in a three part series of $\mathbf{4 5}$ total descriptive statements. In your opinion choose how frequently each statement fits you. The word "others" may mean your peers, clients, direct reports, supervisors, and/or all of these individuals.}

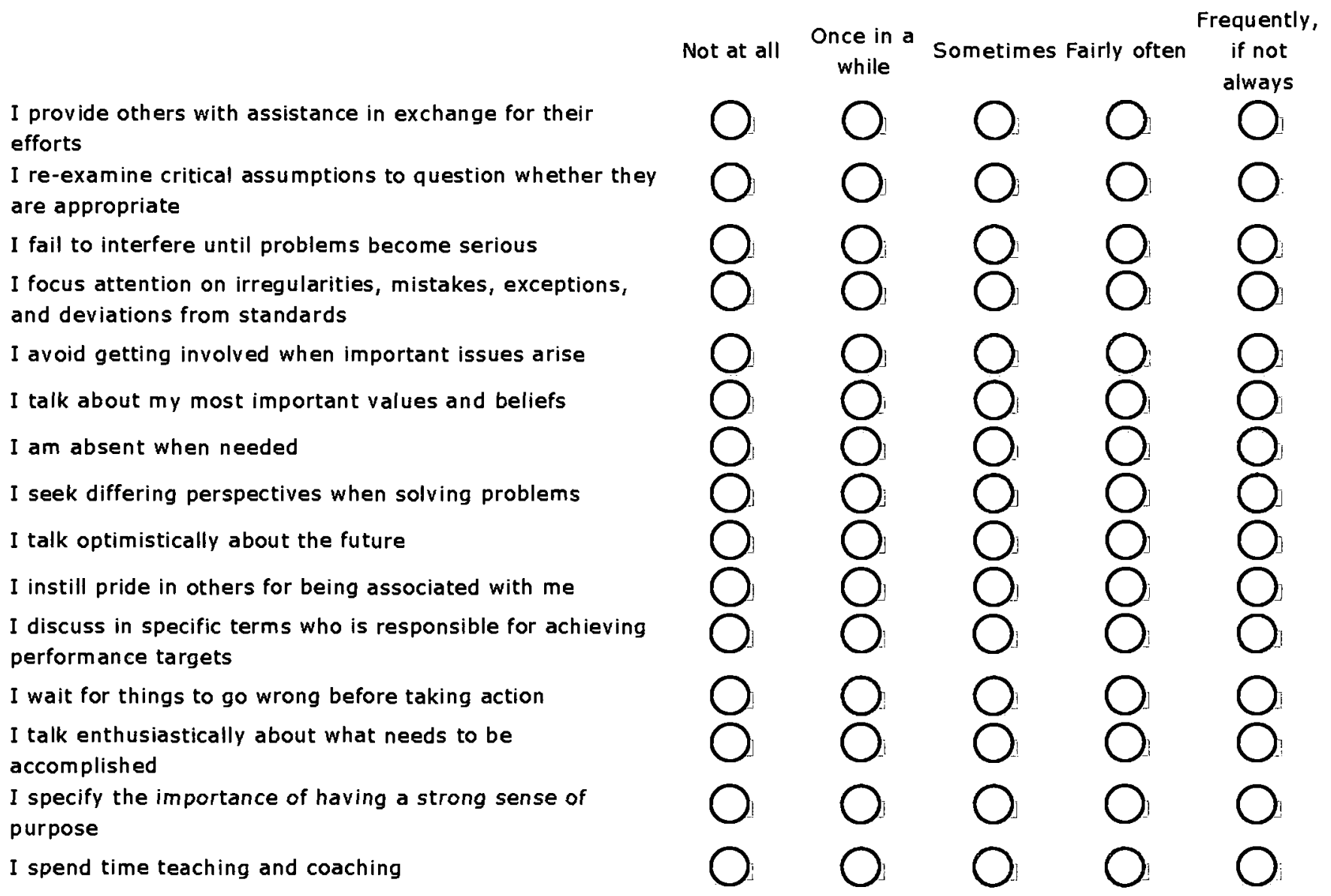


MLQ, Copyright 1995, 2000, 2004 by Bernard Bass and Bruce Avolio. All rights reserved. Published by Mind Garden, Inc. www. mindgarden.com

\section{This is the second series of 15 descriptive statements}

performance goals are achieved.

I show that I am a firm believer in "If it ain't broke, don't fix it."

I go beyond self-interest for the good of the group

I treat others as individuals rather than just as a member of a group

I demonstrate that problems must become chronic before I take action

I act in ways that build others' respect for me

I concentrate my full attention on dealing with mistakes, complaints, and failures

I consider the moral and ethical consequences of decisions

i keep track of all mistakes

I display a sense of power and confidence

I articulate a compelling vision of the future

I direct $\mathrm{my}$ attention toward failures to meet standards

I avoid making decisions

I consider an individual as having different needs, abilities, and aspirations from others

I get others to look at problems from many different angles

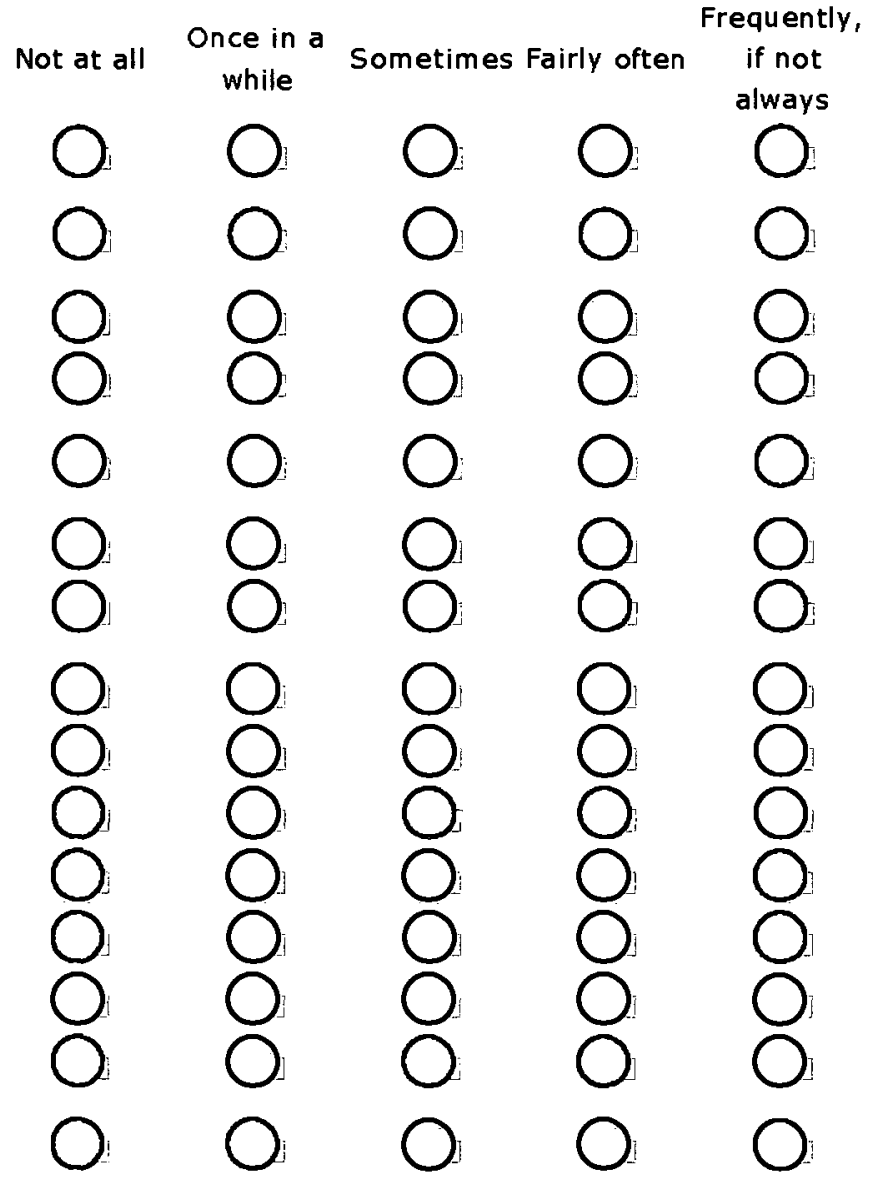




\section{McCoy Dissertation (Leader)}

MLQ, Copyright 1995, 2000, 2004 by Bernard Bass and Bruce Avolio. All rights reserved. Published by Mind Garden, Inc. www.mindgarden.com

\section{These are the last series of $\mathbf{1 5}$ descriptive statements.}

\section{I help others to develop their strengths}

I suggest new ways of looking at how to complete assignments

I delay responding to urgent questions

I emphasize the importance of having a collective sense of mission

I express satisfaction when others meet expectations

I express confidence that goals will be achieved

I am effective in meeting others job-related needs

I use methods of leadership that are satisfying

I get others to do more than they expected to do

I am effective in representing others to higher authority

I work with others in a satisfactory way

I heighten others' desire to succeed

I am effective in meeting organizational requirements

I increase others' willingness to try harder

I lead a group that is effective
Not at all
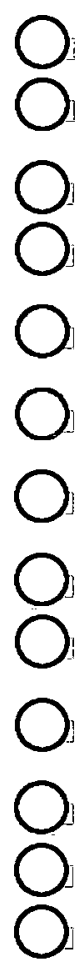

Once in a while

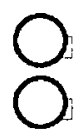
Sometimes
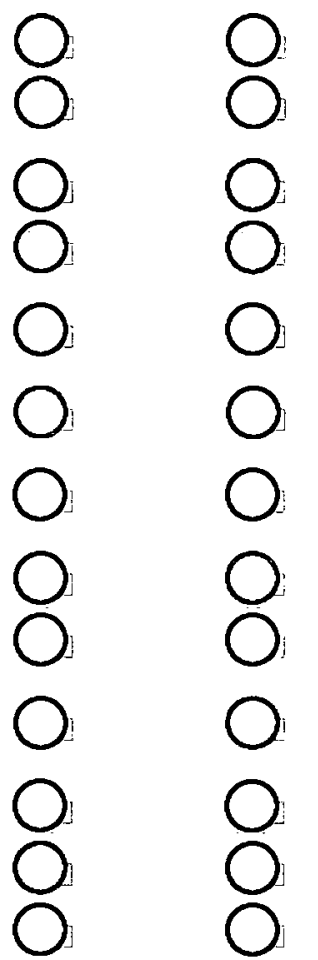

0
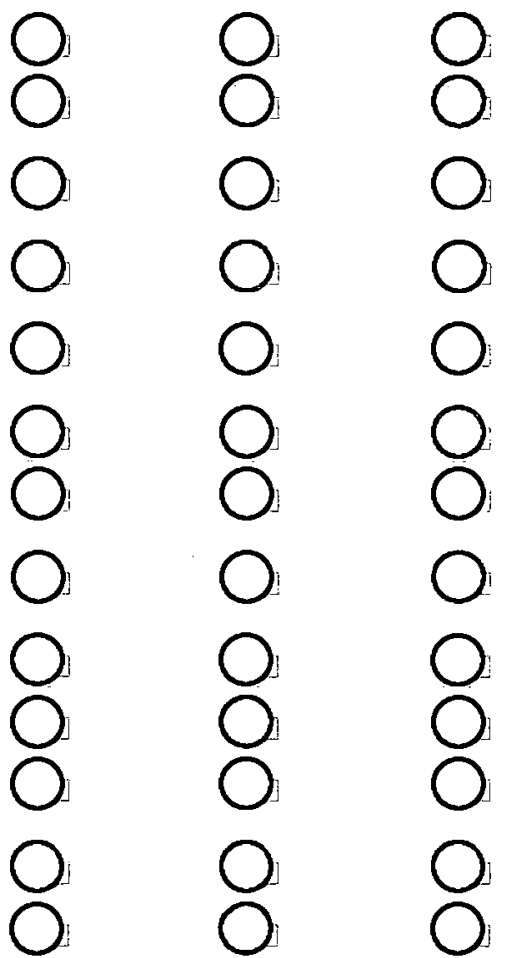

0
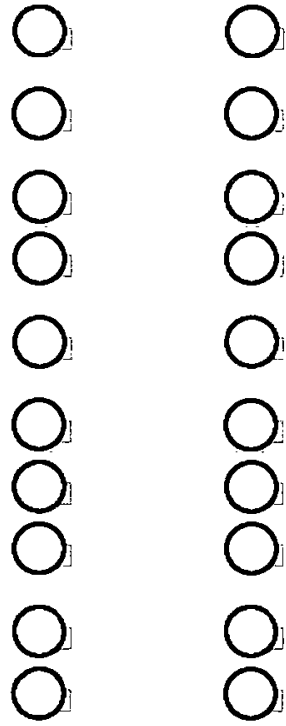

Fairly often

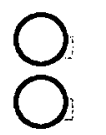

Frequently, if not always
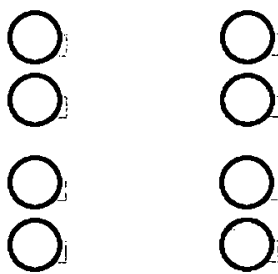

0

0

0
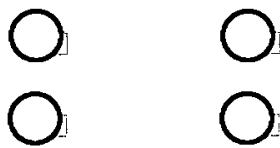

0
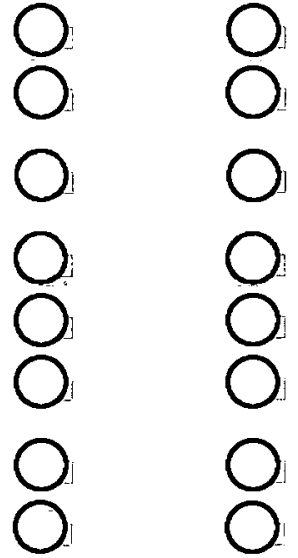
The following questions are for demographic purposes only. All answers will be confidential,

\section{Gender}

Male

OFemale

\section{Age}

C20-30

O $31-40$

O 41-50

C $51-60$

O $61+$

\section{List your highest level of educational attainment}

O Some High School

OHigh School Graduate

Some college

O 2 year College Degree

O 4 year College Degree

Masters Degree

Ooctorate Degree 


\section{McCoy Dissertation (Leader)}

\section{Type of Industry where you work?}

Oeducation

Oinance

O Government

ONon-profit

Oi Health

OHuman Services

Manufacturing

Oilitary

OTransportation

Wholesale

Other (please specify)

\section{Number of years of supervisory experience?}

$\bigcirc<1$ year

O $1-3$ years

( 4-6 years

O $7-9$ years

O 10 or more years 
Appendix G

Rater Pre-Assessment Instrument 


\section{McCoy Dissertation (Rater Form)}

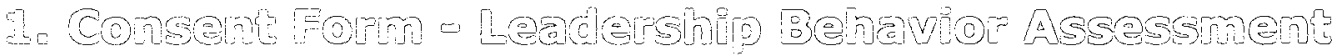

You are invited to participate in a dissertation research study. The purpose of this study is to understand the impact of a leadership development simulation on transformational leadership behavior. You are being asked to participate in this study because you directly report to a manager who is participating in a leadership development program and you directly observe their leadership behavior.

Your participation in this study is completely confidential and voluntary.

The information that you provide will only be shared with the researcher and her committee. Your direct report will only be provided with data from their raters that informs them if they changed behavior or not. Your manager will not have any knowledge of any individual responses. You may refuse to participate in this study or in any part of this study at any time without prejudice to your relations with the University of San Diego or the Center for Creative Leadership. You are encouraged to ask questions about this study at the beginning or any time during the research study.

If you volunteer to participate in this study, you will be asked to fill out a 45 item Multi-factor Leadership Questionnaire assessment two times. The questionnaire will take approximately 5 to 7 minutes to complete each time, for a total time investment of a little more than 14 minutes. The results of your feedback will be confidential and only shared with the researcher of this study and those directly related to the research.

All information gathered in this study will be kept completely confidential. No reference will be made in written or oral material that could link you to the study. All records will be stored in a locked facility for at least three years after completion of this study. After the storage time has elapsed, the information will be shredded.

There may or may not be direct benefits to you as a participant of this study. However, we hope to learn the impact of this leadership development program on a manager's transformational leadership abilities. There will not be any financial cost to you to participate in this study. If you have any questions or concerns about this study, you may contact Robin McCoy at 858-775-6967 or Dr. Fred Galloway at 619-260-7435.

Sincerely,

Robin McCoy

Researcher, PhD Candidate

Visiting Professor

University of San Diego

5998 Alcala Park

San Diego, CA 92110

858-775-6967

\section{* 1. Do you consent to participate in this dissertation research study?}

$$
\begin{aligned}
& O \text { yes } \\
& \text { Ono }
\end{aligned}
$$

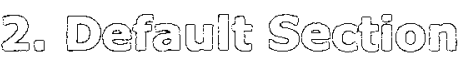

This Questionnaire is used to describe the leadership style of the person you report to as you perceive 


\section{McCoy Dissertation (Rater Form)}

it. Answer all items on this survey. If an item is irrelevant, or if you are unsure or do not know the answer, leave the answer blank.

2. Date

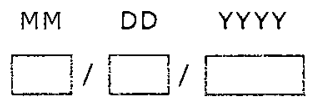

* 3. Please enter your email address

* 4. Name of the person you are rating?

5. Number of months you have been reporting to the person you are rating for this study.
$0<6$ months
6-12 months
O13-24 months
25-36 months
O 3 years

6. My usual interaction with the person that $I$ am rating is:
Multiple times in a day
Daily
A few times a week
$\bigcirc$ weekly
Bi-Monthly
Monthly
Hardly at all
Other (please specify) 
7. How long have you been working for your current organization?

< 1 year
$1-3$ years
$4-6$ years
$7-9$ years
10 or more years

3.

MLQ, Copyright 1995, 2000, 2004 by Bernard Bass and Bruce Avolio. All rights reserved. Published by Mind Garden, Inc. www. mindgarden.com

\section{The following questions are in a three part series of $\mathbf{4 5}$ total descriptive statements. In your opinion, choose how frequently each statement fits the person you are describing.}

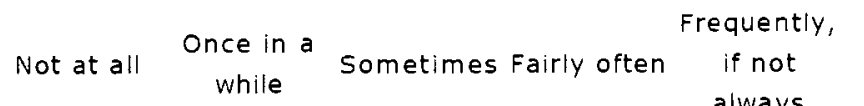

Provides me with assistance in exchange for my efforts

Re-examines critical assumptions to question whether they are appropriate.
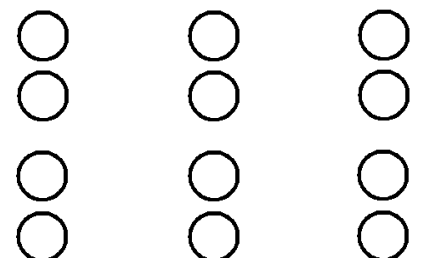

always

Fails to interfere until problems become serious

Focuses attention on irregularities, mistakes, exceptions, and deviations from standards
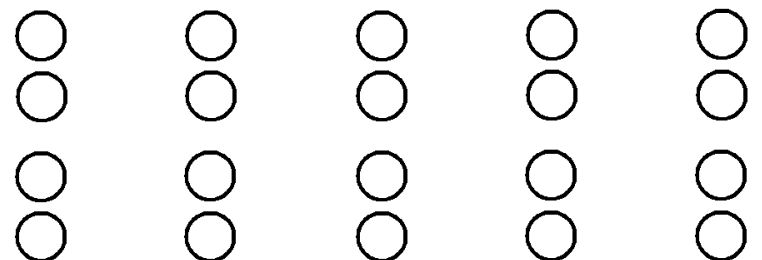

Avoids getting involved when important issues arise

Talks about his/her most important values and beliefs

Is absent when needed

Seeks differing perspectives when solving problems

Talks optimistically about the future

Instills pride in me for being associated with him/her

Discusses in specific terms who is responsible for achieving performance targets

Waits for things to go wrong before taking action

Talks enthusiastically about what needs to be

accomplished
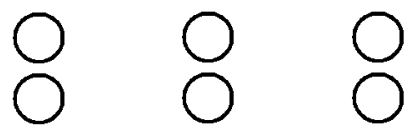

Specifies the importance of having a strong purpose

spends time teaching and coaching
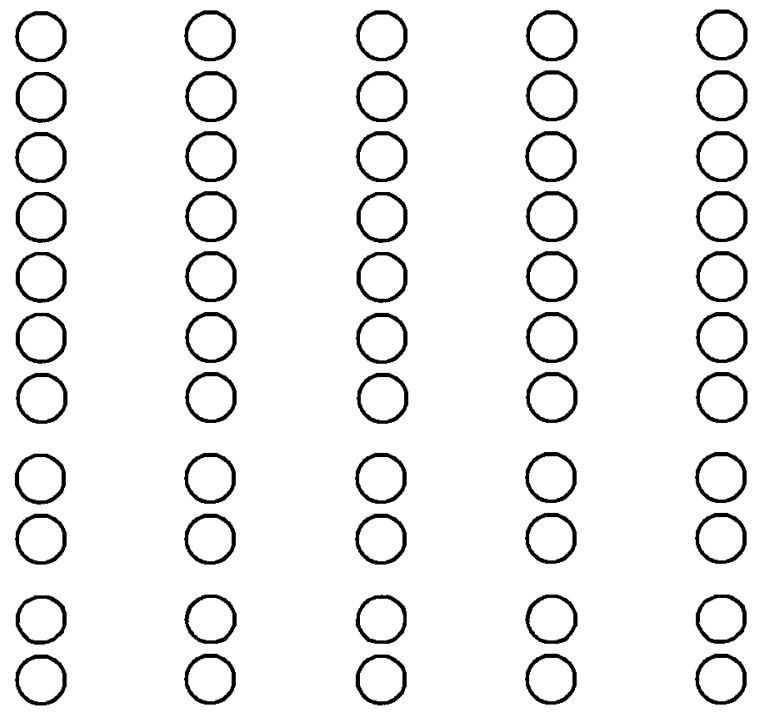

\section{4.}

MLQ, Copyright 1995, 2000, 2004 by Bernard Bass and Bruce Avolio. All rights reserved. Published by Mind Garden, Inc. www. mindgarden.com 


\section{McCoy Dissertation (Rater Form)}

\section{This is the second series of statements}

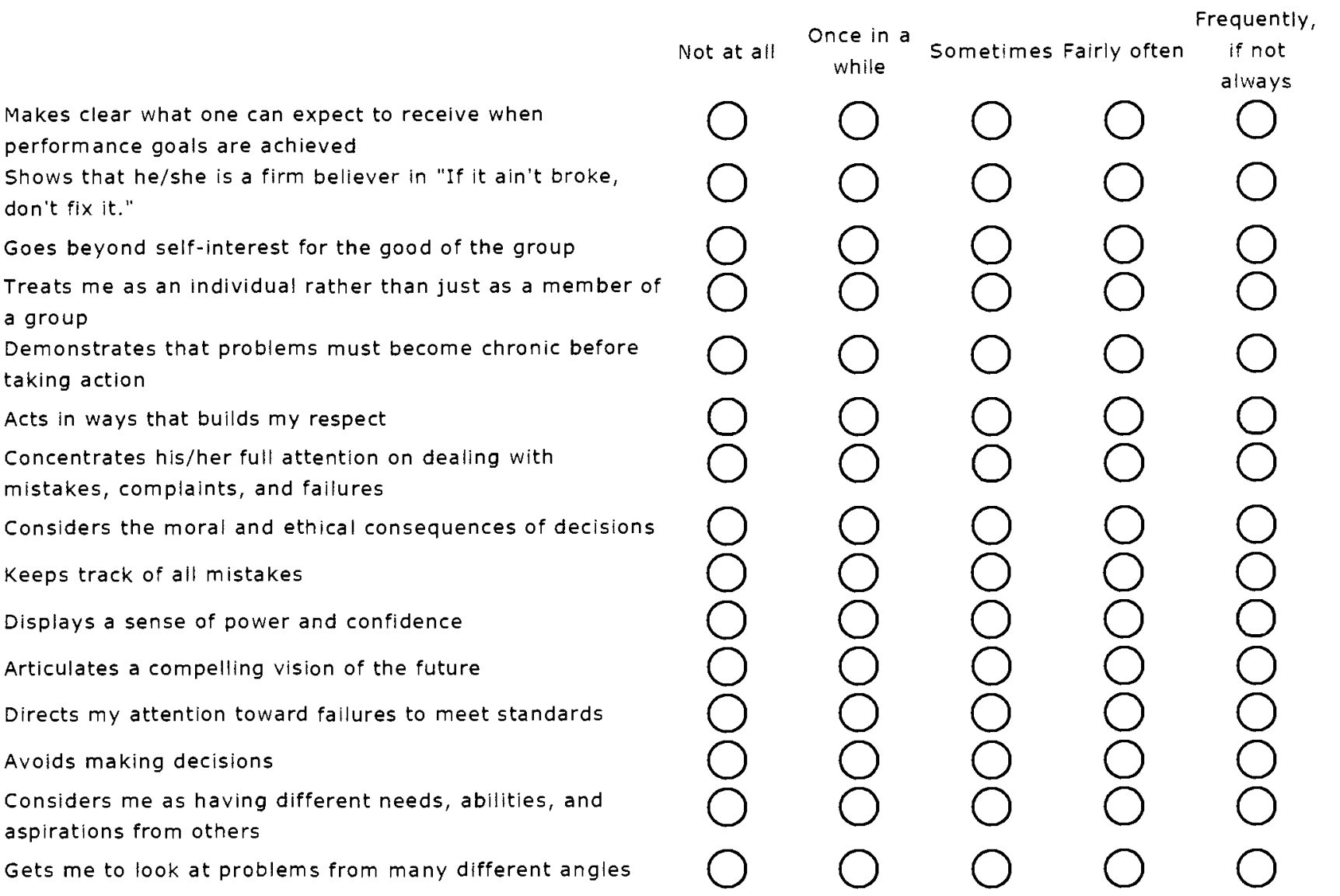

\section{5.}

MLQ, Copyright 1995, 2000, 2004 by Bernard Bass and Bruce Avolio. All rights reserved. Published by Mind Garden, Inc. www.mindgarden.com 


\section{McCoy Dissertation (Rater Form)}

\section{This is the last series of statements}

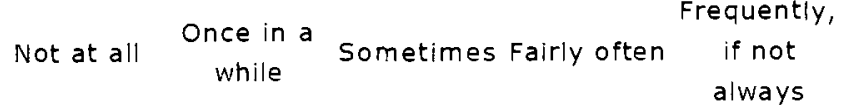

Helps me to develop my strengths

Suggests new ways of looking at how to complete assignments
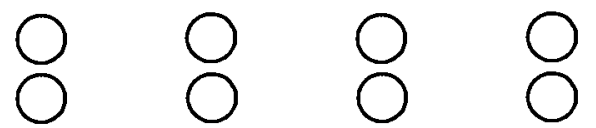

\section{Delays responding to urgent questions}

Emphasizes the importance of having a collective sense of mission
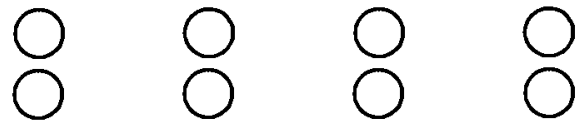

Expresses satisfaction when I meet expectations

Expresses confidence that goals will be achieved

Is effective in meeting my job-related needs

Uses methods of leadership that are satisfying

Gets me to do more than I expected to do

Is effective in representing me to higher authority

Works with me in a satisfactory way

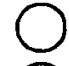

O

$\bigcirc$

0

O

0

0

O

$\bigcirc$

0

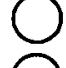

0

0

0

$\bigcirc$

0

0

Heightens my desire to succeed

Is effective in meeting organizational requirements

Increases my willingness to try harder

Leads a group that is effective

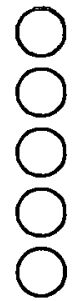

\section{Demographics}

The following questions are for demographic use only. All answers will be confidential.

\section{Gender}

Male

Cremale

\section{Age}

$22-30$

( $31-40$

(41-50

○ 51-60

$\bigcirc 61+$ 


\section{McCoy Dissertation (Rater Form)}

\section{Overall, how satisfied are you with:}

Very dissatisfied

Dissatisfied
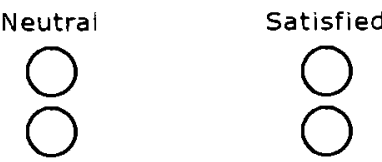

Very Satisfied

Your current job
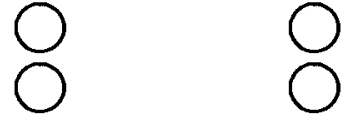

rating for this study

\section{Thank You}

Thank you for taking the time to fill out this survey. 